\title{
Venous cryo surgery of the leg $=$ veneuze cryo chirurgie van het been
}

Citation for published version (APA):

Klem, T. M. A. L. (2011). Venous cryo surgery of the leg = veneuze cryo chirurgie van het been. [Doctoral Thesis, Maastricht University]. Maastricht University. https://doi.org/10.26481/dis.20110929tk

Document status and date:

Published: 01/01/2011

DOI:

10.26481/dis.20110929tk

Document Version:

Publisher's PDF, also known as Version of record

\section{Please check the document version of this publication:}

- A submitted manuscript is the version of the article upon submission and before peer-review. There can be important differences between the submitted version and the official published version of record.

People interested in the research are advised to contact the author for the final version of the publication, or visit the DOI to the publisher's website.

- The final author version and the galley proof are versions of the publication after peer review.

- The final published version features the final layout of the paper including the volume, issue and page numbers.

Link to publication

\footnotetext{
General rights rights.

- You may freely distribute the URL identifying the publication in the public portal. please follow below link for the End User Agreement:

www.umlib.nl/taverne-license

Take down policy

If you believe that this document breaches copyright please contact us at:

repository@maastrichtuniversity.nl

providing details and we will investigate your claim.
}

Copyright and moral rights for the publications made accessible in the public portal are retained by the authors and/or other copyright owners and it is a condition of accessing publications that users recognise and abide by the legal requirements associated with these

- Users may download and print one copy of any publication from the public portal for the purpose of private study or research.

- You may not further distribute the material or use it for any profit-making activity or commercial gain

If the publication is distributed under the terms of Article $25 \mathrm{fa}$ of the Dutch Copyright Act, indicated by the "Taverne" license above, 


\section{VENOUS CRYO SURGERY OF THE LEG}

Taco Marius Adrianus Leonardus Klem 


\section{ACKNOWLEDGEMENTS}

The work presented in this thesis was conducted at the Departments of Surgery of the Sint Franciscus Gasthuis Rotterdam, Albert Schweitzer Hospital Dordrecht, Twee Steden Hospital Tilburg and the department of Epidemiology \& Biostatistics of the Erasmus Medical Center, Rotterdam, The Netherlands.

Venous cryo surgery of the leg; Dissertation, Maastricht University, Maastricht, The Netherlands

Design cover: B. Nijmeijer, Rotterdam, The Netherlands

Layout: Legatron Electronic Publishing, Rotterdam, The Netherlands

Printed by: Ipskamp Drukkers, Enschede, The Netherlands

ISBN: $\quad 9789461910011$

Copyright ${ }^{\odot} 2011$ T.M.A.L. Klem, Rotterdam, The Netherlands

All rights reserved. No part of this thesis may be reproduced, stored in a retrieval system or transmitted in any form or by any means, without permission of the author, or, when appropriate, of the scientific journal in which parts of this thesis may have been published 


\title{
VENOUS CRYO SURGERY OF THE LEG
}

\section{Veneuze cryo chirurgie van het been}

\author{
PROEFSCHRIFT \\ Ter verkrijging van de graad van doctor aan de \\ Universiteit Maastricht \\ op gezag van de \\ Rector Magnificus
}

Prof. Mr. G.P.M.F. Mols

volgens het besluit van het College van Decanen,

in het openbaar te verdedigen op

donderdag 29 september 2011 om 10.00 uur

door

Taco Marius Adrianus Leonardus Klem

Geboren op 19 juni 1972 te Benthuizen 
Promotor:

Co-promotor:

Beoordelingscommissie: Prof. dr. G.W.H. Schurink, voorzitter

Prof. dr. H.A.M. Neumann (ErasmusMC, Rotterdam)

Prof. dr. M. de Maeseneer (ErasmusMC, Rotterdam)

Dr. A. Sommer

Dr. B. Bruijninckx (Velthuis Kliniek, Rotterdam) 
PARANIMFEN

A. Kulk

W.W. Vrijland 



\section{MANUSCRIPTS BASED ON STUDIES DESCRIBED IN THIS THESIS}

\section{Chapter 2}

Klem TM, Sybrandy JE, Wittens CH, Essink Bot ML.

Reliability and validity of the Dutch translated Aberdeen Varicose Vein Questionnaire.

Eur J Vasc Endovasc Surg. 2009 Feb;37(2):232-8.

\section{Chapter 3}

Klem TM, Sybrandy JE, Wittens CH.

Measurement of health-related quality of life with the Dutch translated Aberdeen Varicose Vein Questionnaire before and after treatment.

Eur J Vasc Endovasc Surg. 2009 Apr;37(4):470-6

\section{Chapter 4}

Boezem van der P, Klem TM, le Cocq d'Armandville E, Wittens $\mathrm{CH}$.

The management of superficial venous incompetence.

BMJ. 2011

\section{Chapter 5}

Klem TM, Schnater JM, Schütte PR, Hop W, van der Ham AC, Wittens CH.

A randomized trial of cryo stripping versus conventional stripping of the great saphenous vein.

J Vasc Surg. 2009 Feb;49(2):403-9.

\section{Chapter 6}

Klem TM, Wittens $\mathrm{CH}$.

Minimally invasive procedures for incompetent perforating veins.

Vein Book, ISBN 6452347234

\section{Chapter 7}

Klem TM, Wittens $\mathrm{CH}$.

Cryoperforator surgery: a new treatment of incompetent perforating veins.

Vasc Endovascular Surg. 2008 Jun-Jul;42(3):239-42

\section{Chapter 8}

Klem TM, Wittens $\mathrm{CH}$.

Cryoperforator surgery: results with a modified probe.

Vasc Endovascular Surg. 2010 Jun-Jul;42(3):239-42 



\section{CONTENTS}

Chapter 1 General introduction 11

1.1 Anatomy of the veins in the leg 13

$\begin{array}{ll}1.2 \text { Socio-economic aspects } & 14\end{array}$

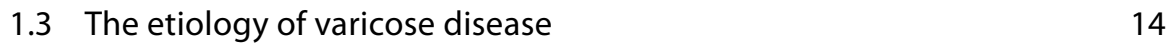

1.4 Outline of the thesis 15

Chapter 2 Validation of the Aberdeen varicose vein questionnaire 17

Chapter 3 Clinical use of the Aberdeen varicose vein questionnaire 25

Chapter 4 Review: surgical treatment of the incompetent great saphenous vein 35

Chapter 5 CRYO stripping versus conventional stripping; a randomized trial 61

Chapter 6 Minimally invasive procedures for incompetent perforating veins 77

$\begin{array}{lll}\text { Chapter } 7 & \text { CRYO perforator surgery } & 89\end{array}$

Chapter $8 \quad$ CRYO perforator surgery: results with a modified probe $\quad 97$

$\begin{array}{lll}\text { Chapter } 9 & \text { Summary and conclusions } & 105\end{array}$

$\begin{array}{ll}\text { Samenvatting en conclusies } & 109\end{array}$

Co-authors 113

$\begin{array}{ll}\text { Dankwoord } & 115\end{array}$

$\begin{array}{ll}\text { About the author } & 119\end{array}$ 



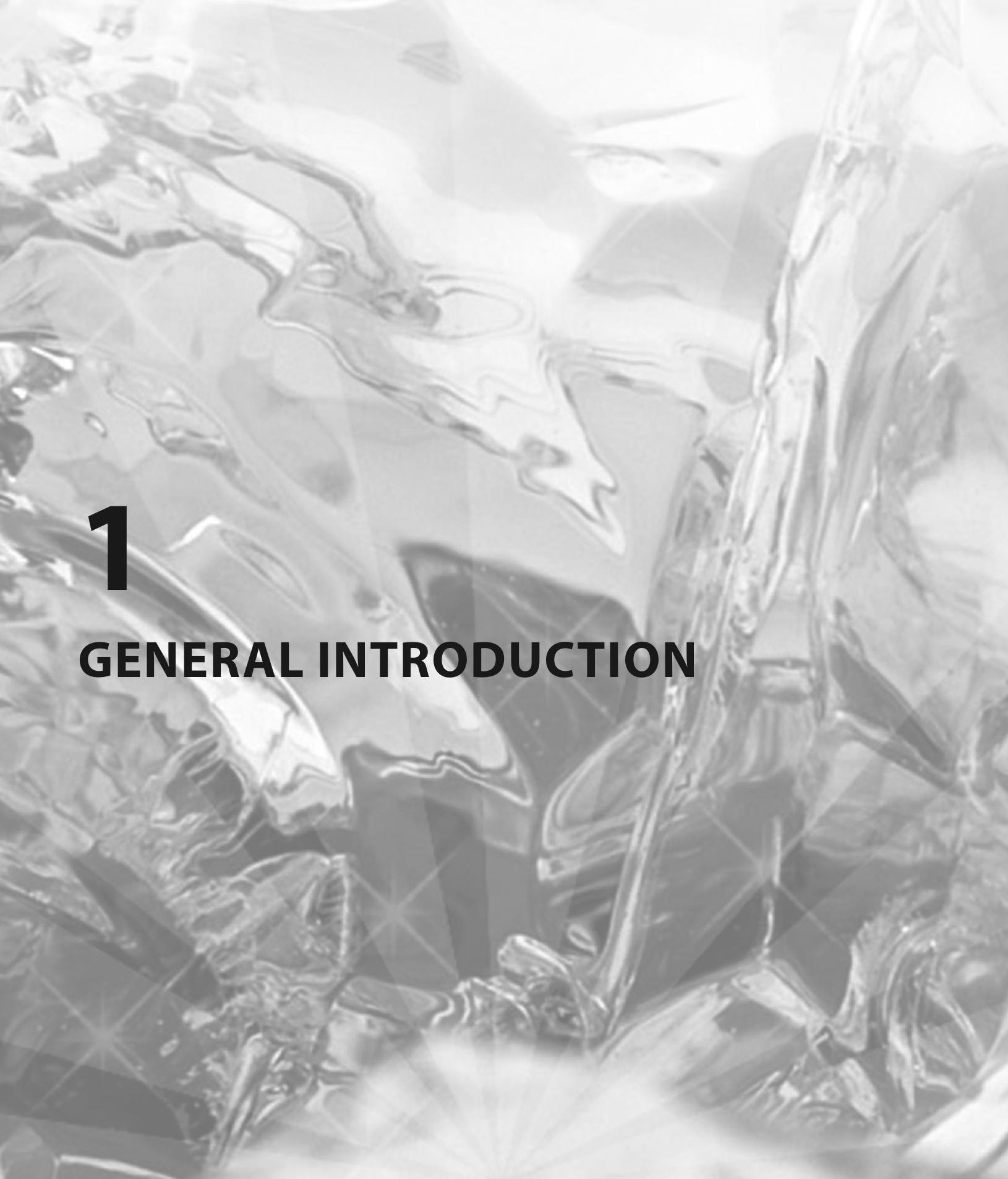




\section{GENERAL INTRODUCTION}

Varicose disease of the leg is a long known disease. With its origin in Egypt, the Papyrus Ebers (1550 BC), mentions the treatment of 'serpent shaped dilatations of lower limb veins'. Ever since, physicians have tried different methods to treat leg varicosis. The most commonly used surgical technique in the $20^{\text {th }}$ century was invented by Keller in 1905 and improved by Mayo in 1906, using an intraluminal device which could strip the great saphenous vein. Modifications of this surgical technique were further explored at the end of the $20^{\text {th }}$ century like inversion stripping and cryostripping. Although venous disease had the interest of most physicians in the last centuries, nowadays venous disease has suffered from a lack of interest and support, especially in academic centers. Whatever the reason is of this decline in interest, it is undeserved. Venous disease accounts worldwide for an enormous morbidity, loss of quality of life and spending of a large amount of the healthcare budget. Therefore small modifications in surgical techniques can result in large financial gains and improvement in quality of life. Although the treatment of the great saphenous vein has moved to a more minimally invasive procedure like endovenous thermo ablation, the surgical stripping technique is still the most used method worldwide.

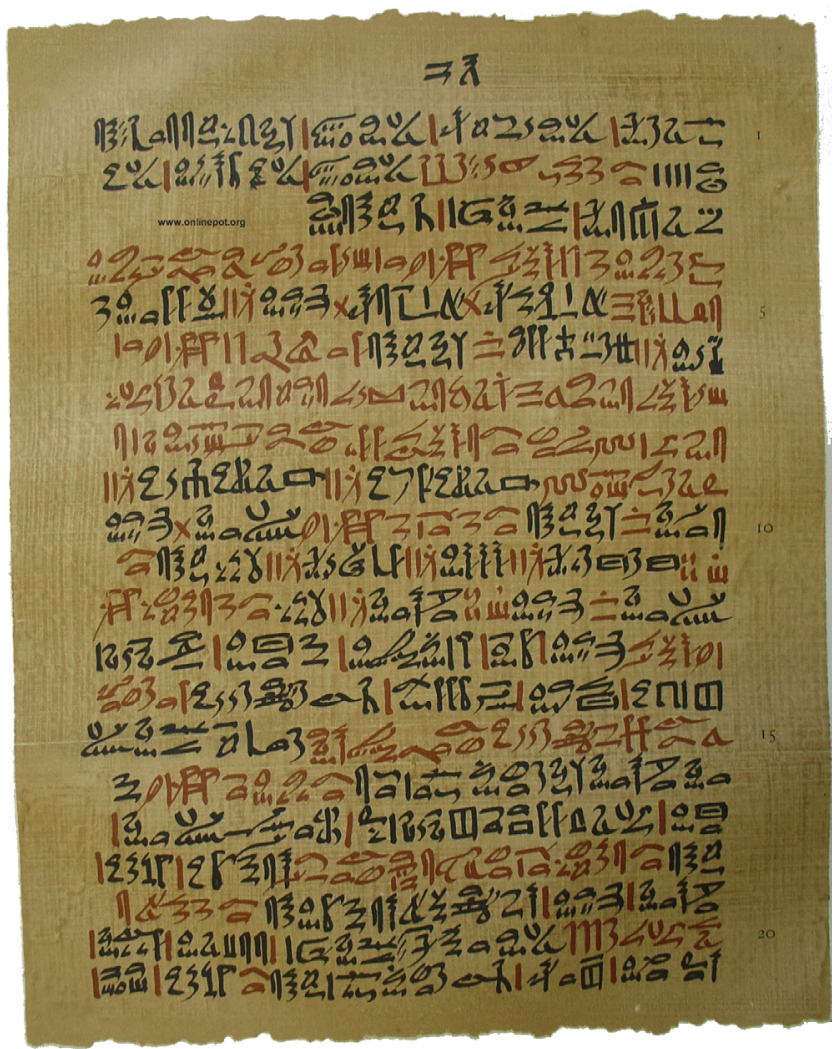

Papyrus of Ebers 


\subsection{ANATOMY OF THE VEINS IN THE LEG}

Contrary to the arterial system, the venous system has many anatomical variations. This fact accounts for the difficulty in the treatment of venous disorders. In a simplified form there are three different venous systems in the leg; the superficial venous system, the deep venous system and the perforating venous system. Blood flows from the superficial system to the deep system. The perforating veins connect the superficial system to the deep system, thereby 'perforating' the muscular fascia, hence their name. All veins in the leg have a number of valves which direct the blood flow from distal to proximal and from superficial to deep. The only exception are the smallest perforating veins $(<1 \mathrm{~mm})$.

The superficial system consists of two important veins which run just beneath the skin. The great saphenous vein, which runs on the medial aspect of the leg and drains in the femoral vein in the groin region. The other superficial vein is the small saphenous vein which runs on the lateral aspect of the leg and drains in the popliteal vein in the knee pit.

The deep system consists of many veins which run deep in the leg, near the bones and muscles. These are the common femoral vein, deep femoral vein, femoral vein, popliteal vein, anterior tibial vein, posterior tibial vein, peroneal vein, gastrocnemial veins and soleal veins.

The perforating system consist of many veins, which had historical a name giving to their discoverers (e.g. Dodd, Hunter, Cockett). Nowadays perforating veins are named to their anatomical location (e.g. medial ankle perforator, medial gastrocnemius perforator).

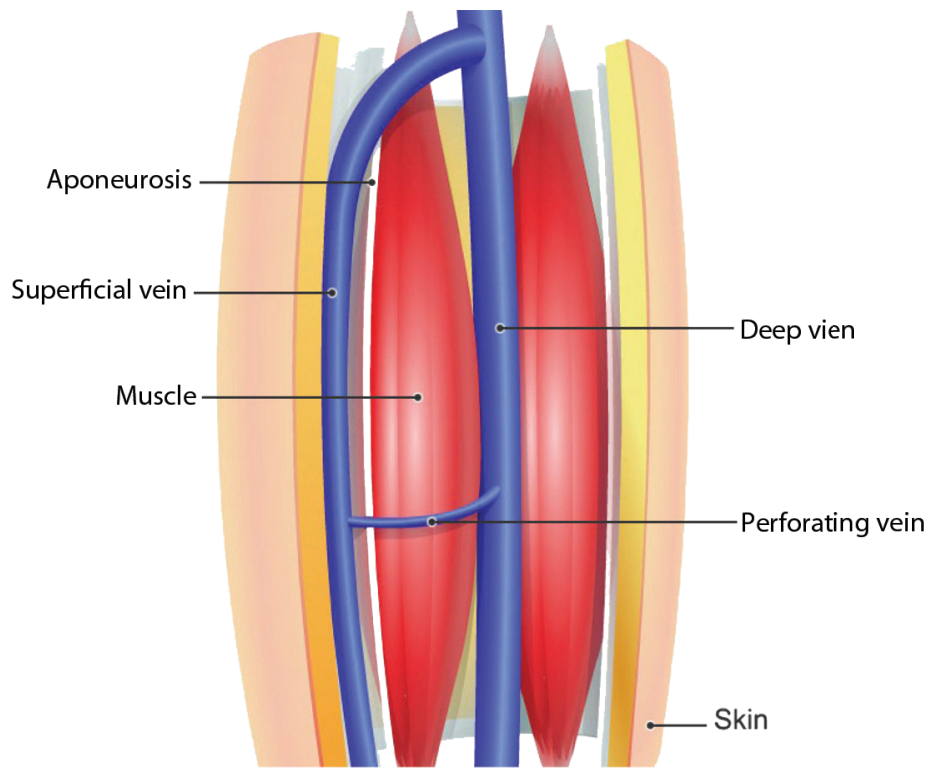

Simplified anatomy 


\subsection{SOCIO-ECONOMIC ASPECTS}

The costs of varicose disease of the leg and the loss of quality of life are substantial. Billions of dollars are annually spent worldwide on the treatment of (chronic) venous disease of the leg. All (surgical) treatment modalities are known to have a high risk of recurrence which results in even more costs, morbidity and loss in quality of life. For a long time physicians used incorrect outcomes to determine success after treatment of venous disease of the leg. A postoperative duplex ultrasound or plethysmography was proof that a treatment was successful or a failure. The patient however could still suffer from edema, pain, cosmetically problems which were not measured. To address these problems (health specific) quality of life questionnaires were developed. Many of these questionnaires measure certain domains in quality of life, like pain, social functioning and physical functioning. Although it is a great step forward to center the quality of life of patients in the treatment of venous disease, a new problem has arisen. These days there are many different questionnaires which are all used in different studies and evaluations of therapy. It is very difficult to compare outcomes of different questionnaires which all measures different aspects of quality of life. Another problem is that many questionnaires are only validated for the English language and cannot be officially used in other languages. The task of validating these questionnaires in the correct language should be performed to result in the ultimate goal; an uniform international quality of life questionnaire which can be used for trials and evaluating the result of (surgical) therapy.

\subsection{THE ETIOLOGY OF VARICOSE DISEASE}

The are many theories considering the etiology of varicose disease of the leg. For many years physicians were taught that incompetence of venous valves resulted in venous hypertension, varicose veins and in some patients venous ulceration. Although this sounds plausible it is an oversimplification of the etiology. Why do venous valves become incompetent? Why do some patients develop venous ulcers and other patients never?

Many theories and hypotheses about varicose veins and ulceration do not hold any longer. The hypothesis that venous hypertension resulted in hypo-oxygenation of local skin areas thereby causing ulceration has been refuted. The hypothesis that local white cell trapping in capillaries resulted in ulceration has also been refuted.

Many proposed risk factors for venous disease like pregnancy and age have not been definitely confirmed in epidemiologic studies. A genetic influence however is confirmed in studies.

The main reason that venous valves become incompetent is still unknown. Histological and biochemical research have shown that in the majority of patients with varicose disease and valve incompetence a inflammatory component is present with leukocytic infiltration. 
New hypotheses for this inflammatory component have been postulated in the past years, ranging from derailed endothelial cells, extracellular matrix alterations, cytokine dysregulation, matrix metalloproteinases and their inhibitors. Even infection with a pathogen (virus, bacterium, prion) has been proposed as the main cause of valve incompetence.

From the first medical notion on varicose disease, $1500 \mathrm{BC}$, till now it is still unclear what lies at the base of this disease. Hopefully further research will eventually shed light on the cause(s) of venous disease and will give us a proper treatment.

\subsection{OUTLINE OF THE THESIS}

This thesis is based on seven publications on the subject of venous cryo surgery and quality of life measurement.

In chapter 2, a health specific English quality of life questionnaire (Aberdeen Varicose Vein Questionnaire) is validated for the Dutch language for further use in the randomized trial which compares cryostripping to conventional stripping.

In chapter 3, the Dutch translated Aberdeen varicose vein questionnaire is tested whether to see if it can differentiate between different severity classes of venous disease. The questionnaire is also tested if it can measure differences in quality of life before and after (surgical) treatment.

In chapter 4, the various surgical treatment options for the great saphenous vein are reviewed. An adapted version of this review for the British Medical Journal describes the treatment of superficial venous incompetence.

In chapter 5, the outcomes are evaluated from a randomized trail comparing conventional stripping to cryo stripping of the great saphenous vein.

In chapter 6, the various surgical treatment options for incompetent perforating veins are reviewed

In chapter 7, the outcomes of cryo perforator surgery are evaluated.

In chapter 8, the outcomes of cryo perforator surgery with a modified cryoprobe are evaluated.

Finally, chapter 9, summarizes the main findings of the preceding chapters. 


\section{REFERENCES}

1. Historical overview of varicose vein surgery.

van den Bremer J, Moll FL. Ann Vasc Surg. 2010 Apr;24(3):426-32.

2. Updated terminology of chronic venous disorders: the VEIN-TERM transatlantic interdisciplinary consensus document. Eklof B, Perrin M, Rutherford RB, Gloviczki P J Vasc Surg. 2009 Feb;49(2):498-501.

3. Economic and outcomes-based analysis of the care of symptomatic varicose veins. Eidson JL 3rd, Atkins MD, Bohannon WT, Bush RL. J Surg Res. 2011 Jun 1;168(1):5-8.

4. Periodontal bacteremia and various vascular diseases. Iwai T. J Periodontal Res. 2009 Dec;44(6):689-94.

5. Venous hypoxia: a poorly studied etiological factor of varicose veins.

Lim CS, Gohel MS, Shepherd AC, Paleolog E, Davies AH. J Vasc Res. 2011;48(3):185-94 



\section{ABSTRACT}

Purpose: To evaluate reliability and validity of the Dutch translated Aberdeen Varicose Vein Questionnaire (AVVQ) for measuring health related quality of life (HR-QOL) in patients with venous disease in the lower limb.

Methods: The AVVQ consists of 13 questions related varicose veins. This study assessed feasibility, reliability and validity of the Dutch translated AVVQ in a sample of 145 patients with venous disease of the leg. Test and retest of the Dutch translated AVVQ were performed within a 2 week interval.

Results: There was a high test (99\%) and retest (97\%) response.

Feasibility; AVVQ showed few missing answers (0.6\%) and non-unique answers (0.2\%).

Regarding internal consistency; Cronbach's alpha exceeded 0.7 indicating a high level of concordance between the AVVQ questions (alpha $=0.76$ ).

Test-retest reliability; Spearman's rho showed a significant strong association between test and retest scores (rho $=0.87$ ).

Discriminative validity; AVVQ score was able to differentiate between subgroups of patients with different severity of venous disease according to the CEAP classification (Mann-Whitney $\mathrm{U}$ test, $\mathrm{p}<0.01$ ).

Conclusions: This study supports applications of the Dutch AVVQ in HR-QOL measurement in patients with venous disease in the Netherlands and the Flemish speaking part of Belgium. 


\section{INTRODUCTION}

Venous disease in the lower limb accounts for substantial healthcare expenditure in the western world. ${ }^{1,2}$ A disease specific quality of life (QOL) measurement should be included in the measurement of outcome to assess the effect of treatment for varicose veins. The Aberdeen Varicose Vein Questionnaire (AVVQ) was developed and validated by Garratt for measuring QOL in patients with varicose veins of the leg..$^{3,4}$ There is no translation and validation of the AVVQ in any other language. We adapted the AVVQ into Dutch following international guidelines, including three independent forward and two backward translations. This is discussed in the Methods. To implement the AVVQ in the Netherlands we assessed feasibility, score distribution, reliability and known-group validity of the Dutch AVVQ in a sample of patients with venous disease of the lower limb.

\section{MATERIALS AND METHODS}

\section{The Aberdeen Varicose Vein questionnaire}

The questionnaire consists of 13 questions (items) related to lower limb venous disease and is shown in Table 1. Question 1 is a diagram, where patients draw the location of their varicose veins. Questions 7 and 9 may only be answered with yes or no. The other questions had multiple response options. Questions 3 and 9 were answered with frequency of pain and use of painkillers. Questions 1, 2, 5, 6, 7, 8 and 9 should be answered for both legs.

Item scores were summed up after recoding the scores, which resulted in a scale score from zero to 100, with zero representing the best score, and 100 the worst score.

\section{Adaptation process}

The process followed to adapt the AVVQ into Dutch was based on Bullinger. ${ }^{5}$ In brief, three translators, all native speakers in Dutch, independently translated the questions and the response options of the original English AVVQ into Dutch. They were instructed to pay attention to conceptual rather than literal equivalence, and to choose words and language constructions that were as simple as possible. The translators were vascular surgeons. The three resulting independent forward translations were compared and discussed in a group meeting of the three translators. Differences were documented and discussed until consensus was reached about the optimal phrasing of the Dutch AVVQ. This common forward translation was then given to two translators who were native speakers in English and fluent in Dutch. They each produced a backward translation that was both compared to the original AVVQ for conceptual equivalence with the original source version. The analysis was documented and necessary adaptations to the Dutch AVVQ version were made. The resulting Dutch AVVQ was then administrated to three patients with venous disease of the lower limbs to provide qualitative testing of readability and comprehension. Because this qualitative testing revealed 
no problem with the Dutch AVVQ, it was subsequently administrated in the study population to collect data for psychometric analysis. The complete Dutch translated AVVQ is provided in the Appendix. It may be used without license fee in scientific projects.

\section{Study population and data collection}

All patients who visited our outpatient clinic in Rotterdam, the Netherlands, with venous disease of the leg, were asked to participate in this study. No patient refused to participate. In total 145 patients were included in 18 months, with at least 20 patients in each C-group of the [Clinical-Etiology-Anatomy-Pathophysiology] (CEAP classification), ranging from C1 to C6 (Table 1). ${ }^{6}$ All patients received the AVVQ on the day of their outpatient clinic visit (questionnaire 1). Questionnaires were filled in at home and returned directly by mail. A second copy of the AVVQ (questionnaire 2) was sent to the participants by mail after two weeks and was returned as well, to determine the test retest reliability. If patients had a delay in returning the questionnaires, a reminder telephone call was made once. No patients were treated for their venous disease of the leg between test and retest.

\section{Analysis}

Only questionnaires with at least a $90 \%$ response to all items were eligible for analysis. In case of non-unique responses (more than one response per item), a random selection of either response was used. In case of a missing item response the total possible score for that item was subtracted from the maximum possible score for the scale. By doing so, a sumscore could still be calculated by dividing the total score by the new maximum possible score and multiplying by 100 . For the items relating to left and right legs, some patients suffering from varicose veins in only one leg had a tendency to miss out boxes for the unaffected leg, rather than ticking the first box implying no symptoms. If a patient consistently missed out the response set for one leg had not drawn in any varicose veins on that leg in question 1 (Figure 1), their missing responses were coded zero (no symptoms). Evaluation of feasibility consisted of the assessment of response rates, and missing/non-unique answers. Score distribution was assessed by floor ( $25 \%$ of respondents or more exhibiting the worst possible score) and ceiling ( $25 \%$ of respondents or more exhibiting the best possible score) effects. Cronbach's a was used to evaluate internal consistency of the AVVQ. ${ }^{7}$ This test assesses the average level of correlation between questions in a questionnaire. If the questionnaire is measuring a specific problem (venous disease of the leg), then there should be a high level of concordance between these questions. If a questionnaire is to be reliable, alpha should exceed 0.7. Testretest reliability of the AVVQ scores was assessed by Spearman's correlation coefficient (rho), by two sided Wilcoxon's signed rank tests, and by effect size: $d=[$ mean(a) - mean(b)]/SD at the first measurement. ${ }^{8}$ Effect sizes can be interpreted as follows: $d=0.2=0.5$ is considered a small effect size, $d=0.5-0.8$ is considered a medium effect size and $d>0.8$ is a large effect size. The discriminative ability between subgroups of patients with different severity of venous disease was assessed by Mann-Whitney $U$ tests, and effect sizes. ${ }^{8}$ 


\section{RESULTS}

\section{Response}

Questionnaire 1 was returned by 143 patients (test response 99\%). There were no incomplete forms. Questionnaire 2 was returned by 140 patients (retest response $97 \%$ ) with no incomplete forms. The five patients who did not return questionnaire 2 included the two patients who also did not return questionnaire 1 . The age range was $23-85$ years (mean 54 ; SD 13 ); $69 \%$ was female. There were at least 20 patients in every C-class of the CEAP classification (Table 1).

\section{Feasibility}

The AVVQ showed few missing answers ( $0.6 \%$ on average) and non-unique answers ( $0.2 \%$ on average). Some spontaneous remarks were made regarding the first item, in which patients had to draw their varicose veins in a picture of both legs (Figure 1) (e.g.'there are only varicose veins on my ankle and foot').

\section{Score distributions and internal consistency}

Two items of the AVVQ had floor effects. These were items 'degree of ankle swelling' $(28 \%)$ and 'any discoloration?' (45\%). None of the items had ceiling effects. Cronbach's alpha was 0.76 .

\section{Test-retest reliability}

Mean AVVQ test score was 19.16 (SD 12.09) and mean AVVQ retest score was 19.62 (SD 11.76). Spearman's rho showed a significant strong association between test and retest scores $(\mathrm{rho}=0.87, \mathrm{p}<0.01)$. Non-parametric testing for differences between the average AVVQ scores at test and retest (two sided Wilcoxon's signed ranks test) was not significant $(p=0.12)$. The effect size was very small (0.04).

\section{Discriminative 'known groups' validity}

The AVVQ score was able to differentiate between subgroups of patients with different severity of venous disease (Mann-Whitney $U$ test, $p<0.01)$; the effect sizes were large $(0.84$ and 1.01$)$ (Table 2). 
Table 1: The Aberdeen Varicose Vein Questionnaire

1. Please draw in your varicose veins in the diagram below (figure 1).

2. In the last two weeks, for how many days did your varicose veins cause you pain or ache?

3. During the last two weeks, on how many days did you take painkilling tablets for your varicose veins?

4. In the last two weeks, how much ankle swelling have you had?

5. In the last two weeks, have you worn support stockings or tights?

6. In the last two weeks, have you had any itching in association with your varicose veins?

7. Do you have purple discolouration caused by tiny blood vessels in the skin, in association with your varicose veins?

8. Do you have a rash or eczema in the area of your ankle?

9. Do you have a skin ulcer associated with your varicose veins?

10. Does the appearance of your varicose veins cause you concern?

11. Does the appearance of your varicose veins influence your choice of clothing including tights?

12. During the last two weeks, have your varicose veins interfered with your work/housework or other daily activities?

13. During the last two weeks, have your varicose veins interfered with your leisure activities (including sport, hobbies and social life?

14. Do you have purple discolouration caused by tiny blood vessels in the skin, in association with your varicose veins?
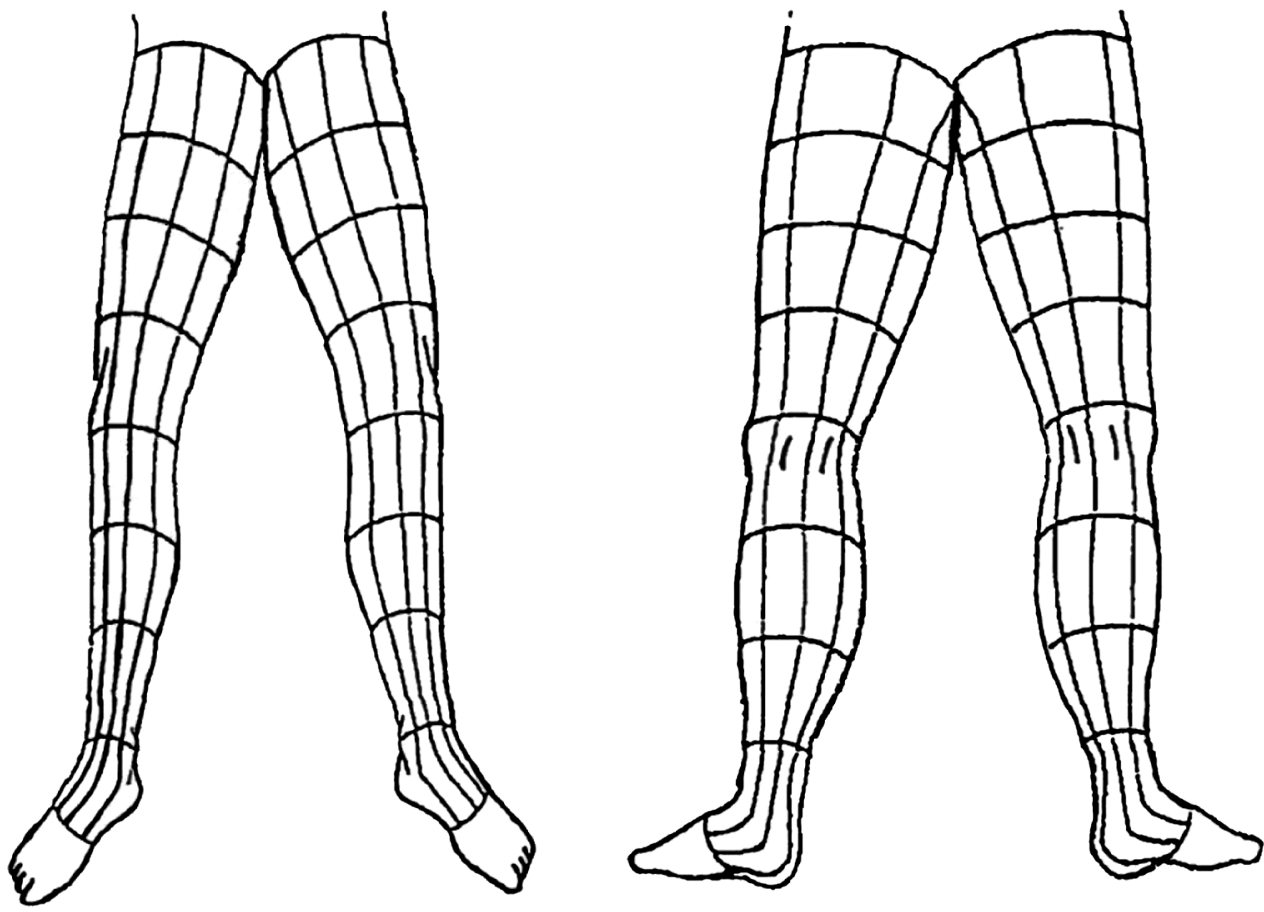
Table 2: Preoperative and postoperative AVVQ scores (standard version)

\begin{tabular}{lccrrr} 
Group & $\begin{array}{c}\text { Preoperative AVVQ } \\
\text { score (SD) }\end{array}$ & $\begin{array}{c}\text { Postoperative AVVQ } \\
\text { score (SD) }\end{array}$ & p $^{\text {a }}$ \\
\hline All patiens $(\mathrm{n}=43)$ & 19.54 & $(11.77)$ & 16.11 & $(12.02)$ & $<0.01$ \\
Subgroep A $(\mathrm{n}=50)$ & 11.12 & $(5.43)$ & 9.24 & $(6.56)$ & $=0.01$ \\
Subgroep B $(\mathrm{n}=50)$ & 18.65 & $(9.04)$ & 14.96 & $(9.84)$ & $<0.01$ \\
Subgroep C $(\mathrm{n}=43)$ & 30.36 & $(11.57)$ & 25.43 & $(13.36)$ & $<0.01$ \\
\hline $\begin{array}{l}\text { Subgroep A: clinical severity classes 1 and 2 } \\
\text { Subgroep B: clinical severity classes 3 and 4 }\end{array}$ & & & & & \\
Subgroep C: clinical severity classes 5 and 6 & & & & & \\
a Two-sided Wilcoxon's signed ranks test. & & & & &
\end{tabular}

\section{DISCUSSION}

This study established the feasibility, reliability and validity of the AVVQ in a Dutch population of outpatients with varicose veins. The psychometric properties of the Dutch AVVQ were similar to the original UK version. Score distributions, internal consistency and test-retest reliability in the Dutch sample have shown similar results as the UK samples. $3,4,9$

In the Dutch sample 2 items showed floor effects: 'degree of ankle swelling' and 'any discoloration?'. Regarding the former item; many patients in the higher C-classification suffered ankle swelling, which accounts for the floor effect in this study. Regarding the latter item; the large proportion of patients with small reticular veins may explain the high number of patients endorsing this item. Cronbach's alpha of 0.76 is comparable to internal consistency reported by Garrat (Cronbach's alpha of $0.72-0.74$ ) in a UK sample. ${ }^{3,9}$

\section{CONCLUSIONS}

The current evaluation of the Dutch AVVQ showed properties that are largely comparable to those found in similar UK samples. This supports applications of the Dutch AVVQ in QOL measurement in patients with venous disease in the Netherlands and the Dutch speaking part of Belgium. 


\section{REFERENCES}

1. Callam MJ. Epidemiology of varicose veins. Br J Surg 1994 Feb;81(2):167-73.

2. McLafferty RB, Lohr JM, Caprini JA, Passman MA, Padberg FT, Rooke TW, et al. Results of the national pilot screening program for venous disease by the American Venous Forum. J Vasc Surg 2007 Jan;45(1):142-8.

3. Garratt AM, Macdonald LM, Ruta DA, Russell IT, Buckingham JK, Krukowski ZH. Towards measurement of outcome for patients with varicose veins. Qual Health Care 1993 Mar;2(1):5-10.

4. Garratt AM, Ruta DA, Abdalla MI, Russell IT. Responsiveness of the SF-36 and a condition-specific measure of health for patients with varicose veins. Qual Life Res 1996 Apr;5(2):223-34.

5. Bullinger $\mathrm{M}$, Alonso J, Apolone G. Translating health status questionnaires and evaluating the quality: the IQOLA project approach. J Clin Epidemiol 1998;51(11):913-23.

6. Eklöf B, Rutherford RB, Bergan JJ, Carpentier PH, Gloviczki P, Kistner RL, et al. American Venous Forum International Ad Hoc Committee for Revision of the CEAP Classification. Revision of the CEAP classification for chronic venous disorders: consensus statement. J Vasc Surg 2004 Dec;40(6):1248-52.

7. Bland JM, Altman DG. Cronbach's alpha. BMJ 1997 Feb 22;314(7080):572.

8. Cohen J. Statistical power analysis for the behavioral sciences. New York: Academic Press; 1977.

9. Smith JJ, Garratt AM, Guest M, Greenhalgh RM, Davies AH. Evaluating and improving health-related quality of life in patients with varicose veins. J Vasc Surg 1999 Oct;30(4):710-9 



\section{ABSTRACT}

Purpose: This clinical trial evaluated the use of the Dutch translated Aberdeen Varicose Vein Questionnaire (AVVQ) and SF-36 before and after treatment in patients with clinical-severity classes 1-6 venous disease of the lower limb.

Methods: A total of 145 patients with symptomatic venous disease of the leg were included. Numbers of patients were evenly distributed among the six clinical-severity classes 1-6 (clinical, etiology, anatomy and pathophysiology; CEAP). Patients completed two preoperative AVVQ questionnaires and one short-form health survey with 36 items (SF-36) questionnaire to evaluate test-retest reliability of the AVVQ. Patients completed one postoperative AVVQ and SF-36 to evaluate the effect of treatment.

Results: The test (99\%) and re-test responses (97\%) of the AVVQ were sufficient. Internal consistency of the Dutch translated AVVQ showed a Cronbach's alpha of 0.76 . Correlation of test and re-test of the AVVQ Q2 was high ( $r h o=0.86, \mathrm{P}<0.001$ ). A significant negative association, by Spearman's correlation coefficient, was found between the preoperative baseline Dutch translated AVVQ score and all eight domains of the preoperative SF-36 $(P<0.001)$. These significant associations were also found in the postoperative scores.

The mean preoperative AVVQ score of 19.5 (SD 11.8) and mean postoperative AVVQ score of 16.1 (SD 12.0) differed significantly $(P<0.01)$. Analysis of three subgroups of clinical-severity classes (C1-2, C3-4 and $\mathrm{C} 5-6)$ showed significant score changes before and after surgery $(\mathrm{P}<0.01)$. Preoperative and postoperative SF-36 scores were not significantly different.

Conclusions: This study established the use of the Dutch translated AVVQ as a valid, health related quality of life $(\mathrm{QOL})$ questionnaire for measuring $\mathrm{QOL}$ before and after treatment in patients with clinical-severity classes 1-6 venous disease of the leg. 


\section{INTRODUCTION}

A large amount of the health-service resources in the Western world is spent on the treatment of venous disease of the legs. ${ }^{1,2}$ Anatomical or physiological tests may not be the best outcome measures when procedures are done to palliate symptoms of venous disease. Instead of only evaluating the outcome with venous duplex, it is better to assess the effect when it is combined with a health-related quality of life (HR-QOL) measurement. The Aberdeen Varicose Vein Questionnaire (AVVQ) was developed by Garratt et al., in 1993, for measuring QOL in patients with venous disease of the leg. ${ }^{3}$ The questionnaire consists of 13 items related to problems of venous disease of the leg. Generic health status in patients with venous disease can be measured with the short-form health survey with 36 items (SF-36). The 36 items results in eight domains after recoding related to physical and mental health and social functioning. To completely assess the QOL of patients with venous disease, a health-related and a generic health status should be obtained to maximize detection of change after treatment. An evaluation of preoperative and postoperative AVVQ scores, in combination with SF-36 scores, in a cohort of patients with symptomatic varicose veins, but with the exclusion of active venous ulceration, has been reported by Smith et al. ${ }^{4}$ This study aims to test the hypothesis that the Dutch translated AVVQ is a useful instrument for measuring HR-QOL in patients with venous disease, before and after treatment.

\section{MATERIALS AND METHODS}

This study was performed in combination with a validation and reliability study of the Dutch translated AVVQ. The study protocol was approved by the local ethics committee. Patients who visited our out-patient clinic in Rotterdam, The Netherlands, with symptomatic venous disease of the leg were asked to participate in this study. The exclusion criteria were: body mass index $(\mathrm{BMI})>40$, recurrence of venous incompetence in the great saphenous vein (GSV) or small saphenous vein (SSV), occlusion of the deep venous system, peripheral arterial disease as indicated by absent pulses and an ankle brachial index $(\mathrm{ABI})<0.9$, already being part of the study with the contra lateral leg, and the inability to understand the Dutch language. None of the patients refused to participate. In total, 145 patients were included, with a minimum of 20 patients in each group of the clinical-severity classes (C1-C6). Most patients had a primary etiology for their venous disease, and only three patients had a secondary etiology (postthrombotic). None of the patients had congenital venous disease. Considering anatomy and pathophysiology, all patients had reflux to some extent in their superficial venous system. Deep venous reflux was found in 42 patients (29\%), while perforating vein reflux was found in 58 patients (41\%). None of the patients had deep venous obstruction. The mean age was 54 years (range: $23-85$ years); $69 \%$ of patients were female. All patients received two AVVQs preoperatively for test and re-test evaluation, with a two week interval. The AVVQ can have a score ranging from 0 to 100 , with 0 representing the best score, and 100 the worst score. 
AVVQs were filled out at home and returned directly by mail. No patients were treated for their venous disease of the leg between test and re-test. On the day of hospital admission, patients were asked to fill out an SF-36 before treatment. SF-36 scores resulted in eight domains after recoding. These were Physical Functioning (PF), Role Limitation due to Physical problems (RP), Bodily Pain (BP), General Health (GH), Vitality (VI), Social Functioning (SF), Role Limitation due to Emotional problems (RE) and Mental Health (MH).

The scores in the domains range from 0 , the worst score, to 100 , the best score. Six weeks after treatment, patients visited our outpatient clinic for physical examination. Immediately after this visit, patients completed their third AVVQ. The SF-36 was given to patients with the instruction to fill in the questionnaire at home and return it by mail. This strategy was chosen to get maximum postoperative AVVQ responders. The SF-36 took too much time to fill in at the out-patient clinic visit; therefore, patients were asked to complete it at home.

\section{Treatment}

Obstruction of the deep venous system was a contraindication for surgical treatment.

Patients with clinical-severity class $\mathrm{C} 1$ and a duplex proven competent GSV and SSV were treated with phlebectomy and sclerotherapy. Phlebectomy was performed under local anesthesia. Patients with clinical-severity classes C2-C5 and duplex proven incompetence of the GSV and/ or SSV were treated surgically. The treatment consisted of Babcock stripping of the GSV and/ or ligation and division of the SSV. Patients with clinical-severity class C6 and duplex proven incompetence of the GSV and/or SSV and/or perforating veins were treated surgically. Surgical treatment consisted of Babcock stripping of the GSV and/or ligation and division of the SSV. Sub-fascial endoscopic perforating vein surgery (SEPS) was performed for incompetent perforating veins. To increase mobility and decrease the risk of deep venous thrombosis, only one leg at a time was treated in all patients. Phlebectomy and/or sclerotherapy in patients with C2-C6 venous disease was performed, if necessary, not less than 2-3 months after the surgery. All patients received preoperative low-molecular-weight heparin injections and graduated elastic compression stockings postoperatively. Conventional stripping of the GSV, ligation and division of the SSV and SEPS were performed under spinal anesthesia. This was normal policy in our hospital and was not specific to the protocol for this study. Endovenous techniques, including radiofrequency ablation and laser ablation, were used in our hospital in separate clinical trials. Therefore, none of the patients in this study underwent these newer techniques.

\section{Validation}

The validity and reliability of the Dutch translated AVVQ was assessed in this cohort of patients and was reported beforehand. Internal consistency was tested using Cronbach's alpha. This is a coefficient of reliability (or consistency), and it assesses the average level of correlation between the questions (items) in a questionnaire. If the questionnaire is measuring a specific problem (venous disease of the leg), there should be a high level of concordance between these 
questions. If a questionnaire is to be reliable, alpha should exceed 0.7. Test-retest reliability was assessed using the two-tailed Wilcoxon's signed ranks test. Assessment for discrimination between subgroups of preoperative patients with different clinical-severity classes was done by Mann-Whitney U-tests.

\section{Analysis}

Statistical analysis was performed using the Statistical Package for the Social Sciences (SPSS 15.0) for Windows. Evaluation of the Dutch translated AVVQ and SF-36 before and after treatment of leg venous disease consisted of preoperative and postoperative Wilcoxon's signed rank tests. Extra validity was evaluated in this study ; the correlation of AVVQ score and SF-36 scores of each of the eight domains using Spearman's correlation coefficient.

\section{RESULTS}

\section{Response}

The first AVVQ (preoperative) was returned by 143 patients resulting in a test response of $99 \%$. The second AVVQ (preoperative) was returned by 140 patients resulting in a re-test response of $97 \%$. The five patients who did not return the second AVVQ included the two patients who also did not return the first AVVQ. These two patients also did not show up on their out-patient clinic appointments and, thus, were not treated for their venous disease. In this cohort, 143 patients were treated for their venous disease of the leg. These 143 patients all completed their first SF-36 (preoperative) on the day of hospital admission. After a reminder telephone call, eventually all postoperative patients attended their out-patient clinic appointment, where all patients completed their third AVVQ. Unfortunately, only 118 patients returned their second SF-36 by mail, resulting in a response of $83 \%$.

\section{Internal consistency, test-retest reliability and discriminative validity}

Internal consistency testing of the AVVQ showed a Cronbach's alpha of 0.76 .

Mean preoperative AVVQ test score was 19.2 (SD 12.1) and mean preoperative AVVQ re-test score was 19.6 (SD 11.8). There was a significant correlation between both preoperative AVVQ scores (Spearman's correlation coefficient, Rho $=0.86, \mathrm{P}<0.01$ ).

No correlations were observed for AVVQ score compared to patients age or gender. The preoperative AVVQ score was able to differentiate between subgroups of patients with different clinical severity classes; C1-C2, C3-C4 and C5-C6 (Mann-Whitney U-test, P $<0.01$ ).

\section{Correlation of the AVVQ and SF-36}

Because of the small differences in scores between the first and second AVVQ (both preoperative), the mean score of both questionnaires was used as a preoperative baseline 
AVVQ score. In three patients we did not receive a second preoperative AVVQ; therefore, we used their first AVVQ as a baseline preoperative AVVQ score. A significant negative association, by Spearman's correlation coefficient (rho) was found between the baseline preoperative Dutch translated AVVQ score and all eight domains of the preoperative SF-36. Three of the four highest associations (rho $<-0.4, P<0.01$ ) were found in the physical domains: PF ( $r h o=-0.541$, $P<0.01$ ), RP (rho $=-0.448, P<0.01$ ), BP (rho $=-0.439, P<0.01$ ) and the remaining high association in SF (rho $=-0.412, P<0.01$ ). These significant associations were also found in the postoperative scores.

\section{Preoperative and postoperative AVVQ scores}

The mean preoperative baseline AVVQ score was 19.5 (SD 11.8) and mean postoperative AVVQ score was 16.1 (SD 12.0). A two-tailed Wilcoxon's signed ranks test was significant $(P<0.01)$ for the differences between preoperative and postoperative AVVQ scores. We examined preoperative and postoperative AVVQ scores of three subgroups of patients with different clinical severity scores. These three subgroups are as follows:

- Subgroup A: clinical-severity classes C1 and C2 $(n=50)$

- Subgroup B: clinical-severity classes C3 and C4 $(n=50)$

- Subgroup C: clinical-severity classes C5 and C6 $(n=43)$

Because of small numbers of patients in subgroup-analyses we combined two clinical-severity classes in each subgroup (Table 1). In all these subgroups, we found significant changes in the mean preoperative AVVQ score and mean postoperative AVVQ score (Wilcoxon's signed ranks test).

Table 1: Preoperative and postoperative AVVQ scores (standard version)

\begin{tabular}{|c|c|c|c|}
\hline Group & $\begin{array}{c}\text { Preoperative AVVQ } \\
\text { score (SD) }\end{array}$ & $\begin{array}{c}\text { Postoperative AVVQ } \\
\text { score (SD) }\end{array}$ & $\mathbf{p}^{a}$ \\
\hline All patiens $(n=143)$ & $19.5 \quad(11.8)$ & $16.11 \quad(12.0)$ & $<0.01$ \\
\hline Subgroep A $(n=50)$ & $11.1 \quad(5.4)$ & $9.24 \quad(6.6)$ & $=0.01$ \\
\hline Subgroep B $(n=50)$ & $18.7 \quad(9.0)$ & $15.0 \quad(9.8)$ & $<0.01$ \\
\hline Subgroep C $(n=43)$ & 30.4 (11.6) & 25.4 (13.4) & $<0.01$ \\
\hline $\begin{array}{l}\text { Subgroep A: clinical sev } \\
\text { Subgroep B: clinical sev } \\
\text { Subgroep C: clinical sev } \\
\text { a Two-sided Wilcoxon's s }\end{array}$ & $\begin{array}{l}C 2 \\
C 4 \\
C 6\end{array}$ & & \\
\hline
\end{tabular}




\section{Preoperative and postoperative SF-36 scores}

Seven of the eight domains of the SF-36 had higher postoperative scores. The domain 'social functioning' had a lower postoperative score. Preoperative and postoperative SF-36 scores were not significantly different (Wilcoxon's signed ranks test). There was a trend of a higher postoperative score in the domains 'physical functioning' and 'vitality', but significance was not reached in both domains (Table 2 ).

Table 2: Preoperative and postoperative SF-36 domain scores

\begin{tabular}{lccc} 
Domain & Preoperatively & Postoperatively & $\mathbf{P a}^{\mathbf{a}}$ \\
\hline $\mathrm{PF}$ & 71.4 & 78.3 & 0.055 \\
$\mathrm{RP}$ & 66.8 & 71.4 & 0.96 \\
$\mathrm{BP}$ & 66.9 & 74.0 & 0.19 \\
$\mathrm{GH}$ & 67.7 & 71.9 & 0.64 \\
$\mathrm{VI}$ & 64.1 & 69.8 & 0.059 \\
$\mathrm{SF}$ & 82.5 & 81.8 & 0.19 \\
$\mathrm{RE}$ & 77.2 & 79.9 & 0.61 \\
$\mathrm{MH}$ & 54.2 & 57.6 & 0.71 \\
\hline
\end{tabular}

a Two-tailed Wilcoxon signed ranks test.

\section{Complications}

There was no major complication. There were six patients with a wound infection that healed with conservative treatment. Four of these patients had $\mathrm{C} 2$, and two patients had $\mathrm{C} 4$, venous disease.

\section{DISCUSSION}

\section{Response}

The response rate of the preoperative and postoperative AVVQ was very good. This was due to the fact that we asked patients to complete the postoperative AVVQ in the outpatient clinic, and that it took around $5 \mathrm{~min}$ to complete the questionnaire. The response rate of the preoperative SF-36 was very good because patients had to complete the questionnaire in the hospital on the day of their admission. The postoperative SF-36 response was disappointing (83\%). A reason could be that patients could complete this questionnaire at home. The reason why so many patients did not return their last SF-36 is speculative. Patients could have forgotten to complete the questionnaire or were 'questionnaire-tired' after completing a lot of the same 
questionnaires in a relatively short time. In a similar study, Smith also found an $80 \%$ of patients lost to follow-up; these patients did not show up on their out-patient clinic appointment. ${ }^{4}$

\section{Validity and reliability}

Internal consistencies, test-retest reliability and discriminative validity of the Dutch translated AVVQ and original AVVQ have been tested and reported before. ${ }^{3,5}$ The original AVVQ and Dutch translated AVVQ showed good validity and reliability.

\section{Correlation of AVVQ score and SF-36 score}

There was a significant negative association of preoperative AVVQ scores and the eight domains of the preoperative SF-36. Smith found only four domains to be significant. ${ }^{4}$ These were exactly the same four domains which showed the strongest association in this cohort of patients. Three of these domains were physical domains: 'physical functioning,' 'role limitation due to physical problems' and 'bodily pain', which was expected because the AVVQ has many questions about physical discomfort and pain. The remaining domain, 'social functioning', also showed a strong association and was expected because the last two questions of the AVVQ are related to social functioning, which was also reported previously. 5 The significant association of the eight domains gives extra validity to the Dutch translated AVVQ as an instrument to measure HR-QOL.

\section{Preoperative and postoperative AVVQ scores}

A highly significant decrease in postoperative AVVQ scores was found in this cohort. Smith found similar results only with lower preoperative and postoperative AVVQ scores. ${ }^{4}$

This is almost certainly due to the fact that patients with active venous ulceration were excluded in their study. This is the group of patients with the highest AVVQ scores. We also found a significant decrease in postoperative AVVQ scores in the three subgroups with different clinical severity classes.

\section{Preoperative and postoperative SF-36 scores}

We found no significant increase in postoperative scores in any of the eight domains of the SF-36. There was a trend of a higher postoperative score in the domain 'physical functioning' which is to be expected because, after treatment, patients will have less physical complaints of their venous disease, like a heavy and tired feeling in the leg, pain and ankle swelling. The domain 'vitality' also showed a trend of a higher postoperative score; this domain is also known as 'energy' and patients could feel better because of a decrease in physical discomfort. Smith et al. found a significant increase in the domain 'mental health'. ${ }^{4}$ Remarkably, this is the only domain that has a very different preoperative score in the Dutch cohort (mean 54.2) compared to the UK cohort (mean about 70). This could be due to a chance or a real difference between the samples because of the exclusion of patients with active venous ulceration in the UK sample. These patients scored the worst in this study on the domain mental health. The other seven 
preoperative domain scores were similar to the UK cohort. The domain 'social functioning' had a non-significant, lower postoperative score. It is reasonable that patients treated for venous disease will engage less in social activities, such as sports, or other leisure activities for a few weeks. Therefore, a slightly lower score was expected in this domain.

\section{CONCLUSIONS}

Treatment of venous disease of the leg can increase QOL. Patients with venous disease of the leg have specific clinical complaints. The SF-36 is a measurement of generic health status; therefore, it cannot fully detect these specific clinical complaints. The AVVQ was designed a year before the introduction of the CEAP-classification system. Although the name 'AVVQ' suggests an instrument which measures HR-QOL in patients with only varicose veins (C1 and $\mathrm{C2}$ ) this study shows that it can be used for the whole spectrum of venous disease (C1-C6). Contrary to the SF-36, the AVVQ can measure the specific clinical complaints in patients with venous disease. This study established the use of the Dutch translated AVVQ as a valid questionnaire for measuring preoperative and postoperative HR-QOL in patients with clinical-severity classes C1-C6 venous disease. 


\section{REFERENCES}

1. Callam MJ. Epidemiology of varicose veins. Br J Surg 1994 Feb;81(2):167-73.

2. McLafferty RB, Lohr JM, Caprini JA, Passman MA, Padberg FT, Rooke TW, et al. Results of the national pilot screening program for venous disease by the American Venous Forum. J Vasc Surg 2007 Jan;45(1):142-8.

3. Garratt AM, Macdonald LM, Ruta DA, Russell IT, Buckingham JK, Krukowski ZH. Towards measurement of outcome for patients with varicose veins. Qual Health Care 1993 Mar;2(1):5-10.

4. Smith JJ, Garratt AM, Guest M, Greenhalgh RM, Davies AH. Evaluating and improving health-related quality of life in patients with varicose veins. J Vasc Surg 1999 Oct;30(4):710-9.

5. Garratt AM, Ruta DA, Abdalla MI, Russell IT. Responsiveness of the SF-36 and a condition-specific measure of health for patients with varicose veins. Qual Life Res 1996 Apr;5(2):223-34. 



\section{INTRODUCTION}

Varicose veins are a common medical problem and often encountered in surgical practice. Prevalence is rising with an increasing age. At the age of 40 years, $40 \%$ of women and $25 \%$ of men have varicose veins. At the age of 70 prevalence has increased to $60 \%{ }^{1-3}$ The high prevalence of venous disease of the leg accounts for enormous costs and loss of quality of life worldwide. ${ }^{4-6}$ The major cause of venous disease is incompetence of the saphenofemoral junction (SFJ) and the great saphenous vein (GSV). ${ }^{7}$

In the last decade several minimally invasive endovenous treatment options for GSV incompetence have become increasingly popular. These new techniques includes endovenous laser ablation (EVLA), radiofrequency ablation (RFA) and endovenous steam ablation (ESVA) ${ }^{8,9}$ Nevertheless the most commonly used surgical treatment is still high ligation at the SFJ followed by a short stripping to the knee. ${ }^{10,11}$ Potential advantages of endovenous techniques include a reduction in postoperative morbidity, a shorter recovery period and an improved cosmetically result.

The objective of this review is to describe the most commonly used procedures, results and complications for treatment of GSV incompetence. Despite the large numbers of procedures done annually for varicose veins, only a few randomized controlled trials with endovenous procedures have been published. Most of them have small numbers of included patients with short term follow up. Neither investigators nor patients were blinded to the treatment method in the randomized trials discussed in this paper.

\section{METHODS}

The literature was searched according to the international guidelines for evidence based research to identify studies describing the surgical treatment of the GSV over the period from January 1985 till June 2011. We carried out an electronic search of Medline and Embase. The medical subject heading (MeSH) term "saphenous OR varicose" was used. This very broad search strategy guaranteed that all possible relevant articles were reviewed. The search was limited to English articles only. All the selected papers were reviewed by two independently physicians. Included papers provided data on patients with primary venous reflux confirmed by duplex ultrasound. Effectiveness of treatment was assessed by abolition of reflux, recanalization, reduction of symptoms and quality of life. 


\section{RESULTS}

\section{Conventional stripping of the GSV}

Conventional surgical treatment for varicose veins due to reflux in the GSV is ligation at the SFJ and its tributaries, followed by a short stripping of the GSV from the groin to knee level. ${ }^{12,13}$ This is a day case procedure that requires general or spinal anaesthesia. A few centers use local anaesthesia (tumescent anaesthesia) these days. Variations to the classic approach, using an acorn tip mounted on the stripper, include the use of inversion strippers. Surgical stripping is one of the most performed procedures in general surgery over the past decades, but there is only little evidence available.

\section{Results}

Three randomized trials compare the inversion technique with the conventional technique and show no difference in the extent of bruising or pain. ${ }^{14-16}$ They report a significantly smaller exit wound using the inversion stripper, ${ }^{15,16}$ and lower rates of paresthesia following an invagination stripping. ${ }^{15}$

Recurrence rates vary, depending on definition and length of follow up. After surgery recurrence rates on duplex ultrasound are 13 to $29 \%$ with a follow up of 2 to 5 years. ${ }^{17-19}$ A study with a mean follow up period of 34 years showed recurrence on duplex ultrasound in $60 \%$ of 125 limbs after surgery, mostly due to neovascularisation. ${ }^{20}$

\section{Complications}

Problems arising from varicose vein surgery are the single most common reason for litigation in the UK. ${ }^{24}$ Most settled claims result from a failure to warn patients for nerve damage. A short stripping, from groin to knee level, proposes a far less risk for nerve damage compared to a groin to ankle stripping. Nerve damage is then reduced from $40 \%$ to $8 \%{ }^{25-27}$

Deep vein thrombosis (DVT) poses a risk for pulmonary embolism. Based on clinical grounds, the incidence is thought to be $0.5 \%{ }^{28,29}$ van Rij et al assessed 377 legs after surgery by duplex ultrasound. ${ }^{30}$ DVT was detected in $5 \%$ of the patients. The majority was confined to the calf veins and no patient developed a pulmonary embolism. Although the incidence of DVT following varicose vein surgery was higher than previously thought, there was minimal shortor long- term clinical significance. Hematoma formation is common after stripping the GSV. Wound infection occurs in about $10 \%$ and is responsible for delayed return to normal activity and work. ${ }^{31}$ Another complication is the formation of a lymphocele or lymphoedema of the leg. 


\section{Cryo stripping of the GSV}

Cryo stripping was popular in France, Germany, The Netherlands and Eastern Europe around 1990 till 2000. Cryo stripping is a day case procedure that requires general or spinal anaesthesia. After SFJ ligation and its tributaries, the cryoprobe is advanced intraluminal in the GSV from groin level towards the knee. A separate incision near the knee is not necessary which was the main cosmetic reason to use cryostripping. After freezing for 10 seconds (liquid dinitrousoxide, -89 degrees Celsius), vigorously pulling the probe results in 'breaking' of the frozen GSV at knee level. While freezing, the cryoprobe is slowly pulled back towards the groin, thereby stripping the GSV in the upper leg.

\section{Results}

Two randomized trials comparing cryostripping to conventional stripping were performed. 32,33

In a large, well organized trial, 494 patients were randomized for either conventional stripping or cryostripping of the GSV. The primary outcome of this trial was residual GSV, 6 months after surgery. Secondary endpoint was quality of life. Considering residual GSV after cryostripping: the percentage of patients with residual GSV at 6 months was 44\% in the cryo group and 15\% in the conventional group (difference 29\%; $P<0.01$ ). Regarding quality of life after cryostripping in both studies: scores showed no significant change between cryostripping and conventional stripping.

\section{Complications}

Compared to conventional stripping, in these two studies there were no more or different complications observed in cryostripping.

\section{Endovenous procedures}

RFA, EVLA and ESVA are catheter based endovenous procedures in which thermal energy is delivered into the vein wall of the GSV. The GSV is cannulated adjacent to the knee under duplex ultrasound guidance. A catheter is inserted over a guidewire. The tip of the catheter is positioned $2 \mathrm{~cm}$ distally to the SFJ. After administration of perivenous tumescent anaesthesia the laserfiber, RFA catheter or steam catheter is introduced. Perivenous tumescent anaesthesia is applied to decrease pain and prevent neural damage and skin burn. ${ }^{34}$ These procedures do not require spinal or general anaesthesia and can be performed in a outpatient setting.

\section{Radiofrequency ablation (RFA)}

The most commonly used device is the ClosureFast catheter (VNUS Medical Technologies Inc, Sunnyvale, CA). Local tissue is heated up to $90^{\circ} \mathrm{C}$ at the site of contact. Vein wall collagen contraction in response to thermal energy causes immediate vein wall thickening and lumen reduction. Endothelium destruction and an inflammatory response followed by fibrosis result in permanent occlusion. ${ }^{35,36}$ A thermocouple located on the catheter monitors the temperature and provides feedback to the generator, which, in turn, controls the power delivery and 
the treatment temperature. The thermocouple also monitors impedance. Control of energy delivery is an important feature of the RFA technique.

\section{Results}

Three randomized clinical trials have compared RFA with surgical stripping of the GSV. The EVOLVeS trial is a multicenter prospective randomized trial sponsored by the manufacturer with 80 procedures. They reported significant early advantages, mainly on patient recovery. ${ }^{37}$ Patients undergoing RFA showed a quicker return to normal activity; 1.15 days compared to 3.89 days. Mean duration of the time to return to work were also in favour of the RFA group, 4.7 days compared to 12.4 days in the conventional stripping group. Quality of life analysis showed superior outcome in the RFA group for global score and pain score between 1 week and 4 months. Clinical outcomes were also evaluated with a two year follow up period. Clinical and hemodynamic outcomes and varicose vein recurrence rates were similar for both groups at 2 years. ${ }^{38}$ In a second, smaller trial Rautio et al randomized 28 patients between RFA and conventional stripping. ${ }^{39}$ These patients were followed up at 3 years post procedure. ${ }^{40}$ Significantly less post operative pain was reported and shorter sick leaves and faster return to normal activities. There was no difference in the quality of life scores between the two groups following treatment. The results of these two randomized trials are possibly flawed by their low number of included patients. Elkaffas et al randomized 180 limbs with a follow up of 2 years and reported equal recurrence rates. ${ }^{41}$ Primary occlusion rates were $95 \%$ in the RFA group versus $100 \%$ in the surgical group.

Reports of non-randomised case series of RFA procedures showed that that RFA was effective in $85 \%$ to $90 \%$ of the treated limbs with follow up periods varying from 2 to 5 years. Effectiveness was assessed with duplex ultrasound. $34,42,43,44$

\section{Laser ablation (EVLA)}

Thermal laser energy is applied along the length of the vein by withdrawing the laser fiber. The temperature of the laser tip increases to $800^{\circ} \mathrm{C}$. Direct contact with the venous wall results in local destruction and may lead to (micro) perforation of the GSV and induces blood carbonization. ${ }^{34,45}$ patients also report the taste of burned blood during EVLA.

There are three randomized controlled trials comparing EVLA with surgical stripping of the GSV. Darwood et al randomized 114 legs with a follow up period of 3 months. ${ }^{46}$ The primary outcomes were abolition of reflux (technical success) and improvement of quality of life (clinical success). Both treatments were equally effective in abolition of reflux. However, return to normal activity and work was significant quicker after EVLA. Rasmussen et al described similar results, with no important outcome differences between surgery and EVLA. ${ }^{47}$ Both treatments were performed with tumescent anaesthesia as an office based procedure. Postoperative pain and bruising was slightly higher in the conventional stripping group. Surprisingly they found no difference in return to normal activity and work between the two groups. Recently 
Rasmussen et al published their 2 year follow up data. ${ }^{48}$ No significant differences in clinical or ultrasound recurrences were found between EVLA and surgery. Similar improvements were gained in clinical severity scores and quality of life scores in both treatments. Both studies had problems with recruiting patients, many patients expressed a preference for EVLA. The third RCT comparing EVLA with surgical stripping of the GSV is the largest study reported until now. Christenson et al randomized 200 patients with a follow up of 2 years. ${ }^{49}$ Abolition of GSV reflux, safety, improvement in QOL, and clinical severity score were similar. Also the time needed to return to work was equal with 7 days. The recanalization rate of symptomatic limbs was 3.2\% in the EVLA group. There were no cases of neovascularisation in both groups as to be expected with mid-term follow up. Two randomized controlled trials focused on high ligation combined with stripping versus high ligation combined with EVLA. ${ }^{50,51}$ Both studies reported a significant difference in bruising and swelling in favour of the EVLA group. Disselhoff et al compared EVLA with cryostripping. ${ }^{52}$ Both procedures were similarly effective, but patients favoured EVLA because of less pain and postoperative morbidity, and quicker return to normal activity.

Table 2: Endovenous laser ablation (EVLA) versus conventional surgery (S)

\begin{tabular}{lccc} 
& Darwood & Rasmussen & Christenson \\
\hline legs $(\mathrm{n})$ & 114 & 137 & 204 \\
follow up (months) & 12 & 24 & 24 \\
laser $(\mathrm{nm})$ & $810 \mathrm{~nm}$ & 980 & $980 \mathrm{~nm}$ \\
laser energy $(\mathrm{J} / \mathrm{cm})$ & 65 & 74 & 76 \\
time to resume work (days) & & & \\
$\quad$ laser ablation & 4.4 & 7.0 & 6.9 \\
$\quad$ surgical stripping & 17 & 7.6 & 6.6 \\
occlusion rates (duplex) & & & $93 \%$ \\
$\quad$ laser ablation & $88 \%$ & $93 \%$ & $100 \%$ \\
$\quad$ surgical stripping & $92 \%$ & $96 \%$ & \\
complications (EVLA/S) & & & $0 / 0$ \\
$\quad$ DVT & $0 / 0$ & $1 / 0$ & $1 / 1$ \\
paresthesia & $2 / 4$ & $1 / 1$ & $0 / 0$ \\
$\quad$ wound infection & $1 / 3$ & $0 / 1$ & $12 / 5$ \\
$\quad$ hematoma & - & $3 / 5$ &
\end{tabular}


Several large case series with follow up periods varying from 1 to 4 year and at least 100 treated limbs have been reported. ${ }^{53-56}$ Success rates are as high as $100 \%$ post procedure and remain well above the $90 \%$ after midterm follow up. Desmyttere et al. presented a closure rate of $97 \%$ after treating 511 GSV with a follow up of 4 years. ${ }^{56}$

\section{EVLA versus RFA}

Recently several trials comparing the short term results of EVLA and RFA were published. Almeida et al concluded that RFA was significantly superior to EVLA in terms of post procedural recovery and quality of life. ${ }^{57}$ In the RECOVERY trial, a randomized, multicenter trial sponsored by VNUS, eighty seven patients were included and followed for 1 month. All scores referable to pain, hematoma, and tenderness were statistically lower in the RFA group at 48 hours, 1 week, and 2 weeks. The LARA trial is another randomized comparison between RFA and EVLA. ${ }^{58}$ This trial had two cohorts, patients with bilateral GSV incompetence and those with unilateral GSV incompetence. In total 87 legs were treated in this study. Limbs in the bilateral group were treated with RFA in one leg and EVLA in the other. In the unilateral group limbs were randomised to RFA or EVLA. Occlusion rates were equal around 95\%. In the bilateral group RFA resulted in significantly less pain and bruising compared to EVLA. In the unilateral group no significant differences were seen. The third RCT is by Shepherd et al. ${ }^{59} 131$ patients were enrolled and treated with RFA or EVLA under general anaesthesia. Primary outcome was mean post procedural pain over the first 3 days. Over the first 10 days pain scores and the use of analgesics were significant lower in the RFA group. However, these reductions could not be translated into faster recovery times. This study didn't report occlusion rates.

\section{Complications of endovascular procedures}

The most serious complication is DVT. Propagation of thrombus into the common femoral vein is thought to be the mechanism of DVT formation. The incidence of DVT is low with rates less than $1 \% .54-56,60,61$ The risk of DVT is increased by performing the procedure under general or spinal anaesthesia and concomitant multiple stab phlebectomies. ${ }^{62}$ The total procedure time is then much longer and patients are not able to mobilize early, thus creating a higher risk of DVT. A push for early ambulation is imperative.

Initially, neural damage resulting in paresthesia and skin burns were reported relatively frequently, but the incidence decreased significantly. ${ }^{8,34,61,63}$ Procedural changes such as tumescent anaesthesia and introduction of the catheter at knee level instead of the ankle are responsible for this decrease. Skin burns are reported in approximately 0-2\%.37,64 


\section{DISCUSSION}

Conventional and cryo surgical treatment carries a risk of scarring, hematoma formation and wound infection. Other disadvantages are the use of general or spinal anaesthesia and therefore day care treatment. Endovenous thermal ablation techniques like RFA and EVLA are minimal invasive treatment options of the insufficient GSV. These procedures leave no scars and wound infections are seldom seen. Midterm follow up shows that endovascular treatment is at least as effective and durable as traditional high ligation and stripping of the GSV. The endovascular procedures are superior in terms of recovery and return to daily activities when compared to conventional surgery. In contrast to the conventional stripping, endovascular procedures are carried out under local anaesthesia in a outpatient setting, thereby reducing costs. Only one RCT compared EVLA with surgery using tumescent anaesthesia for both groups. ${ }^{49}$ Rasmussen et al found no significant advantage in terms of clinical outcome, severity scores or recurrence between both groups with short and midterm follow up. The outcome of this trial suggests that the short term advantages of the endovenous procedures could be due to the different anaesthesia techniques. Stripping and high ligation was well tolerated using tumescent anaesthesia.

Randomized trials using RFA catheters report a significant better patient recovery phase after RFA compared to EVLA. ${ }^{57,58,65}$ Treatment related side effects such as pain and bruising are less after RFA treatment. The superior results in terms of patient recovery can be due to the fact that perforation of the GSV is rarely seen with RFA.

It remains unclear what the clinical relevance is of these results. Two trials did not find a significant difference in return to normal activities 58,66 and the third one reported no data on this subject. ${ }^{57}$ All of the three trials focussed on the short term, longer term clinical results are awaited.

Neovascularisation is frequent after conventional surgery and is thought to be the primary cause for recurrent reflux and varicose vein. ${ }^{67}$ Pichot et al. performed duplex ultrasound 2 years after RFA treatment. All of the 63 limbs treated did not show neovascularisation. ${ }^{68}$ Failure after surgery may be due to neovascularisation, double saphenous vein system, technical or tactical failure and incomplete procedure. ${ }^{69-71}$ There are several reasons accounting for the lower rates with endovenous techniques. An advantage of the endovenous techniques is the absence of the groin incision. It is believed that the surgical trauma is a potential trigger for neovascularisation. In addition, during the endovenous procedures the superficial epigastric vein remains patent. This means that the drainage of the abdominal wall is not disturbed, thus avoiding another trigger for neovasularisation. ${ }^{72}$

Neural damage is a common adverse effect of conventional stripping. Even after a short stripping, nerve injury occurs in about 7\%. Both EVLA and RFA report significantly better 
results with low rates of paresthesia. Skin burns can be easily avoided by applying tumescent fluid. Other adverse effects like wound infection are rare.

\section{CONCLUSION}

All treatment modalities appear to be effective and safe with short and midterm follow up. Before considering endovenous treatments as first choice treatment, large high quality randomized trials with long term follow up are needed. 


\section{REFERENCES}

1. Evans CJ, Fowkes FG, Ruckley CV, Lee AJ. Prevalence of varicose veins and chronic venous insufficiency in men and women in the general population: Edinburgh Vein Study. J Epidemiol Community Health 1999;53(3):149-153.

2. Beebe-Dimmer JL, Pfeifer JR, Engle JS, Schottenfeld D. The epidemiology of chronic venous insufficiency and varicose veins. Ann Epidemiol 2005; 15(3):175-184.

3. Krijnen RM, de Boer EM, Bruynzeel DP. Epidemiology of venous disorders in the general and occupational populations. Epidemiol Rev 1997; 19(2):294-309.

4. Callam MJ. Epidemiology of varicose veins. Br J Surg 1994; 81(2):167-173.

5. Smith JJ, Garratt AM, Guest M, Greenhalgh RM, Davies AH. Evaluating and improving health-related quality of life in patients with varicose veins. J Vasc Surg 1999; 30(4):710-719.

6. Van den OR, Hepp B, Debbaut B, Simon I. Socio-economic impact of chronic venous insufficiency. An underestimated public health problem. Int Angiol 1998; 17(3):161-167.

7. Labropoulos N, Leon M, Nicolaides AN, Giannoukas AD, Volteas N, Chan P. Superficial venous insufficiency: correlation of anatomic extent of reflux with clinical symptoms and signs. J Vasc Surg 1994; 20(6):953-958.

8. Sybrandy JE, Wittens $\mathrm{CH}$. Initial experiences in endovenous treatment of saphenous vein reflux. J Vasc Surg 2002; 36(6):1207-1212.

9. Navarro L, Min RJ, Bone C. Endovenous laser: a new minimally invasive method of treatment for varicose veins-preliminary observations using an $810 \mathrm{~nm}$ diode laser. Dermatol Surg 2001; 27(2):117-122.

10. Winterborn RJ, Corbett CR. Treatment of varicose veins: the present and the future--a questionnaire survey. Ann R Coll Surg Engl 2008; 90(7):561-564.

11. Edwards AG, Baynham S, Lees T, Mitchell DC. Management of varicose veins: a survey of current practice by members of the Vascular Society of Great Britain and Ireland. Ann R Coll Surg Engl 2009; 91(1):77-80.

12. Holme JB, Skajaa K, Holme K. Incidence of lesions of the saphenous nerve after partial or complete stripping of the long saphenous vein. Acta Chir Scand 1990; 156(2):145-148.

13. Winterborn RJ, Corbett CR. Treatment of varicose veins: the present and the future--a questionnaire survey. Ann R Coll Surg Engl 2008; 90(7):561-564.

14. Lacroix $\mathrm{H}$, Nevelsteen A, Suy R. Invaginating versus classic stripping of the long saphenous vein. A randomized prospective study. Acta Chir Belg 1999; 99(1):22-25.

15. Scheltinga MR, Wijburg ER, Keulers BJ, de Kroon KE. Conventional versus invaginated stripping of the great saphenous vein: a randomized, double-blind, controlled clinical trial. World J Surg 2007; 31(11):2236-2242.

16. Durkin MT, Turton EP, Scott DJ, Berridge DC. A prospective randomised trial of PIN versus conventional stripping in varicose vein surgery. Ann R Coll Surg Engl 1999; 81(3):171-174.

17. Dwerryhouse S, Davies B, Harradine K, Earnshaw JJ. Stripping the long saphenous vein reduces the rate of reoperation for recurrent varicose veins: five-year results of a randomized trial. J Vasc Surg 1999; 29(4):589-592.

18. Jones L, Braithwaite BD, Selwyn D, Cooke S, Earnshaw JJ. Neovascularisation is the principal cause of varicose vein recurrence: results of a randomised trial of stripping the long saphenous vein. Eur J Vasc Endovasc Surg 1996; 12(4):442445.

19. Turton EP, Scott DJ, Richards SP, Weston MJ, Berridge DC, Kent PJ et al. Duplex-derived evidence of reflux after varicose vein surgery: neoreflux or neovascularisation? Eur J Vasc Endovasc Surg 1999; 17(3):230-233.

20. Fischer R, Linde N, Duff C, Jeanneret C, Chandler JG, Seeber P. Late recurrent saphenofemoral junction reflux after ligation and stripping of the greater saphenous vein. J Vasc Surg 2001; 34(2):236-240. 
21. De Maeseneer MG, Philipsen TE, Vandenbroeck CP, Lauwers PR, Hendriks JM, De Hert SG et al. Closure of the cribriform fascia: an efficient anatomical barrier against postoperative neovascularisation at the saphenofemoral junction? A prospective study. Eur J Vasc Endovasc Surg 2007; 34(3):361-366.

22. De Maeseneer MG, Vandenbroeck CP, Lauwers PR, Hendriks JM, De Hert SG, Van Schil PE. Early and late complications of silicone patch saphenoplasty at the saphenofemoral junction. J Vasc Surg 2006; 44(6):1285-1290.

23. De Maeseneer MG, Giuliani DR, Van Schil PE, De Hert SG. Can interposition of a silicone implant after sapheno-femoral ligation prevent recurrent varicose veins? Eur J Vasc Endovasc Surg 2002; 24(5):445-449.

24. Goodwin H. Litigation and surgical practice in the UK. Br J Surg 2000; 87(8):977-979.

25. Morrison C, Dalsing MC. Signs and symptoms of saphenous nerve injury after greater saphenous vein stripping: prevalence, severity, and relevance for modern practice. J Vasc Surg 2003; 38(5):886-890.

26. Holme JB, Skajaa K, Holme K. Incidence of lesions of the saphenous nerve after partial or complete stripping of the long saphenous vein. Acta Chir Scand 1990; 156(2):145-148.

27. Subramonia S, Lees T. Sensory abnormalities and bruising after long saphenous vein stripping: impact on short-term quality of life. J Vasc Surg 2005; 42(3):510-514.

28. Hagmuller GW. [Complications in surgery of varicose veins]. Langenbecks Arch Chir Suppl Kongressbd 1992; 470-474.

29. Critchley G, Handa A, Maw A, Harvey A, Harvey MR, Corbett CR. Complications of varicose vein surgery. Ann R Coll Surg Engl 1997; 79(2):105-110.

30. van Rij AM, Chai J, Hill GB, Christie RA. Incidence of deep vein thrombosis after varicose vein surgery. Br J Surg 2004; 91(12):1582-1585.

31. Corder AP, Schache DJ, Farquharson SM, Tristram S. Wound infection following high saphenous ligation. A trial comparing two skin closure techniques: subcuticular polyglycolic acid and interrupted monofilament nylon mattress sutures. J R Coll Surg Edinb 1991; 36(2):100-102.

32. Menyhei G, Gyevnar Z, Arato E, Kelemen O, Kollar L. Conventional stripping versus cryostripping: a prospective randomised trial to compare improvement in quality of life and complications. Eur J Vasc Endovasc Surg 2008; 35(2):218223.

33. Klem TM, Schnater JM, Schutte PR, Hop W, van der Ham AC, Wittens CH. A randomized trial of cryo stripping versus conventional stripping of the great saphenous vein. J Vasc Surg 2009; 49(2):403-409.

34. Weiss RA, Weiss MA. Controlled radiofrequency endovenous occlusion using a unique radiofrequency catheter under duplex guidance to eliminate saphenous varicose vein reflux: a 2-year follow-up. Dermatol Surg 2002; 28(1):38-42.

35. Weiss RA. Comparison of endovenous radiofrequency versus $810 \mathrm{~nm}$ diode laser occlusion of large veins in an animal model. Dermatol Surg 2002; 28(1):56-61.

36. Schmedt CG, Sroka R, Steckmeier S, Meissner OA, Babaryka G, Hunger K et al. Investigation on radiofrequency and laser $(980 \mathrm{~nm})$ effects after endoluminal treatment of saphenous vein insufficiency in an ex-vivo model. Eur J Vasc Endovasc Surg 2006; 32(3):318-325.

37. Lurie F, Creton D, Eklof B, Kabnick LS, Kistner RL, Pichot $O$ et al. Prospective randomized study of endovenous radiofrequency obliteration (closure procedure) versus ligation and stripping in a selected patient population (EVOLVeS Study). J Vasc Surg 2003; 38(2):207-214.

38. Lurie F, Creton D, Eklof B, Kabnick LS, Kistner RL, Pichot $O$ et al. Prospective randomised study of endovenous radiofrequency obliteration (closure) versus ligation and vein stripping (EVOLVeS): two-year follow-up. Eur J Vasc Endovasc Surg 2005; 29(1):67-73.

39. Rautio T, Ohinmaa A, Perala J, Ohtonen P, Heikkinen T, Wiik H et al. Endovenous obliteration versus conventional stripping operation in the treatment of primary varicose veins: a randomized controlled trial with comparison of the costs. J Vasc Surg 2002; 35(5):958-965. 
40. Perala J, Rautio T, Biancari F, Ohtonen P, Wiik H, Heikkinen T et al. Radiofrequency endovenous obliteration versus stripping of the long saphenous vein in the management of primary varicose veins: 3-year outcome of a randomized study. Ann Vasc Surg 2005; 19(5):669-672.

41. Elkaffas KH, Elkashef O, Elbaz W. Great Saphenous Vein Radiofrequency Ablation Versus Standard Stripping in the Management of Primary Varicose Veins: A Randomized Clinical Trial. Angiology 2010.

42. Merchant RF, DePalma RG, Kabnick LS. Endovascular obliteration of saphenous reflux: a multicenter study. J Vasc Surg 2002; 35(6):1190-1196.

43. Merchant RF, Pichot O. Long-term outcomes of endovenous radiofrequency obliteration of saphenous reflux as a treatment for superficial venous insufficiency. J Vasc Surg 2005; 42(3):502-509.

44. Merchant RF, Pichot O, Myers KA. Four-year follow-up on endovascular radiofrequency obliteration of great saphenous reflux. Dermatol Surg 2005; 31(2):129-134.

45. Amzayyb M, van den Bos RR, Kodach VM, de Bruin DM, Nijsten T, Neumann HA et al. Carbonized blood deposited on fibres during 810,940 and 1,470 nm endovenous laser ablation: thickness and absorption by optical coherence tomography. Lasers Med Sci 2010; 25(3):439-447.

46. Darwood RJ, Theivacumar N, Dellagrammaticas D, Mavor Al, Gough MJ. Randomized clinical trial comparing endovenous laser ablation with surgery for the treatment of primary great saphenous varicose veins. Br J Surg 2008; 95(3):294-301.

47. Rasmussen LH, Bjoern L, Lawaetz M, Blemings A, Lawaetz B, Eklof B. Randomized trial comparing endovenous laser ablation of the great saphenous vein with high ligation and stripping in patients with varicose veins: short-term results. J Vasc Surg 2007; 46(2):308-315.

48. Rasmussen LH, Bjoern L, Lawaetz M, Lawaetz B, Blemings A, Eklof B. Randomised clinical trial comparing endovenous laser ablation with stripping of the great saphenous vein: clinical outcome and recurrence after 2 years. Eur J Vasc Endovasc Surg 2010; 39(5):630-635.

49. (Christenson JT, Gueddi S, Gemayel G, Bounameaux H. Prospective randomized trial comparing endovenous laser ablation and surgery for treatment of primary great saphenous varicose veins with a 2-year follow-up. J Vasc Surg 2010.

50. Kalteis M, Berger I, Messie-Werndl S, Pistrich R, Schimetta W, Polz W et al. High ligation combined with stripping and endovenous laser ablation of the great saphenous vein: early results of a randomized controlled study. J Vasc Surg 2008; 47(4):822-829.

51. de Medeiros CA, Luccas GC. Comparison of endovenous treatment with an $810 \mathrm{~nm}$ laser versus conventional stripping of the great saphenous vein in patients with primary varicose veins. Dermatol Surg 2005; 31(12):1685-1694.

52. Disselhoff BC, der Kinderen DJ, Kelder JC, Moll FL. Randomized clinical trial comparing endovenous laser with cryostripping for great saphenous varicose veins. Br J Surg 2008; 95(10):1232-1238.

53. Min RJ, Khilnani N, Zimmet SE. Endovenous laser treatment of saphenous vein reflux: long-term results. J Vasc Interv Radiol 2003; 14(8):991-996.

54. Agus GB, Mancini S, Magi G. The first 1000 cases of Italian Endovenous-laser Working Group (IEWG). Rationale, and longterm outcomes for the 1999-2003 period. Int Angiol 2006; 25(2):209-215.

55. Ravi R, Rodriguez-Lopez JA, Trayler EA, Barrett DA, Ramaiah V, Diethrich EB. Endovenous ablation of incompetent saphenous veins: a large single-center experience. J Endovasc Ther 2006; 13(2):244-248.

56. (56) Desmyttere J, Grard C, Wassmer B, Mordon S. Endovenous 980-nm laser treatment of saphenous veins in a series of 500 patients. J Vasc Surg 2007; 46(6):1242-1247.

57. Almeida Jl, Kaufman J, Gockeritz O, Chopra P, Evans MT, Hoheim DF et al. Radiofrequency endovenous ClosureFAST versus laser ablation for the treatment of great saphenous reflux: a multicenter, single-blinded, randomized study (RECOVERY study). J Vasc Interv Radiol 2009; 20(6):752-759.

58. Goode SD, Chowdhury A, Crockett M, Beech A, Simpson R, Richards T et al. Laser and radiofrequency ablation study (LARA study): a randomised study comparing radiofrequency ablation and endovenous laser ablation (810 nm). Eur J Vasc Endovasc Surg 2010; 40(2):246-253. 
59. Shepherd AC, Gohel MS, Brown LC, Metcalfe MJ, Hamish M, Davies AH. Randomized clinical trial of VNUS ClosureFAST radiofrequency ablation versus laser for varicose veins. Br J Surg 2010; 97(6):810-818.

60. Merchant R, Jr. Is there an increased risk for DVT with the VNUS closure procedure? 2003.

61. Almeida Jl, Raines JK. Radiofrequency ablation and laser ablation in the treatment of varicose veins. Ann Vasc Surg 2006; 20(4):547-552.

62. Puggioni A, Marks N, Hingorani A, Shiferson A, Alhalbouni S, Ascher E. The safety of radiofrequency ablation of the great saphenous vein in patients with previous venous thrombosis. J Vasc Surg 2009; 49(5):1248-1255.

63. Nicolini P. Treatment of primary varicose veins by endovenous obliteration with the VNUS closure system: results of a prospective multicentre study. Eur J Vasc Endovasc Surg 2005; 29(4):433-439.

64. Merchant RF, Pichot O, Myers KA. Four-year follow-up on endovascular radiofrequency obliteration of great saphenous reflux. Dermatol Surg 2005; 31(2):129-134.

65. Shepherd AC, Gohel MS, Brown LC, Metcalfe MJ, Hamish M, Davies AH. Randomized clinical trial of VNUS ClosureFAST radiofrequency ablation versus laser for varicose veins. Br J Surg 2010; 97(6):810-818.

66. Shepherd AC, Gohel MS, Brown LC, Metcalfe MJ, Hamish M, Davies AH. Randomized clinical trial of VNUS ClosureFAST radiofrequency ablation versus laser for varicose veins. Br J Surg 2010; 97(6):810-818.

67. Jones L, Braithwaite BD, Selwyn D, Cooke S, Earnshaw JJ. Neovascularisation is the principal cause of varicose vein recurrence: results of a randomised trial of stripping the long saphenous vein. Eur J Vasc Endovasc Surg 1996; 12(4):442445.

68. Pichot O, Kabnick LS, Creton D, Merchant RF, Schuller-Petroviae S, Chandler JG. Duplex ultrasound scan findings two years after great saphenous vein radiofrequency endovenous obliteration. J Vasc Surg 2004; 39(1):189-195.

69. Perrin MR, Labropoulos N, Leon LR, Jr. Presentation of the patient with recurrent varices after surgery (REVAS). J Vasc Surg 2006; 43(2):327-334.

70. van Rij AM, Jiang P, Solomon C, Christie RA, Hill GB. Recurrence after varicose vein surgery: a prospective long-term clinical study with duplex ultrasound scanning and air plethysmography. J Vasc Surg 2003; 38(5):935-943.

71. Dwerryhouse S, Davies B, Harradine K, Earnshaw JJ. Stripping the long saphenous vein reduces the rate of reoperation for recurrent varicose veins: five-year results of a randomized trial. J Vasc Surg 1999; 29(4):589-592.

72. Fischer R, Chandler JG, De Maeseneer MG, Frings N, Lefebvre-Vilarbedo M, Earnshaw JJ et al. The unresolved problem of recurrent saphenofemoral reflux. J Am Coll Surg 2002; 195(1):80-94. 

An adapted version of this review was published in the British Medical Journal 2011:

THE MANAGEMENT OF SUPERFICIAL VENOUS INCOMPETENCE 


\section{INTRODUCTION}

Superficial venous disease of the leg is common, disabling and costly and impacts negatively on patients' quality of life. ${ }^{1} \mathrm{~A}$ UK cross sectional survey found a prevalence of trunk varicosities of more than $30 \%{ }^{2}$ Trunk varicosities originate from the great saphenous vein in almost $50 \%$, the small saphenous vein in $30 \%$ and in $20 \%$ from both veins ${ }^{3}$ (Figure 1).

We review the management of superficial venous incompetence of the leg focusing on the effectiveness of the procedures most commonly used and their complication rates.

Figure 1: Venous anatomy of the leg

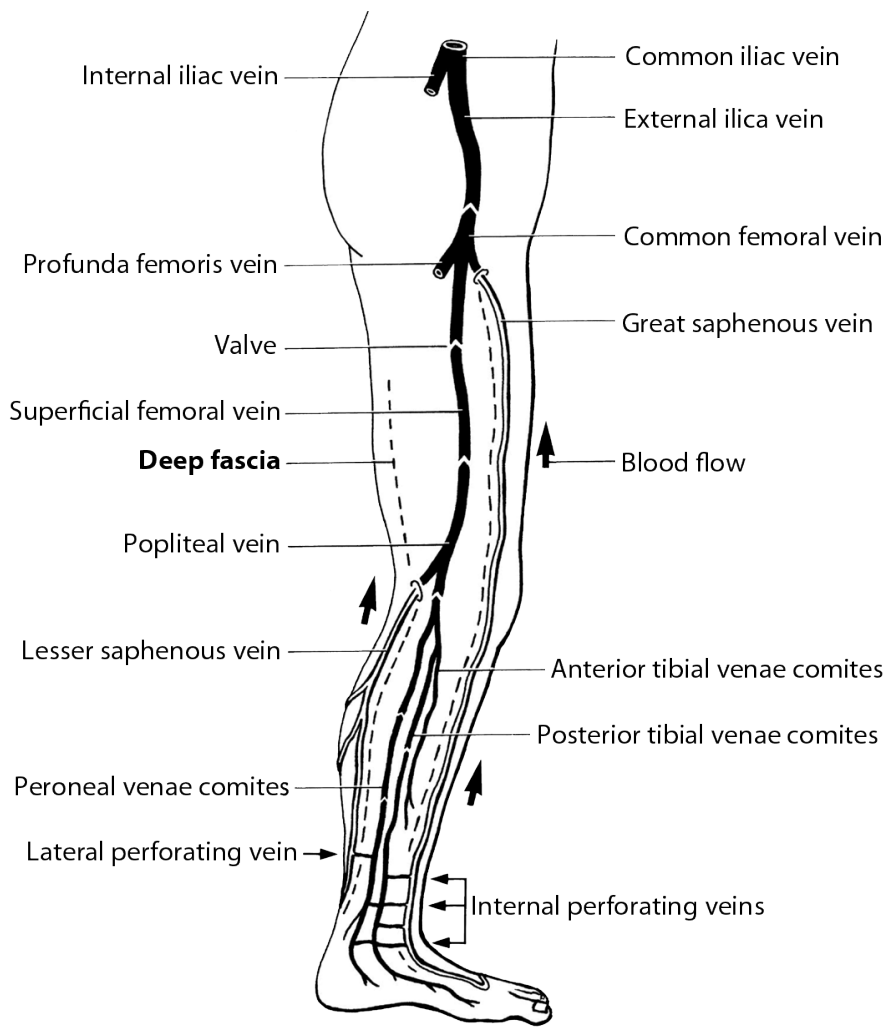




\section{SOURCES AND SELECTION CRITERIA}

We performed a search of PubMed, Medline, Cochrane and Embase for the terms "varicose" or "saphenous" and extracted data from the most valid prospective cohort studies and available randomized controlled trials of the past 25 years. Efficacy of treatment was assessed by recurrence rate, quality of life, pain scores, return to daily activities and work.

Numerous trials comparing treatment modalities have low numbers of included patients, absence of a clinically relevant primary outcome and involvement of the manufacturer. Several studies report problems with recruiting patients because many patients expressed a preference for endovenous procedures. Neither investigators nor patients were blinded to the treatment method in all randomized trials. Aforementioned problems are very likely to induce bias.

\section{Who gets superficial venous incompetence?}

A positive family history, increasing age and pregnancy are proven risk factors in developing superficial venous incompetence. Controversial risk factors are obesity, standing occupation and decreased mobility. ${ }^{4}$ There is no convincing evidence that venous incompetence is more common in women.

\section{How is superficial venous incompetence diagnosed?}

Patients may complain of aching, itching, cramps, swelling and restless legs relieved by walking. Symptoms are mostly worse during the evening and night. Clinical signs vary from small reticular veins and varicosities, to oedema, eczema like skin changes and venous ulcers. The gold standard for diagnosis of superficial venous incompetence is a duplex ultrasound to identify valve incompetence. The sensitivity of duplex ultrasound for the great and small saphenous vein varies between $91 \%$ and $95 \%$. The specificity varies between $95 \%$ and $100 \% .{ }^{5}$

\section{Classification of venous disease}

The CEAP classification is used for clinical description of venous disease in general and can be used for superficial venous incompetence. ${ }^{6}$ CEAP is an acronym for Clinical, Etiology, Anatomy, Pathophysiology. The ' $C$ ' is the most frequent used part of the classification to rate the clinical severity of venous disease. It ranges from C0 to C6 (Table 1). Etiology of superficial venous incompetence is often unknown. Anatomy and pathophysiology of venous disease can only be described after a venous duplex ultrasound..$^{5}$ 


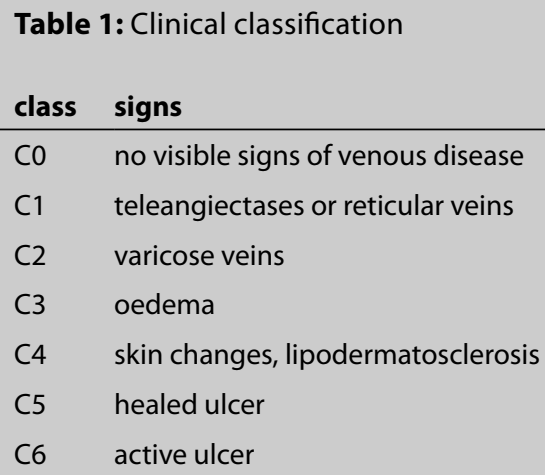

\section{To treat or not to treat?}

There is no evidence that asymptomatic patients with venous disease need treatment or that 'prophylactic treatment' in these patients reduces the progression of venous disease. A good quality observational study concluded that venous disease will progress without further treatment. $^{7}$

Symptomatic patients with $\mathrm{C} 1$ to $\mathrm{C} 6$ disease can be treated to reduce symptoms.

Since patients may experience poor quality of life because of the way varicose veins look we argue that cosmesis is a valid reason for treatment. 8,9

\section{What are the treatment options?}

Treatment of great and small saphenous vein incompetence is either conservative with compression stockings or invasive. The objective is to reduce symptoms. Surgical treatment has consisted of high ligation and stripping of the great saphenous vein and high ligation for the small saphenous vein for decades. In recent years minimally invasive treatments such as endovenous thermo ablation and foam sclerotherapy have become popular. Suggested advantages of these approaches are reduced postoperative pain, faster recovery and improved cosmesis.

A good quality randomized trial with long term follow up recommended to perform a venous duplex ultrasound of the deep and superficial venous system prior to an intervention ${ }^{10}$. Treatment of the great or small saphenous vein is contra-indicated if there is an occlusion of the deep venous system identified with duplex ultrasound, because venous blood return is then only possible through the superficial venous system. 


\section{Conservative management}

Patients with symptoms but no wish for invasive interventions can be treated with short (below knee) class 2 compression stockings (20-30 mm Hg ankle pressure). Compression stockings improves both symptoms and venous hemodynamics. However, this benefit is limited to the period during which the stocking is worn. Stockings also have a poor patient compliance. ${ }^{11}$

\section{Surgery for superficial venous incompetence}

Short stripping of the great saphenous vein has been the treatment of choice for great saphenous vein incompetence in past decades. The saphenofemoral junction and its tributaries in the groin are ligated and divided followed by a strip of the great saphenous vein from groin to knee level. An alternative stripping method, cryostripping, has no benefits compared to conventional stripping. ${ }^{12}$

The incompetent small saphenous vein is only ligated and divided near the popliteal vein in the knee pit since stripping carries the risk of damaging the sural nerve. Nowadays a preoperative duplex ultrasound localisation of the small saphenous vein is performed prior to surgery. The venous system of the leg has a large residual capacity and will take over the function of the great or small saphenous vein. These surgical procedures are performed in day care and usually under general or spinal anaesthesia. Some specialized venous centers perform stripping using local anaesthesia (peri-venous tumescent anaesthesia) and peri-operative duplex ultrasound.

Recurrence after stripping of the great saphenous vein on duplex ultrasound is $13-29 \%$ after 5 years in a randomized trial. ${ }^{13} \mathrm{~A}$ low evidence observational study suggests a recurrence rate of $60 \%$ after more than 30 years. ${ }^{14}$ Recurrence after ligation of the small saphenous vein after 5 years, confirmed by duplex ultrasound is $30 \% .^{15}$

Problems arising from superficial venous surgery are the single most common reason for litigation in the UK. ${ }^{16}$ Most settled claims result from a failure to warn patients for nerve damage. A short strip (groin to knee level) proposes a far less risk (8\%) for saphenous nerve damage compared to the risk of a strip from groin to ankle level (40\%). ${ }^{17}$ Incidence of deep vein thrombosis following conventional stripping confirmed by duplex ultrasound is about $5 \%$, mostly confined to the calf veins. About $2.1 \%$ of these patients are symptomatic. ${ }^{18}$ Hematoma formation is common after stripping and wound infection occurs in about $10 \%$ and is responsible for delayed return to normal activity and work. ${ }^{19}$ Sural nerve damage after small saphenous vein ligation has an incidence of $2.1 \%$ and paresthesia rates of $1.7-34 \%{ }^{15}$ 


\section{ENDOVENOUS THERMO ABLATION FOR SUPERFICIAL VENOUS INCOMPETENCE}

Radiofrequency ablation and endovenous laser ablation are minimally invasive catheter based procedures in which thermal energy is delivered into the vein wall. Thermal energy causes an inflammatory response resulting in fibrosis and closure of the vein (Figure 2).

The great or small saphenous vein is cannulated under duplex ultrasound guidance. A catheter is inserted and positioned near the saphenofemoral or saphenopopliteal junction. Local anaesthesia is administered as peri-venous tumescent anaesthesia. In this technique a large volume of local anaesthetic in saline solution is administered duplex ultrasound guided around the great or small saphenous vein which also prevents neural damage and skin burn due to cooling. These procedures do not require spinal or general anaesthesia and can be performed in an outpatient setting. The saphenofemoral and saphenopopliteal junction is, in contrast to the surgical procedure, not disconnected. Although this is a radical change from the conventional treatment, a small observational study concluded that there is no adverse impact on clinical outcome. ${ }^{20}$

\section{Endovenous laser and radiofrequency ablation}

Endovenous laser ablation and conventional stripping are equally effective after two years. ${ }^{21}$ Return to normal activity and work however was faster after endovenous laser ablation. ${ }^{22}$

When surgical stripping is performed duplex ultrasound guided with tumescent anaesthesia no difference was found in postoperative pain, recurrence rates, return to normal activity or work compared to endovenous laser ablation according to good randomised controlled trials. $^{23,24}$

Endovenous radiofrequency ablation shows only slightly better short term results than conventional stripping, mainly on patient recovery. ${ }^{25,26}$

A randomized trial sponsored by a manufacturer suggested that endovenous radiofrequency ablation is less painful than endovenous laser ablation and has a lower incidence of bruising. ${ }^{27}$ Both procedures are equally effective for the treatment of the great saphenous vein in the long term, with a success rate of $95 \% .28$

There are no studies comparing surgical and endovenous treatment of the small saphenous vein. Available data shows that endovenous laser ablation of the small saphenous is far more used than radiofrequency ablation. Success rates of endovenous thermo ablation of the small saphenous vein in large case series varies between $91-100 \%{ }^{15}$ 
Figure 2: Endovenous ablation of the great saphenous vein by withdrawing the catheter.

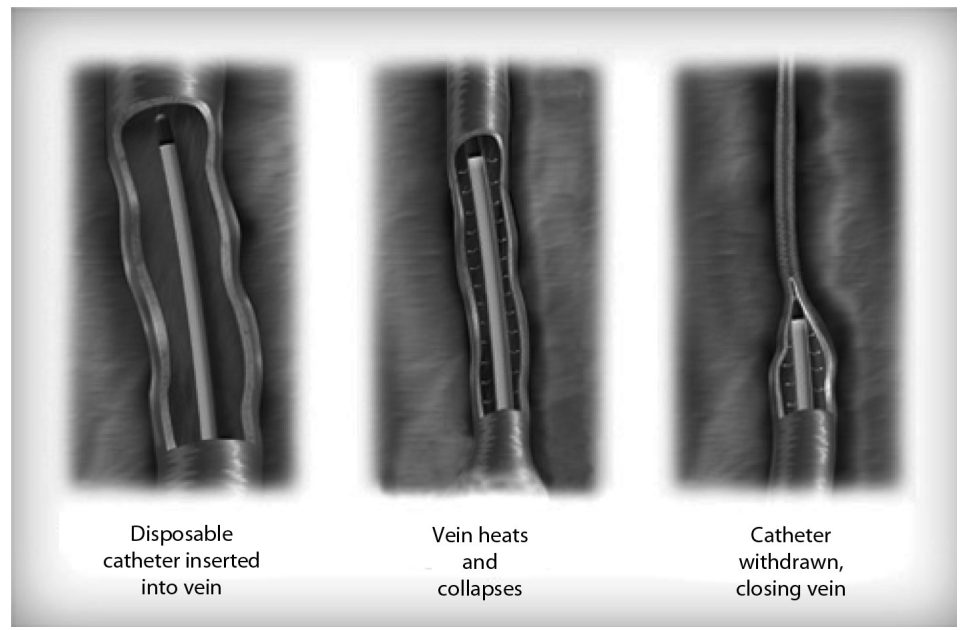

\section{Problems that may occur after an endovenous procedure}

The incidence of deep vein thrombosis following endovenous procedures of the great saphenous vein is less than $1 \%$ and for the small saphenous vein between $1.3 \%-5.7 \%{ }^{15,29}$ Early ambulation is essential. The risk of deep vein thrombosis is increased by performing the procedure under general or spinal anaesthesia and with concomitant multiple stab phlebectomies, as total procedure time is increased and patients are not able to mobilize early. ${ }^{30}$ Complications like neural damage and skin burns occur seldom because of the use of tumescent anaesthesia. ${ }^{31}$

\section{FOAM}

Foam sclerotherapy is an office based treatment. Sclerosing foam is injected through a cannula in the vein under duplex ultrasound guidance until the foam reaches the saphenofemoral or saphenopopliteal junction and vasospasm occurs. Compression therapy is immediately started after the procedure.

Foam sclerotherapy is popular because it is well tolerated, safe, easy to perform and can be repeated easily according to a large prospective study. ${ }^{32}$ In two small randomized trials, a slightly faster recovery after foam sclerotherapy compared to conventional surgery was observed. ${ }^{33,34}$

There are no studies comparing surgical and foam treatment of the small saphenous vein. Success rates of foam sclerotherapy of the small saphenous vein varies between $82-100 \%$ according to observational studies. ${ }^{15}$ 
Bruising, tromboflebitis and skin pigmentation are frequent complications after foam therapy ${ }^{15}$. Trombo-embolic complication rates are low (0.4\%). ${ }^{15,32}$ There have been some concerns about neurologic complications after foam sclerotherapy. Theoretically, micro-embolism can reach the systemic circulation through a patent foramen ovale. In a recent prospective case study of over 1250 treated legs, only five self limiting visual disturbances were seen. The risk of microembolism causing serious adverse events was considered negligible. ${ }^{32}$

A good quality randomized trial, comparing stripping, endovenous laser ablation, endovenous radiofrequency ablation and foam sclerotherapy showed that the technical failure rate was highest after foam sclerotherapy. Endovenous radiofrequency ablation and foam sclerotherapy were associated with a faster recovery and less postoperative pain than laser ablation and stripping. 35

\section{CONCLUSION}

All treatment modalities appear to be effective and safe with short and mid term follow up. Before considering endovenous treatments as first choice treatment, large high quality randomized trials with long term follow up are needed.

\section{SUMMARY POINTS}

- Venous disease should be classified according to the CEAP classification.

- The gold standard for diagnosis of superficial venous incompetence is a duplex ultrasound.

- The objective of therapy for superficial venous incompetence is to reduce symptoms.

- All treatment modalities appear to be safe and effective with short and midterm follow up.

- Endovenous procedures are associated with a faster postoperative recovery compared to conventional surgery.

- A surgical strip under tumescent anaesthesia shows no differences on patient recovery compared to endovenous procedures.

\section{QUESTIONS FOR FUTURE RESEARCH}

- Long term follow up of endovenous procedures.

- Comparison between a modernized surgical strip with or without a ligation of the tributaries at the saphenofemoral junction.

- Comparison of new minimally invasive catheter based techniques like Clarivein and Steam Vein Sclerosis to the current procedures.

- Comparison between compression stockings or no compression stockings after treatment. 


\section{TIPS FOR NON SPECIALISTS}

- Use the ' $C$ ' of the CEAP classification when classifying venous disease.

- In symptomatic patients, with no wish for operation, below knee stockings can be useful in the treatment of superficial venous incompetence.

- Pre-treatment venous duplex ultrasound is recommended before proceeding with an intervention of the superficial venous system.

- Always refer patients with an active or healed venous ulcer.

\section{PATIENT'S STORY}

I have stalled treatment of my varicose veins for years. I suffered from fatigue, swelling and restless legs almost every day. I hated the idea of an operation, but forgot to wear my stockings too often. Then my doctor proposed a laser treatment under local anesthesia. Finally I got on with it and went to the laser lab. The local anesthesia was not so bad, but I will never forget the awful taste of burned flesh during the laser treatment.

The first 8 days I suffered little pain but then it got really bad. I needed painkillers for another week. Two years after treatment my legs are so much better now and I am very glad I went on with this treatment. 


\section{REFERENCE}

1. Carradice D, Mazari FA, Samuel N, Allgar V, Hatfield J, Chetter IC. Modelling the effect of venous disease on quality of life. Br J Surg 2011; 98(8):1089-98.

2. Evans CJ, Fowkes FG, Ruckley CV, Lee AJ. Prevalence of varicose veins and chronic venous insufficiency in men and women in the general population: Edinburgh Vein Study. J.Epidemiol.Community Health 1999; 53(3):149-53.

3. Labropoulos N, Leon M, Nicolaides AN, Giannoukas AD, Volteas N, Chan P. Superficial venous insufficiency: correlation of anatomic extent of reflux with clinical symptoms and signs. J.Vasc.Surg. 1994; 20(6):953-58.

4. Lim CS, Davies AH. Pathogenesis of primary varicose veins. Br J Surg 2009; 96(11):1231-42.

5. Mercer KG, Scott DJ, Berridge DC. Preoperative duplex imaging is required before all operations for primary varicose veins. Br J Surg 1998; 85(11):1495-7.

6. klof B, Rutherford RB, Bergan JJ, Carpentier PH, Gloviczki P, Kistner RL, et al. Revision of the CEAP classification for chronic venous disorders: consensus statement. J.Vasc.Surg. 2004; 40(6):1248-52.

7. Maurins U, Hoffmann BH, Losch C, Jockel KH, Rabe E, Pannier F. Distribution and prevalence of reflux in the superficial and deep venous system in the general population--results from the Bonn Vein Study, Germany. J Vasc Surg 2008; 48(3):680-7.

8. Darvall KA, Bate GR, Sam RC, Adam DJ, Silverman SH, Bradbury AW. Patients' expectations before and satisfaction after ultrasound guided foam sclerotherapy for varicose veins. Eur J Vasc Endovasc Surg 2009; 38(5):642-7.

9. Klem TM, Sybrandy JE, Wittens CH. Measurement of health-related quality of life with the Dutch translated Aberdeen Varicose Vein Questionnaire before and after treatment. Eur J Vasc Endovasc Surg 2009; 37(4):470-6.

10. Blomgren L, Johansson G, Emanuelsson L, Dahlberg-Akerman A, Thermaenius P, Bergqvist D. Late follow-up of a randomized trial of routine duplex imaging before varicose vein surgery. Br J Surg 2011.

11. Beale RJ, Gough MJ. Treatment options for primary varicose veins--a review. Eur J Vasc Endovasc Surg 2005; 30(1):83-95.

12. Klem TM, Schnater JM, Schutte PR, Hop W, van der Ham AC, Wittens $\mathrm{CH}$. A randomized trial of cryo stripping versus conventional stripping of the great saphenous vein. J.Vasc.Surg. 2009; 49(2):403-09.

13. Dwerryhouse S, Davies B, Harradine K, Earnshaw JJ. Stripping the long saphenous vein reduces the rate of reoperation for recurrent varicose veins: five-year results of a randomized trial. J.Vasc.Surg. 1999; 29(4):589-92.

14. Fischer R, Linde N, Duff C, Jeanneret C, Chandler JG, Seeber P. Late recurrent saphenofemoral junction reflux after ligation and stripping of the greater saphenous vein. J.Vasc.Surg. 2001; 34(2):236-40.

15. Tellings SS, Ceulen RP, Sommer A. Surgery and endovenous techniques for the treatment of small saphenous varicose veins: a review of the literature. Phlebology 2011.

16. Goodwin H. Litigation and surgical practice in the UK. Br.J.Surg. 2000; 87(8):977-79.

17. Subramonia S, Lees T. Sensory abnormalities and bruising after long saphenous vein stripping: impact on short-term quality of life. J.Vasc.Surg. 2005;42(3):510-14.

18. van Rij AM, Chai J, Hill GB, Christie RA. Incidence of deep vein thrombosis after varicose vein surgery. Br J Surg 2004;91(12):1582-5.

19. Corder AP, Schache DJ, Farquharson SM, Tristram S. Wound infection following high saphenous ligation. A trial comparing two skin closure techniques: subcuticular polyglycolic acid and interrupted monofilament nylon mattress sutures. J.R.Coll.Surg.Edinb. 1991; 36(2):100-02.

20. Theivacumar NS, Dellagrammaticas D, Beale RJ, Mavor Al, Gough MJ. Fate and clinical significance of saphenofemoral junction tributaries following endovenous laser ablation of great saphenous vein. Br J Surg 2007; 94(6):722-5.

21. Christenson JT, Gueddi S, Gemayel G, Bounameaux H. Prospective randomized trial comparing endovenous laser ablation and surgery for treatment of primary great saphenous varicose veins with a 2-year follow-up. J.Vasc.Surg. 2010. 
22. Darwood RJ, Theivacumar N, Dellagrammaticas D, Mavor Al, Gough MJ. Randomized clinical trial comparing endovenous laser ablation with surgery for the treatment of primary great saphenous varicose veins. Br.J.Surg. 2008; 95(3):294-301.

23. Rasmussen LH, Bjoern L, Lawaetz M, Lawaetz B, Blemings A, Eklof B. Randomised clinical trial comparing endovenous laser ablation with stripping of the great saphenous vein: clinical outcome and recurrence after 2 years. Eur.J.Vasc. Endovasc.Surg. 2010; 39(5):630-35.

24. Pronk P, Gauw SA, Mooij MC, Gaastra MT, Lawson JA, van Goethem AR, et al. Randomised controlled trial comparing sapheno-femoral ligation and stripping of the great saphenous vein with endovenous laser ablation (980 $\mathrm{nm}$ ) using local tumescent anaesthesia: one year results. Eur J Vasc Endovasc Surg 2010; 40(5):649-56.

25. Elkaffas KH, Elkashef O, Elbaz W. Great Saphenous Vein Radiofrequency Ablation Versus Standard Stripping in the Management of Primary Varicose Veins: A Randomized Clinical Trial. Angiology 2010.

26. Subramonia S, Lees T. Randomized clinical trial of radiofrequency ablation or conventional high ligation and stripping for great saphenous varicose veins. Br.J.Surg. 2010; 97(3):328-36.

27. Almeida Jl, Kaufman J, Gockeritz O, Chopra P, Evans MT, Hoheim DF, et al. Radiofrequency endovenous ClosureFAST versus laser ablation for the treatment of great saphenous reflux: a multicenter, single-blinded, randomized study (RECOVERY study). J.Vasc.Interv.Radiol. 2009; 20(6):752-59.

28. Shepherd AC, Gohel MS, Brown LC, Metcalfe MJ, Hamish M, Davies AH. Randomized clinical trial of VNUS ClosureFAST radiofrequency ablation versus laser for varicose veins. Br.J.Surg. 2010; 97(6):810-18.

29. Almeida Jl, Raines JK. Radiofrequency ablation and laser ablation in the treatment of varicose veins. Ann.Vasc.Surg. 2006; 20(4):547-52.

30. Puggioni A, Marks N, Hingorani A, Shiferson A, Alhalbouni S, Ascher E. The safety of radiofrequency ablation of the great saphenous vein in patients with previous venous thrombosis. J.Vasc.Surg. 2009; 49(5):1248-55.

31. Van Den Bos RR, Neumann M, De Roos KP, Nijsten T. Endovenous laser ablation-induced complications: review of the literature and new cases. Dermatol Surg 2009; 35(8):1206-14.

32. Bradbury AW, Bate G, Pang K, Darvall KA, Adam DJ. Ultrasound-guided foam sclerotherapy is a safe and clinically effective treatment for superficial venous reflux. J Vasc Surg 2010; 52(4):939-45.

33. Bountouroglou DG, Azzam M, Kakkos SK, Pathmarajah M, Young P, Geroulakos G. Ultrasound-guided foam sclerotherapy combined with sapheno-femoral ligation compared to surgical treatment of varicose veins: early results of a randomised controlled trial. Eur J Vasc Endovasc Surg 2006; 31(1):93-100.

34. Wright D, Gobin J, Bradbury AW. varisolve polidocanol microfoam compared with surgery or sclerotherapy in the management of varicose veins in the presence of trunk vein incompetence: european randomized controlled trial. Phlebology 2006; 21:180-90.

35. Rasmussen LH, Lawaetz M, Bjoern L, Vennits B, Blemings A, Eklof B. Randomized clinical trial comparing endovenous laser ablation, radiofrequency ablation, foam sclerotherapy and surgical stripping for great saphenous varicose veins. Br J Surg 2011; 98(8):1079-87. 




\section{ABSTRACT}

Purpose: This multicenter randomized clinical trial compared cryo stripping of the great saphenous vein (GSV) with conventional stripping.

Methods: The study randomized 494 patients with symptomatic (CEAP) clinical severity class 2 to 4 to cryo stripping $(n=249)$ or conventional stripping $(n=245)$. The primary outcome was residual GSV 6 months after surgery measured by venous duplex ultrasound imaging. Secondary outcomes were quality of life, operation time, and postoperative neural damage. Duration of follow-up was 6 months. Quality of life was measured at 6 and 26 weeks postoperatively with the Aberdeen Varicose Vein Questionnaire (AVVQ) and Medical Outcomes Study Short-Form 36 (SF-36) Health Survey.

Results: The two groups were well matched at baseline. The percentage of patients with residual GSV at 6 months (primary outcome) was 44\% (102 of 230) in the cryo group and 15\% (33 of 215) in the conventional group (difference 29\%; 95\% confidence interval $[\mathrm{Cl}], 21 \%-37 \%, P<.001$ ). Median operation time was significantly shorter in the cryo group (30 minutes) compared with the conventional group (39 minutes). Neural damage was $12 \%$ in both groups, and thus not significantly different. Scores on the subdomains of the SF-36 showed no significant change between the groups. The AVVQ after conventional stripping was 8.0, which was a better result than the 11.7 result after cryo stripping (difference 2.6 points; $95 \% \mathrm{Cl}, 1.0-4.2 ; P=.001$, repeated measurements analysis of variance with adjustment for baseline scores).

Conclusions: Cryo stripping accounts for numerous procedural failures and hence residual GSV in patients. The AVVQ showed small but significantly better results for patients after a conventional stripping. Cryo stripping has no benefits over conventional stripping. 


\section{INTRODUCTION}

The high prevalence of venous disease of the leg accounts for enormous costs and loss of quality of life (QOL) worldwide. ${ }^{1-4}$ Venous disease is caused by venous incompetence of the superficial venous system, with or without venous incompetence of the deep or perforator vein system, or both. ${ }^{5-7}$ If we can reduce the number of patients with venous disease of the leg by improving the outcome of the current surgical therapy, it will reduce the costs and use of health care resources and improve QOL. Surgical treatment of the great saphenous vein (GSV) is indicated when there is valve incompetence at the saphenofemoral junction (SFJ) and GSV. Although endovenous laser and radiofrequency thermo ablation of the GSV are often used, the most commonly performed surgical treatment of the GSV in Europe is still conventional stripping. Cryo stripping of the GSV has been introduced in Europe as a faster and cosmetically better procedure compared with conventional stripping. Although there is insufficient evidence that cryo stripping can actually adequately strip the GSV, the technique is widespread throughout Europe. ${ }^{8-16}$ The outcomes in patients with symptomatic venous disease of the leg and duplex ultrasound (DU)-proven venous incompetence of the SFJ and GSV treated by conventional or cryo stripping were assessed in a multicenter, randomized clinical trial.

\section{PATIENTS AND METHODS}

This study was done accordance with the Consolidated Standards of Reporting Trials (CONSORT) statement. ${ }^{17,18}$ The study protocol was approved by the local ethics committee for every participating hospital. This trial was funded with local funds from the participating hospitals. There was no involvement of any company. The primary outcome was residual GSV 6 months after surgery. Secondary outcomes were QOL, operation time, and postoperative neural damage. Patients had to be aged $>18$ years to be part of the study, and written informed consent was obtained from all participants. Patients were eligible for the trial if they had duplexproven venous incompetence of the SFJ and GSV and symptomatic venous disease of the leg in the CEAP clinical severity class of $C 2$ to $C 4: C 2$, varicose veins, distinguished from reticular veins by a diameter of $>3 \mathrm{~mm} ; \mathrm{C} 3$, edema; $\mathrm{C4}$, changes in skin and subcutaneous tissue secondary to chronic venous disease like pigmentation, eczema, lipodermatosclerosis or atrophy blanche. ${ }^{19}$ All patients had primary etiology and reflux pathophysiology concerning their venous disease. Regarding anatomy, patients could have an incompetent deep venous system or incompetent perforating veins, which would not exclude them from the trial. Exclusion criteria were healed or active venous ulcer ( $C 5$ to 6 ), body mass index (BMI) $>40 \mathrm{~kg} / \mathrm{m}^{2}$, recurrence of venous incompetence in the GSV, occlusion of the deep venous system, venous incompetence of the small saphenous vein, peripheral arterial disease as indicated by a non palpable pulse and an $\mathrm{ABI}<0.9$, already being part of the study with the contralateral leg, and the inability to understand the Dutch language. Patients were recruited from three district general hospitals. After confirmed diagnosis by venous DU imaging, patients were randomized to conventional 
stripping or cryo stripping. Patient and surgeon were not blinded to the treatment. All surgeons who participated in this trial had to have performed at least five cryo stripping procedures to avoid the learning curve effect.

\section{Venous DU imaging}

An expert vascular technician did all DU scanning of the venous system. We used an ATL 5000 scanner (Advanced Technology Laboratories, Bothell, Wash) with a 5- to 12-MHz linear array transducer. Venous incompetence of the GSV was defined when reflux times were $>0.5$ seconds in the full supine position. Venous incompetence of the perforating veins was defined when reflux times were $>0.35$ seconds in half-supine position. ${ }^{20}$

\section{Conventional stripping}

The procedure was performed with spinal or general anesthesia. A 3-cm groin incision in the femoral skin crease was made. The common femoral vein (CFV) was dissected $1 \mathrm{~cm}$ cranial and distal to the GSV. All SFJ tributaries were ligated and divided. The GSV was ligated and divided, flush on the CFV. Conventional stripping was performed by passing a plastic stripper (Dormostrip, TapMed, Schauenburg, Germany) through the GSV from proximal to distal, to $8 \mathrm{~cm}$ below the knee. A 1-cm skin incision parallel to Langer's lines was made over the tip of the plastic stripper. The end of the distal GSV was tied to the stripper, and a medium cone was attached to the plastic stripper. The distal incision was closed, and grade 2 stockings were applied. By pulling the stripper from distal to proximal, an antegrade stripping of the GSV was performed. The groin incision was closed with 4-0 subcutaneous suture (Vicryl, Ethilon, or Monocryl, Ethicon/Johnson \& Johnson, Somerville, NJ).

\section{Cryo stripping}

This procedure started the same as the conventional stripping and was performed by passing a 3.5-mm diameter cryoprobe (Angiology Cryoprobe, Erbe, Germany) through the GSV from proximal to distal, to $8 \mathrm{~cm}$ below the knee. After freezing for 10 seconds at $-85^{\circ} \mathrm{C}$ (expansion of liquid nitrous oxide in the cryoprobe), the tip of the probe freeze attaches to the GSV. Antegrade cryo stripping the GSV was performed by pulling back the probe. Grade 2 stockings were applied, and the groin incision was closed in the same fashion as in conventional stripping.

\section{Postoperative protocol}

The following data were entered in the patient case record form directly after the operation: total operating time; as measured from skin incision to skin closure. Length of stripped GSV. The length of residual GSV was calculated by subtracting measured stripped GSV from measured length on the leg (from the proximal to distal wound). Grading of the operative procedure as "no problems during procedure" or "problems during procedure" with a written explanation of the problems. If necessary, phlebectomy or sclerotherapy, or both, were performed a minimum of 2 to 3 months after surgery. Stab avulsions of varices were not performed during surgery. This policy has been in use in the participating hospitals for years because it was found that 
most patients with varicose veins did not need extra interventions 2 to 3 months after stripping the GSV. This was also confirmed by van Neer et al. ${ }^{21}$ All patients were given subdermal lowmolecular weight heparin injections (2500 U, Dalteparin, Pfizer) preoperatively and for 1 day postoperatively. Patients had to wear the stockings continuously for the first 48 hours and 2 weeks postoperatively only in daytime. They were instructed to mobilize as soon as possible. Only one leg at a time was operated on. This was normal policy in the participating hospitals. It is thought that this decreases morbidity and increases mobility. The second leg was treated, if needed, outside the scope of this trial after 6 months, which was the average time on the waiting list. So the included number of patients equals the number of legs in this study.

\section{Follow-up}

All patients were reviewed by an independent surgeon at the outpatient clinic at 2, 6, and 26 weeks after treatment. Wound problems were assessed. Neural damage was examined with cotton sticks on the treated leg and compared with the untreated leg. Neural damage was graded as "numb feeling" or "hyperesthesia" of the leg. Venous DU imaging was performed 26 weeks after surgical treatment. The result of the venous DU imaging was graded as a successful stripping or a non successful stripping. A successful stripping procedure was defined as a DU proven absent GSV without residual GSV. A non successful stripping procedure (primary outcome) was defined as residual GSV, subdivided in the following two categories:

1. Competent residual GSV was defined as DU-proven competence of a residual GSV.

2. Incompetent residual GSV was defined as DU-proven incompetence of a residual GSV.

\section{Quality of life measurement}

Quality of life was measured preoperatively and 6 and 26 weeks postoperatively using the Aberdeen Varicose Vein Questionnaire (AVVQ) and the Medical Outcomes Study Short-Form 36 (SF-36) Health Survey. Garratt et al. ${ }^{22}$ designed the AVVQ in 1993 for measuring health-related $\mathrm{QOL}$ in patients with varicose veins. The AVVQ consists of 13 questions related to problems of venous disease such as pain and dysfunction, cosmesis, complications of venous disease, and extent of varicosity. The AVVQ results in a score from 0 to 100, with 0 representing the best score and 100 the worst. We used the validated Dutch AVVQ. Generic health status in patients with venous disease of the leg can be measured with the SF-36 survey. ${ }^{23}$ The 36 items result in eight domains after recoding related to physical and mental health and social functioning. The scores in the domains range from 0 (worst score) to 100 (best score), which is exact the opposite of the AVVQ score system.

\section{Statistical analysis}

Central randomization was performed using a computer-generated randomization list prepared by the trial statistician. Stratification was done according to center, venous incompetence of the deep venous system, and venous incompetence of the perforating vein system. To exclude a difference (cryo stripping minus conventional stripping) of $10 \%$ or more regarding the percentage of patients with residual GSV at 6 months, we calculated (alpha $=0.05,80 \%$ 
power) that 260 patients were needed in each arm of this non inferiority study. Percentages were compared using the $\mathrm{chi}^{2}$ test or the Fisher exact test. Continuous data were compared using the Mann-Whitney test. Center effects for the primary end point were investigated using multiple logistic regression analysis. A repeated measurements analysis of variance (ANOVA; SAS proc mixed) was used to evaluate changes from baseline of the various domains and scores of the SF-36 and AVVQ with adjustment for baseline value. Patients were analyzed in their allocated group (intention to treat principle). A two-sided $P=.05$ was considered the limit of significance in all analyses.

\section{RESULTS}

The study randomized 536 patients: 268 to cryo stripping and 268 to conventional stripping. After randomization, 42 patients were excluded: 25 went to another hospital because of a shorter waiting list, 16 cancelled their operation for personal reasons, and one patient had a small transient ischemic attack, after which he cancelled his operation. This resulted in 249 patients in the cryo strip group and 245 patients in the conventional strip group (Figure 1).

Figure 1: Flow diagram shows inclusion of trial patients

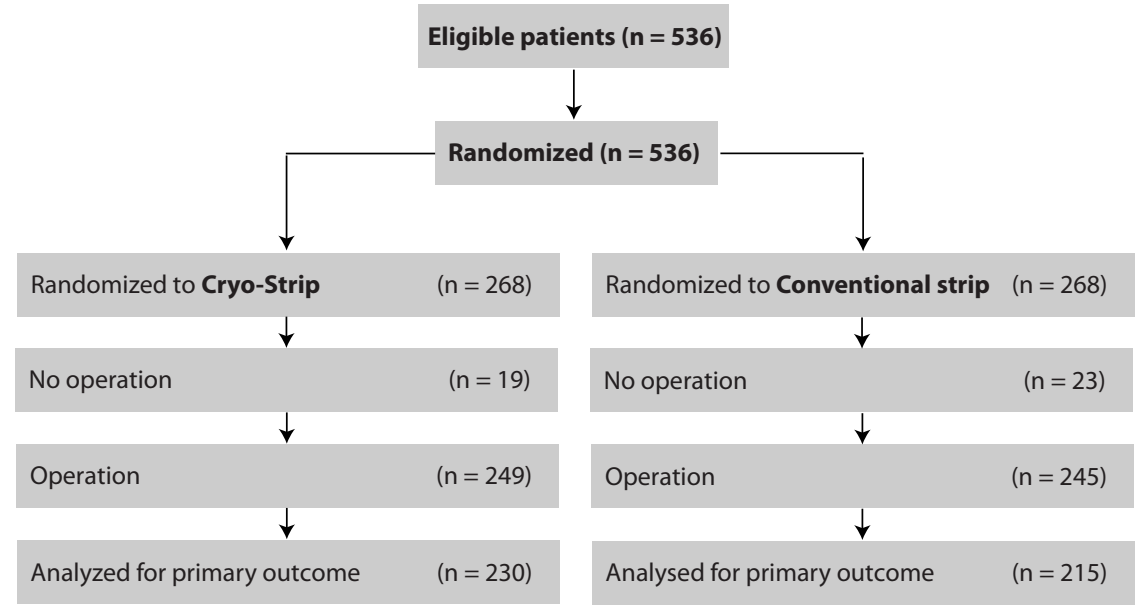

Patient demographics are reported in Table 1. There were 121 men (25\%) and 373 women (75\%), with a mean age of 55 (SD 14.1). Mean BMI was 25.4 (SD 4.2) kg/m². Comorbidity included hypertension, 25 patients; diabetes mellitus, 6; pulmonary disease, 17; cerebrovascular accident or transient ischemic attack, 5; and cardiac disease, 11. The full CEAP score for both groups is reported in Table 2. As a result of stratification, both groups had similar numbers of patients 
with an incompetent deep venous system or incompetent perforating vein system. Nine patients underwent conventional stripping instead of cryo stripping because on six occasions no experienced surgeon was available to perform cryo stripping and on three occasions the cryo stripping device was being used in another operating room. One patient underwent cryo stripping instead of conventional stripping because of a miscommunication. A total of 19 patients in the cryo strip group and 30 patients in the conventional strip group were lost to follow-up for the primary outcome. A total of 38 patients were contacted several times by mail and telephone but refused to visit the outpatient clinic. The other 11 patients had given a wrong address or telephone number and could not be traced. In the cryo strip group, 230 patients could be analyzed for primary outcome. In the conventional strip group, 215 patients could be analyzed for primary outcome. The number of operations performed in the different hospitals was as follows: 374 in Sint Franciscus Hospital, 111 in Albert Schweitzer Hospital, and nine in Twee Steden Hospital.

\begin{tabular}{|c|c|c|}
\hline Variable & Cryo & Conventional \\
\hline Patients, No. & 249 & 245 \\
\hline Age, mean (SD), y & $56 \quad(14.3)$ & $54 \quad(14.0)$ \\
\hline Male, No. (\%) & $52 \quad(21)$ & $70 \quad(29)$ \\
\hline Female, No. (\%) & $197 \quad(79)$ & (71) \\
\hline Body mass indes, mean (SD) $\mathrm{kg} / \mathrm{m}^{2}$ & $25.1 \quad(4.2)$ & $25.8 \quad(4.3)$ \\
\hline Hypertension, No. & 10 & 15 \\
\hline Diabetes mellitus, No. & 3 & 3 \\
\hline Pulmonary disease, No. & 9 & 8 \\
\hline CVA or TIA, No. & 2 & 3 \\
\hline Cardiac disease, No. & 5 & 6 \\
\hline
\end{tabular}

\section{Primary outcome}

We found a significant difference of residual GSV between cryo stripping and conventional stripping in this study. The percentage of patients with residual GSV at 6 months was $44 \%$ (102 of 230) in the cryo strip group and 15\% (33 of 215) in the conventional strip group (difference 29\%; 95\% confidence interval [Cl], 21\%-37\%, $P=.001$ ). Competent residual GSV was found in 47 patients (20\%) after cryo stripping and in 15 (7\%) after conventional stripping. Incompetent residual GSV was found in 55 patients (24\%) after cryo stripping and in 18 (8\%) 
after conventional stripping. Multiple logistic regression analysis showed that this difference was not affected by center.

\section{Secondary outcomes}

Recurrence at the SFJ is a known phenomenon. ${ }^{24}$ The stripping technique in this study had no influence on the incidence, because groin incision and dissection at the SFJ were identical in both techniques. There was no significant difference between the stripping techniques in recurrence at the SFJ: 42 patients (18\%) after cryo stripping and 37 patients (17\%) after conventional stripping. Operation time was significantly different between cryo stripping and conventional stripping. Median operation time was 30 minutes (range, 10-120 min) in the cryo strip group and 39 minutes (range 15-100 min) in the conventional strip group $(P=.001)$. Significantly more problems during operation were encountered in the cryo strip group. Cryo stripping was problematic in 84 patients (34\%), and conventional stripping was problematic in 28 patients $(11 \% ; P=.001)$. The most common problems were perforation of the GSV by the rigid cryoprobe and detachment of the GSV from the probe during stripping. Neural damage occurred in 31 patients (12\%) after cryo stripping and in 30 patients (12\%) after conventional stripping, which was not a statistically significant difference $(P=.787)$.

Table 2: Number of patients by treatment group according to the CEAP classification

Conventional stripping, No.

\begin{tabular}{|c|c|c|c|c|c|c|c|c|}
\hline \multirow[b]{2}{*}{ C } & \multicolumn{3}{|c|}{$\mathbf{E}$} & \multicolumn{3}{|c|}{ A } & \multicolumn{2}{|c|}{$\mathbf{P}$} \\
\hline & Primary & Secondary & Congenital & Superficial & Deep & Perforating & Reflux & Obstuction \\
\hline 2 & 208 & 0 & 0 & 208 & 51 & 66 & 208 & 0 \\
\hline 3 & 18 & 0 & 0 & 18 & 10 & 15 & 18 & 0 \\
\hline 4 & 19 & 0 & 0 & 19 & 15 & 17 & 19 & 0 \\
\hline \multicolumn{9}{|c|}{ Cryostripping, No. } \\
\hline 2 & 211 & 0 & 0 & 211 & 51 & 65 & 211 & 0 \\
\hline 3 & 18 & 0 & 0 & 18 & 11 & 17 & 18 & 0 \\
\hline 4 & 20 & 0 & 0 & 20 & 17 & 19 & 20 & 0 \\
\hline
\end{tabular}

\section{Quality of life}

The AVVQ and SF-36 questionnaires were returned by 419 patients (85\%) preoperatively, 334 $(67 \%)$ at 6 weeks postoperatively, and 265 (53\%) at 26 weeks postoperatively. The AVVQ change for baseline scores were compared for randomized treatments using repeated measurements ANOVA with adjustment for baseline scores (Table 3). All changes from baseline scores within groups were significantly lower at both time intervals. At 26 weeks the adjusted baseline score difference between groups was 2.6 points in favor of conventional stripping ( $95 \% \mathrm{Cl}, 1.0-4.2$; 
$P=.001)$. In the SF-36 (Table 4), significant changes of baseline score were found after cryo stripping and conventional stripping for the domains of physical functioning and bodily pain.

Table 3: Aberdeen Varicose Vein Questionnaire score change by treatment group

\begin{tabular}{|c|c|c|c|}
\hline \multirow[b]{2}{*}{ Time } & \multicolumn{2}{|c|}{ AVVQ score (standard error) } & \multirow[b]{2}{*}{$\mathbf{p a}^{\mathbf{a}}$} \\
\hline & Cryo & Conventional & \\
\hline Baseline & $18.3(0.57)$ & $16.4(0.59)$ & \\
\hline 6 weeks & $13.5(0.57)$ & $12.5(0.60)$ & \\
\hline 26 weeks & $11.7(0.60)$ & $8.0(0.65)$ & .001 \\
\hline $\mathrm{pb}$ & $<.001$ & $<.001$ & \\
\hline
\end{tabular}

Table 4: Medical Outcomes Study Short-Form 36 Health Survey score change by treatment group

\begin{tabular}{|c|c|c|c|c|c|c|c|c|}
\hline Group $^{a}$ & PF & $\mathbf{R P}$ & BP & GH & VT & SF & RE & MH \\
\hline \multicolumn{9}{|l|}{ Cryo } \\
\hline Baseline & 78.5 & 72.3 & 68.5 & 272.6 & 66.0 & 85.7 & 86.2 & 58.2 \\
\hline 6 weeks & 82.5 & 78.0 & 78.1 & 72.5 & 65.3 & 85.1 & 84.5 & 58.2 \\
\hline 26 weeks & 85.8 & 84.1 & 81.7 & 72.2 & 69.8 & 87.0 & 87.8 & 57.8 \\
\hline $\mathrm{pb}$ & $<.001$ & $<.001$ & $<.001$ & .71 & .01 & .58 & .80 & .66 \\
\hline \multicolumn{9}{|l|}{ Conventional } \\
\hline Baseline & 80.9 & 79.7 & 73.3 & 74.7 & 69.3 & 88.2 & 87.1 & 59.9 \\
\hline 6 weeks & 83.7 & 79.8 & 78.6 & 72.9 & 67.8 & 88.2 & 88.0 & 58.6 \\
\hline 26 weeks & 84.5 & 83.2 & 82.2 & 72.3 & 69.1 & 89.2 & 89.4 & 58.1 \\
\hline $\mathrm{pb}$ & .02 & 0.19 & $<.001$ & .07 & .96 & .58 & .47 & .08 \\
\hline
\end{tabular}

PF, Physical functioning; RP, role limit (physical problems); GH, general health perception; $V T$, vitality; SF, social functioning; RE, role limit (emotional problems); $\mathrm{MH}$, mental health.

${ }^{\text {a }}$ No significant differences were found between both groups at 6 and 26 weeks.

b Statistical significance was set at $\mathrm{P}<.05$. 
Significant changes of baseline score were only found after cryo stripping for the domains of role limitations due to physical problems and vitality. The domains of general health, social functioning, role limitations due to emotional problems, and mental health did not significantly change from baseline scores in either group. For none of the domains did the mean changes differ between both groups. This applies to both the 6 weeks and 26 weeks results.

\section{Complications}

Seven patients presented with complications, of which five were in the cryo strip group:

- A small groin hemorrhage required operative exploration.

- A postoperative neurapraxia of the peroneal nerve developed, which healed after 4 months with no clinical complaints.

- A deep venous leg thrombosis developed in an operated leg, confirmed by venous DU imaging, 2 weeks after surgery. This patient was treated with warfarin for 6 months, after which there were no clinical complaint, and DU imaging showed an open, although incompetent deep system.

- Persistent lymph leakage from the groin incision required operative exploration, after which there were no clinical complaints.

- In one patient the surgeon mistook the CFV for the GSV and had thus divided the CFV. An expert vascular surgeon anastomosed the CFV, and the GSV was not stripped. After receiving warfarin for 6 months, the patient had no clinical complaints and an open, although incompetent, deep venous system. One year later, cryo stripping of the GSV was performed.

Two complications occurred in the conventional strip group:

- A clamp on the GSV was pulled which caused a lesion of the CFV. The CFV was sutured using a patch.

- A small myocardial infarction occurred that required no invasive interventions. The patient was discharged from the cardiology ward after 2 days.

Secondary phlebectomy or sclerotherapy for non-truncal varicosities was performed in 108 patients (22\%) after 2 to 3 months. There was an even distribution among the groups: cryo stripping, 52 patients (10.5\%); conventional stripping, 56 patients (11.3\%).

\section{DISCUSSION}

\section{Primary outcome}

When the primary outcome was examined, cryo stripping performed significantly worse than conventional stripping in terms of residual GSV. The participating surgeons graded the cryo stripping in $34 \%$ of the cases as a procedure with minor or major problems compared with $11 \%$ who had conventional stripping. Although every participating surgeon had performed at 
least five cryo strip operations to avoid the learning curve effect, it could be argued that this number was too small. There was an indication of a learning curve effect for one of the centers in the cryo strip group. For that center, the first 25 patients who had cryo strip procedures did somewhat worse than later patients $(P=.048)$. However, comparing the percentages of residual disease at 6 months after disregarding the first 25 patients within each center and treatment group gave similar results as for the total group: $42 \%$ for cryo stripping versus $15 \%$ for conventional stripping $(P=.001)$. The cryo stripping technique is substantially different from a conventional technique. Instead of a flexible plastic stripper, a rigid metal probe has to be advanced in retrograde fashion through the GSV. Although the cryoprobe provides some tactile feedback to the surgeon, it is much less compared with a plastic stripper. When the probe cannot easily be pushed further through the GSV, it is difficult to differentiate between a competent valve and the wall of the GSV. This is probably the cause of many procedural failures during cryo stripping where perforation through the GSV had occurred. Another problem was caused during the initial freezing of the distal GSV. Although the cryo probe has to be pulled vigorously to break the frozen GSV, too much force can detach the probe from the GSV, which results in a partially stripped GSV. It could be argued that retrograde cryo stripping could decrease the procedural problems, but the possible cosmetic advantage is then lost because of the need for a distal incision under the knee. Schouten et al $^{16}$ also reported more residual GSV after cryo stripping, with a mean length of stripped GSV of $27 \mathrm{~cm}$ after cryo stripping compared with $40 \mathrm{~cm}$ after conventional stripping. This was because an alternative cryo strip technique was used in this study; the GSV was stripped from the groin to above the knee to avoid possible difficult guiding of the cryo probe past the knee. Although Stötter et al ${ }^{25}$ also found residual GSV after cryo stripping (10\%), the low number of patients $(n=20)$ randomized in the cryo stripping arm makes a conclusion of that study difficult. Menyhei et $\mathrm{al}^{26}$ found major procedural problems in the cryo strip group in six of the 79 included patients (8\%). These patients were further excluded from the trial. The primary outcome of that study was QOL; therefore, no venous DU follow-up was described. Regarding recurrence at the SFJ, no significant difference between cryo stripping and conventional stripping was found. This was expected because the operation technique of groin exploration was the same in both groups. This recurrence rate is similar to that reported by de Maeseneer. ${ }^{27}$

\section{Operation time}

Median operation time was significantly shorter in the cryo strip group (30 minutes), which was expected because a distal incision at the knee is not needed. The outliers in the operation time range were caused by complications in both groups. It took 120 minutes in the cryo strip group and 100 minutes in the conventional group to repair the CFV. Stötter et $\mathrm{al}^{25}$ reported a shorter mean operation time of 19 minutes, whereas Schouten et al. ${ }^{16}$ reported an operation time of 18 minutes. A possible reason for these faster operation times could be that all the cryo stripping procedures were performed by a standard team of two surgeons, as described by Schouten et al. A faster operation time makes it possible to treat more patients in a given time and shorten the long waiting lists that exist in the Netherlands for GSV stripping. Although this 
is a positive finding of the cryo strip technique, it is overshadowed by the high incidence of postoperative residual GSV.

\section{Neural damage}

No significant difference in postoperative neural damage between cryo stripping and conventional stripping were expected or found. The incidence of neural damage at 26 weeks was similar as that reported by Tennant et al. ${ }^{28}$ and Critchley et al. ${ }^{29}$ Most patients had a hyperesthesia or numb feeling of the medial aspect of the upper or lower leg, which can be explained by a lesion or neurapraxia of the saphenous nerve. Because both techniques performed a short stripping of the GSV, no difference was expected.

\section{Complications}

Of the seven complications, two major complications were a direct result of the surgical stripping technique. In one patient in the cryo strip group with a BMI of $18 \mathrm{~kg} / \mathrm{m}^{2}$, a transection of the CFV was made, caused by a surgeon who misidentified the GSV. The misidentification occurred because the GSV was extremely superficial and had such a small diameter that it was mistaken for an accessory vein. When dissecting to the deep venous system, the CFV had the diameter of a regular GSV. This complication could have been prevented if the surgeon had anticipated a small diameter GSV in this thin patient and had tried to identify the SFJ. ${ }^{30}$ In another patient in the conventional strip group, the CFV was torn when a clamp on the GSV was accidentally pulled. It is not certain if this complication could have been prevented. There is always a small complication risk during surgical procedures, and one can only try to decrease this risk by working meticulously. Accidental deep vein lesions during superficial vein surgery have been described before in the literature, but mostly as case reports.

\section{Quality of life}

Patients in both groups had significantly better AVVQ scores postoperatively. Patients in the conventional strip group scored significantly better than those in the cryo strip group. The AVVQ is a health-related QOL questionnaire that has been proven to measure small changes in QOL before and after treatment. The reason that conventional stripping scored better than cryo stripping could be the high incidence of residual GSV after cryo stripping. Although the small change in AVVQ score (2.6) between both groups is numerically significant, one could argue if this has any clinical relevance on a total score of 100. A long term follow-up study of all patients with venous DU imaging, AVVQ, and SF-36 is now being conducted to answer this question. Smith et al2 also found minute AVVQ changes before (18.8) and after (14.1) surgical treatment. The AVVQ scores can significantly increase when patients with healed or active venous ulcers ( $C 5$ and $(6)$ are included, because these AVVQ-related items account for much higher scores. Because this study excluded patients with clinical severity class $C 5$ and $C 6$, one can expect to have patients with lower preoperative AVVQ scores and hence smaller changes postoperatively. Possibly two new health-related QOL questionnaires could be designed. One questionnaire needs to emphasize items specifically related to patients with clinical severity 
class 1 to 4 . Most patients with venous disease would be appropriate for this questionnaire. The other questionnaire would need to emphasize items specifically for severity class 5 to 6 , because pain and socially related items carry more weight in these patients. This would have the benefit that QOL scores in patients with $\mathrm{C} 1$ to 4 are not diminished by items related to $C 5$ to $\mathrm{C} 6$, such as in the AVVQ. No significant changes were found in the SF-36 results postoperatively in any of the eight domains between the cryo strip group and the conventional strip group. Studies have shown that a generic QOL questionnaire like the SF-36 poorly reflects the effects of chronic venous disease. This may well explain that no difference was found between the groups. There were significantly better scores postoperatively in the domains of physical functioning and bodily pain in both groups. These results were similar to those reported by Menyhei et al $^{26}$ in which QOL was the primary end point It was to be expected that the domains of physical functioning and bodily pain would have better scores postoperatively because most patients have fewer problems from swollen legs, restless legs, heavy feeling, and pain in the legs after their operation. The cryo strip group had significantly better scores postoperatively in the domains of vitality and role limitation because of physical problems (RP). There is no ready explanation for these higher scores except perhaps the lower baseline scores in the cryo strip group compared with the conventional strip group. Menyhei et al. ${ }^{26}$ found no significant difference for the RP domain but a significant change for the vitality domain, which was also unexplained. In both AVVQ and SF-36 pain was found to be significantly less 26 weeks after stripping of the GSV, regardless of which strip was used. Future use of generic QOL questionnaires like the SF-36 for measuring the often-small changes in QOL after (surgical) therapy in patients with clinical severity class 1 to 4 should be dissuaded.

\section{CONCLUSIONS}

Cryo stripping with a rigid cryoprobe accounts for numerous procedural failures and hence residual GSV in patients. Health-related QOL measured by the AVVQ showed small but significantly better results for patients after conventional stripping. Cryo stripping has no benefits over conventional stripping. 


\section{REFERENCES}

1. Callam MJ. Epidemiology of varicose veins. Br J Surg 1994; 81:167-73.

2. Smith JJ, Garratt AM, Guest M, Greenhalgh RM, Davies AH. Evaluating and improving health-related quality of life in patients with varicose veins. J Vasc Surg 1999; 30:710-9.

3. Van den Oever R, Hepp B, Debbaut B, Simon I. Socio-economic impact of chronic venous insufficiency. An underestimated public health problem Int Angiol 1998; 17:161-7.

4. Ruckley CV, Evans CJ, Allan PL, Lee AJ, Fowkes FG. Chronic venous insufficiency: clinical and duplex correlations. The Edinburgh Vein Study of venous disorders in the general population. J Vasc Surg 2002; 36:520-5.

5. Bradbury A, Evans CJ, Allan P, Lee AJ, Ruckley CV, Fowkes FG. The relationship between lower limb symptoms and superficial and deep venous reflux on duplex ultrasonography: The Edinburgh Vein Study. J Vasc Surg 2000; 32:921-31.

6. Delis KT, Husmann M, Kalodiki E, Wolfe JH, Nicolaides AN. In situ hemodynamics of perforating veins in chronic venous insufficiency. J Vasc Surg 2001; 33:773-82.

7. Labropoulos N, Giannoukas AD, Delis K, Mansour MA, Kang SS, Nicolaides AN, et al. Where does venous reflux start? J Vasc Surg 1997; 26:736-42.

8. Milleret R. My experience with cryosurgery of varicose veins [French]. Phlébologie 1989; 42:573-7.

9. Milleret R. Cryosurgery of varicose veins [French]. Soins Chir 1992; 18-9.

10. Cheatle TR, Kayombo B, Perrin M. Cryostripping the long and short saphenous veins. Br J Surg 1993; 80:1283.

11. Etienne G, Constantin JM, Hevia M. Cryo-stripping: an advance in the treatment of varicose veins. 3811 operated limbs [French]. Presse Med 1995;24:1017-20.

12. Etienne G, Constantin JM, Hevia M. Cryo-stripping: an alternative to perforate-invaginate stripping. Ann Vasc Surg 1997; 11:325-8.

13. Constantin JM, Etienne G, Hévia M. Technique and results of cryostripping in the treatment of varicose veins of the lower limbs [French]. Ann Chir 1997; 51:745-8.

14. Manner M, Koeth T, Geelhaar G, Stickel W. Cryotechnique in varicose vein surgery [German]. Chirurg 1999; 70:79-84.

15. Cappendijk VC, Schutte PR, Tan KG. Cryostripping of the great saphenous vein [Dutch]. Scripta Phlebologica 1999: 23-5.

16. Schouten R, Mollen RM, Kuijpers HC. A comparison between cryosurgery and conventional stripping in varicose vein surgery: perioperative features and complications. Ann Vasc Surg 2006; 20:306-11.

17. Moher D, Schulz KF, Altman DG. The CONSORT statement: revised recommendations for improving the quality of reports of parallel-group randomised trials. Lancet 2001; 357:1191-4.

18. Altman DG, Schulz KF, Moher D, Egger M, Davidoff F, Elbourne D, Gøtzsche PC, Lang T. The revised CONSORT statement for reporting randomized trials: explanation and elaboration. Ann Intern Med 2001; 134: 663-94.

19. Eklöf B, Rutherford RB, Bergan JJ, Carpentier PH, Gloviczki P, Kistner RL, et al; American Venous Forum International Ad Hoc Committee for Revision of the CEAP Classification. Revision of the CEAP classification for chronic venous disorders: consensus statement. J Vasc Surg 2004;40:1248-52.

20. Labropoulos N, Tiongson J, Pryor L, Tassiopoulos AK, Kang SS, Ashraf Mansour M, et al. Baker WH. Definition of venous reflux in lowerextremity veins. J Vasc Surg 2003; 38:793-8.

21. van Neer P, Kessels A, de Haan E, Estourgie R, Veraart J, Lijnen R, et al. Residual varicose veins below the knee after varicose vein surgery are not related to incompetent perforating veins. J Vasc Surg 2006; 44:1051-4.

22. Garratt AM, Macdonald LM, Ruta DA, Russell IT, Buckingham JK, Krukowski ZH. Towards measurement of outcome for patients with varicose veins. Qual Health Care 1993; 2:5-10. 
23. Aaronson NK, Muller M, Cohen PD, Essink-Bot ML, Fekkes M, Sanderman R, et al. Translation, validation, and norming of the Dutch language version of the SF-36 Health Survey in community and chronic disease populations. J Clin Epidemiol 1998; 51:1055-68.

24. Glass GM. Neovascularization in recurrent sapheno-femoral incompetence of varicose veins: Surgical anatomy and morphology. Phlebology 1995; 10:136-42.

25. Stötter L, Schaaf I, Bockelbrink A. Comparative outcomes of radiofrequency endoluminal ablation, invagination stripping, and cryostripping in the treatment of great saphenous vein insufficiency. Phlebology 2006; 21:60-4.

26. Menyhei G, Gyevnár Z, Arató E, Kelemen O, Kollár L. Conventional stripping versus cryostripping: a prospective randomised trial to compare improvement in quality of life and complications. Eur J Vasc Endovasc Surg 2008; 35:218-23.

27. de Maeseneer M. Neovascularization; an adverse response to proper groin dissection. In: Bergan Jl, editor. The vein book. San Diego, CA: Elsevier Acad Press; 2007. p. 239-46.

28. Tennant WG, Ruckley CV. Medicolegal action following treatment for varicose veins. Br J Surg 1996; 83:291-2.

29. Critchley G, Handa A, Maw A, Harvey A, Harvey MR, Corbett CR. Complications of varicose vein surgery. Ann R Coll Surg Engl 1997; 79:105-10.

30. Wakefield SE, Elewa AA. Improving exposure and safety at the saphenofemoral junction. Ann R Coll Surg Engl 1995; 77:139-40. 




\section{INTRODUCTION}

The treatment of incompetent perforating veins (ICPV) in combination with superficial venous system treatment is perceived to be the best treatment for patients with chronic venous leg ulceration ( $\mathrm{C} 6$ according to the Clinical-Etiology-Anatomy-Pathophysiology [CEAP] classification). ${ }^{1}$ Improvements in surgical techniques could bring down costs and result in a higher patient satisfaction. Dissection of ICPV can be performed with subfascial endoscopic perforating vein surgery (SEPS). First performed by Dr. G. Hauer in Germany, SEPS is the most common used surgical technique worldwide but has is its limitations. ${ }^{2}$ SEPS can show poor results because of a challenging learning curve but even in experienced hands it still has its limitation. The narrow confines due to tapering at the ankle have been proven to be the most important limitation. Clinical important ICPV cannot be reached. Wittens et al showed the consequences of leaving important perforating veins and stressed that they should all be treated. ${ }^{3}$ Other limitations of SEPS are mentioned in the previous chapter. The need to overcome these problems has resulted in alternative minimal invasive techniques. Although few reports and cohort studies have been published about these alternative techniques, most of these studies are done as feasibility studies. A randomized controlled trial on any of these techniques has never been performed, which is essential for selecting one of these methods on evidence based facts.

\section{Sclerotherapy of ICPV}

This technique, also known as ultrasound-guided sclerotherapy (USGS) of ICPV, was first described by Thibault. ${ }^{4}$ Under local anaesthesia the ICPV are duplex guided entered with a needle. After venous blood is aspired, a sclerosant is injected into the vein. After the treatment patients get a compressive bandage or stockings around the limb. In a cohort study, Masuda et al describes their technique and results with USGS on a group of patients with isolated ICPV a patent deep and superficial system ${ }^{5}$. In a period of 4 years, 80 limbs in 68 patients were treated with USGS. Perforator vein incompetence was defined as presence of outward flow or bidirectional flow. Retrograde flow lasting more than 0.5 seconds was used as a cut-off value for defining incompetence. Before USGS all significant perforators were identified by duplex scanning. After sterile preparation of the leg a 25 -gauge needle was duplex guided introduced into the ICPV. After venous blood aspiration, $1.5 \mathrm{ml}$ sodium morrhuate was injected in the ICPV. Extra care was taken to prevent arterial damage by injecting the sclerosant just after the ICPV has exit the fascia. If the sclerosant was injected extraluminal or if there was high resistance the procedure was aborted. All patients continued with compression bandage one week after USGS and were then instructed to use their elastic stockings. Follow up consisted of an interview, clinical examination and duplex scanning at 1, 3 and 6 months intervals. Clinical outcomes were measured by using the Venous Clinical Severity Score (VCSS) and Venous Disability Score (VDS) and CEAP classification. 
The results showed an initial success percentage of 98\%. Mean ICPV size was $3.7 \mathrm{~mm}$ and the number of treated ICPV ranged from 1 to 8 per patient. The following distribution of clinical status according to CEAP was found: C1: 0 / C2: 6.25\% / C3: 17.5\% / C4: $28.75 \%$ / C5: 1.25\% / C6: $46.25 \%$.

Follow up duplex scanning after one month was performed on 57 limbs. In 19 limbs (33.3\%) new or recurrent ICPV were found, 12 of these were patients with C6. All VCSS and VDS scores were lower post USGS, but only in patients with C4 and C6 these results were statistically significant. Group size of C2 and C5 was too small to investigate.

Ulcer healing rate was $67.6 \%$ with one USGS treatment. Ulcer recurrence rate was $32.4 \%$. Average time for ulcer healing was 35.6 days.

Complications were skin necrosis in one patient, because of intra arterial injecting of the sclerosant. Skin necrosis healed after 4 months.

There is only one very small study mentioning ICPV treatment with ultrasound guided sclerotherapy using foam. ${ }^{6} \mathrm{~A}$ lot of data show the superiority of foam versus liquid sclerotherapy in other veins, especially the GSV or SSV. It can be theorized that if ICPV will be treated with foam the results might improve significantly. Results from future trials have to be awaited.

\section{Cryo treatment of ICPV}

This technique, also known as Cryo Perforator Surgery (CPS) was first described by Klem and Wittens in 2008. ${ }^{7}$ CPS makes use of a cryo device (Erbe) and a small cryoprobe (Figure 1). In a feasibility study 15 patients with 28 ICPV were treated with CPS. All patients had isolated ICPV and no incompetent deep system.

\section{Figure 1}

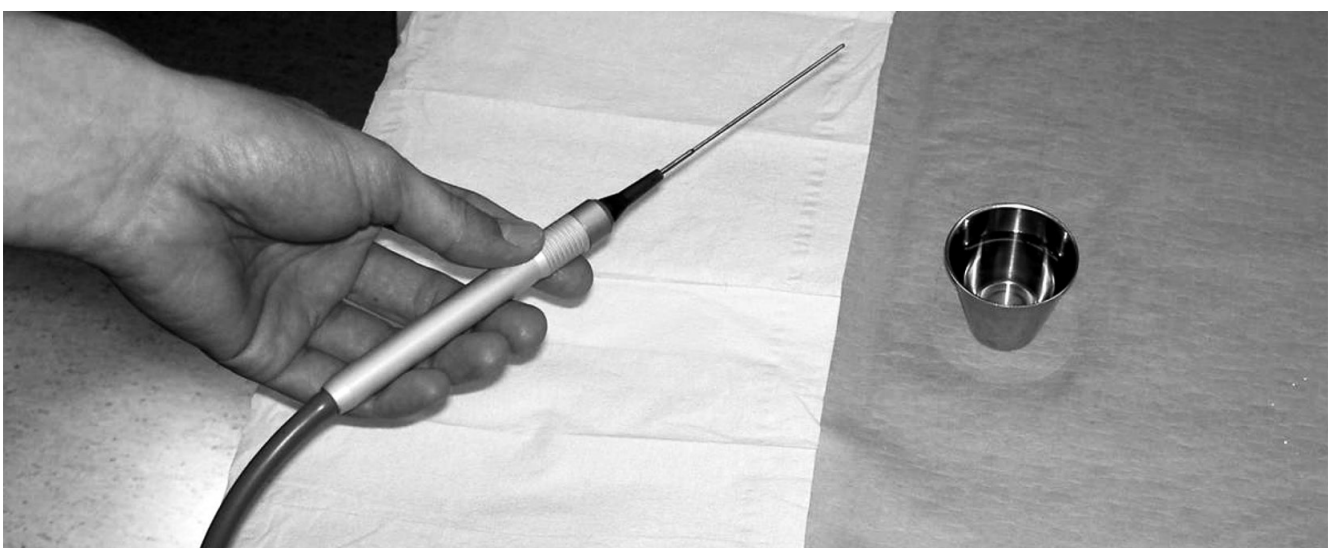


The superficial system had already been treated or was competent. Because the effects of CPS in the proximity of (healed) ulcers were uncertain, avoiding all risks, patients with C5 and C6 (CEAP classification) venous disease were not enrolled in this study. Before treatment all ICPV were ink-marked on the skin using duplex scanning. Incompetence was defined when reflux times exceeded 0.35 seconds.

CPS was performed under local anaesthesia (lidocaine 1\%). The ICPV were approached percutaneously with a 14 gauge cannula at the fascia defect under duplex scanning guidance (Figure 2). The cannula could be placed intraluminal or extraluminal in small diameter ICPV. The cryoprobe with a diameter of $1.6 \mathrm{~mm}$ was introduced through the cannula and frozen for 15 seconds at -89 degrees Celsius (Liquid dinitrous-oxide, $\mathrm{N}_{2} \mathrm{O}$ ).

\section{Figure 2}

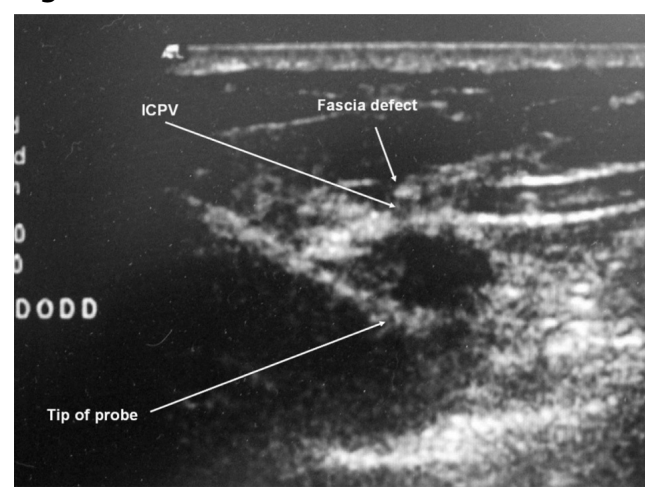

During the freezing, an ice cone was formed at the tip of the cryoprobe (Figure 3) The ICPV was freeze-attached to the ice cone, and dissection was obtained by withdrawing the probe vigorously.

\section{Figure 3}

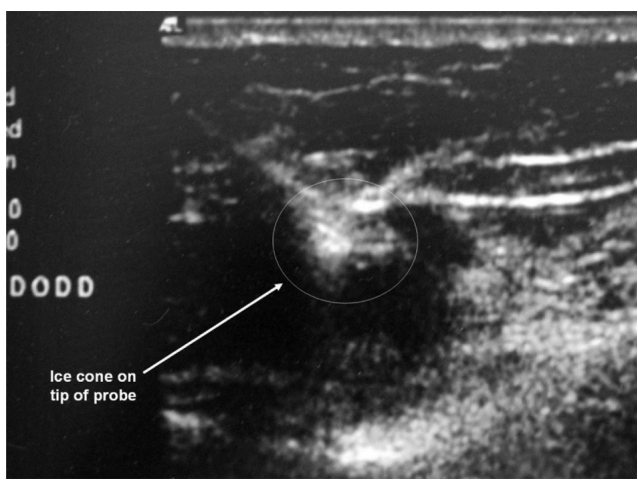


Treatment was considered successful perioperative when ICPV showed no signs of flow despite augmentation on the duplex scan. A compression bandage was applied in all patients and they were discharged 1 hour after the operation. Follow-up duplex scans were performed 2, 4, and 20 weeks after treatment. Total follow-up for all patients was 20 weeks. Patients consisted of 3 men and 12 women with a median age of 55 years (range, 22-76 years) and complaints of chronic venous disease. There was no comorbidity.

Preoperative duplex scanning showed 28 ICPV in 15 patients. All ICPV were treated with CPS. Distribution of the ICPV was as follows: posterior tibial perforator, 12; paratibial perforator, 11; intergemellar perforator, 1; lateral leg perforator, 4 (range, 1-5 per patient). The diameter (median) of the fascia defect was $2.8 \mathrm{~mm}$ (range, 1.8-6.8 $\mathrm{mm}$ ) and depth (median) of the fascia defect was $10.4 \mathrm{~mm}$ (range, 3.7-22.0 mm). Perioperative duplex showed no signs of flow in all treated ICPV. Follow-up duplex after 2, 4, and 20 weeks showed successful treatment in 12 perforating veins (43\%).

Distribution of perforating veins in successful treatment: posterior tibial perforator, 4; Paratibial perforator, 6; intergemellar perforator, 0; lateral leg perforator, 2.

There were no perioperative complications. Five patients developed a small haematoma on the leg, which healed within 2 weeks. All patients completed the follow-up period.

\section{Radiofrequency ablation of ICPV}

The most common used method is the radiofrequency (RF) ablation technique with the device from VNUS Medical technologies, San Jose, California. RF ablation is a thermal ablation technique in which delivery of heat is controlled by a RF generator which measures power, impedance, temperature and elapsed time so that precise temperature control is obtained. For ICPV treatment there is the RF system ClosureRFS and ClosurePLEX catheters. Whitely et al was the first to publish the results of RF ablation in ICPV. ${ }^{8}$ In an overview article of RF ablation techniques, Roth describes in short the technique for RF ablation of ICPV with use of VNUS catheters ${ }^{9}$. The technique requires a more detailed duplex scanning because perforating veins are not linear in orientation like the superficial veins and are more curvilinear and angulated throughout their course. After visualisation the ICPV were ink-marked on the skin. After sterile preparation the skin was locally infiltrated with lidocaine $1 \%$. Through a small skin incision the ICPV were accessed directly with a rigid RF stylet (ClosureRFS) (Figure 4) Another technique make use of a Seldinger technique with a 21 gauge needle and guide wire to access the ICPV after which a flexible ClosurePLEX catheter (Figure 5) was used to perform RF ablation. Either catheter was positioned at the fascia level. When the stylet was removed, the tip of the ClosureRFS catheter was at the right position, between 5-10 mm from the fascia. The ClosurePLEX had to be pulled back 5-10 mm. After tumescent fluid infiltration above and below the catheter the patient was positioned in Trendelenburg. RF ablation temperature was 85-90 degrees Celsius for 5 minutes. During the first 4 minutes the catheter was rotated 
every minute, 12, 6, 3 and 9 o'clock positions. In the last minute the catheter was pulled back 1-10 mm. When RF ablation was performed the deep venous system and arterial system were assessed for patency and the catheters were removed. Patients had stockings applied after the treatment for minimal 3 to 4 days. Patients could resume daily activities immediately and follow up duplex scan was performed after 72 hours.

\section{Figure 4}

\section{Closure $R F S^{\mathrm{Tm}}$ Stylet}

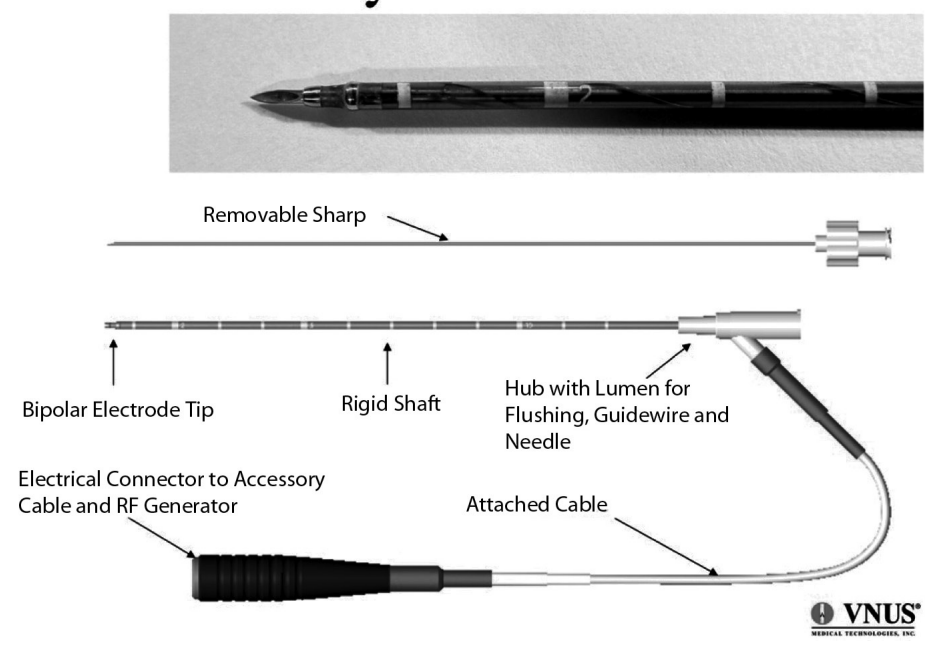

\section{Figure 5}

\section{Closure $P L E X^{\mathrm{TM}}$ Catheter}

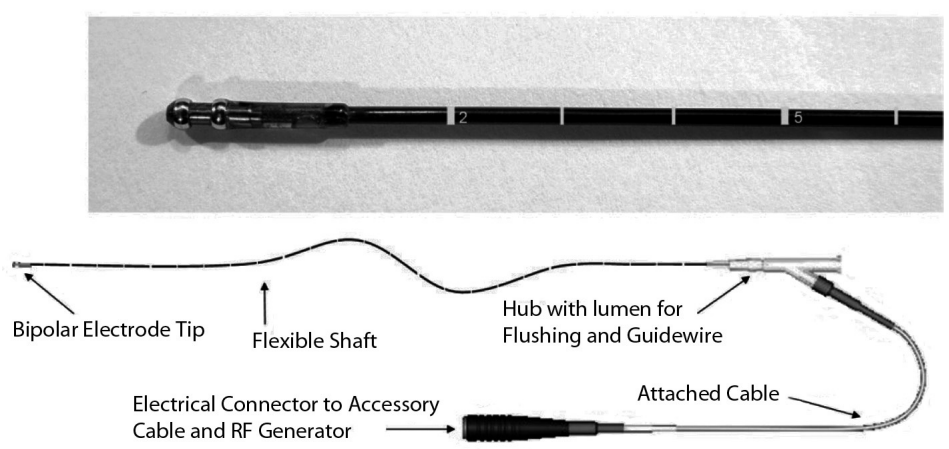


In a large cohort study, Peden and Lumsden describe RF ablation of 770 ICPV in 506 limbs. ${ }^{10}$ From this article it is not clear what the distribution of $C$ (according to the CEAP-classification) among the patients was. All of the patients had C4-C6 venous disease. The authors claim a success rate of $79 \%$ after 1 year and $76 \%$ after 2 years. There was no information about the amount of patients who were lost to follow-up. No information was given about the definition used for incompetence of ICPV or procedural complications.

\section{LASER ablation of ICPV}

Thermal ablation of ICPV with use of LASER has been first described by Proebstle et al ${ }^{11}$. In this feasibility study 67 ICPV in 60 patients were treated with LASER (Figure 6). Patients with all stages of chronic venous insufficiency and duplex proven ICPV were included in the study. Technique is as follows: the ICPV was accessed was duplex guided punctured just above the fascia plane with an 18-gauge cannula.

\section{Figure 6}

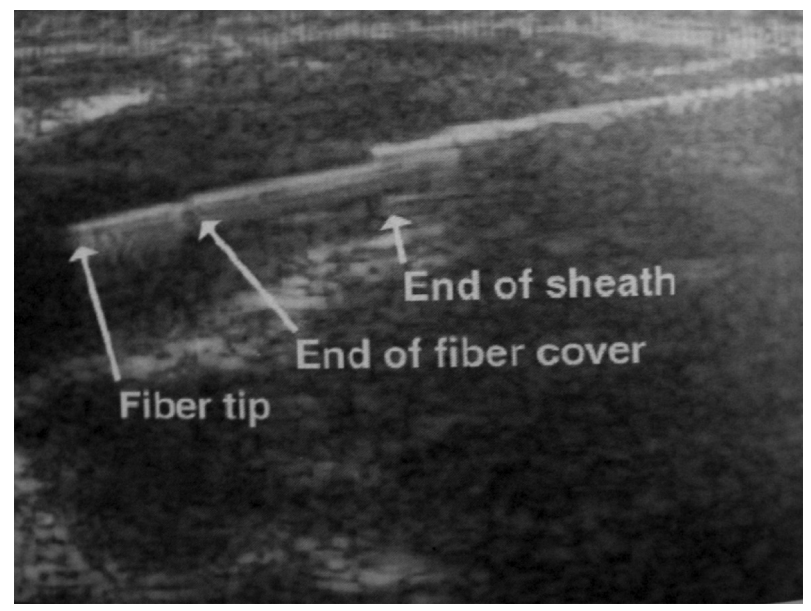

The catheter was then advanced 3-5 mm subfascial, with a distance of at least $10 \mathrm{~mm}$ from the deep system. After placement of the LASER fiber, local anaesthesia was given (prilocaine 0.5\%). The fiber was connected to a $940 \mathrm{~nm}$ diode LASER or to a $1320 \mathrm{~nm} \mathrm{Nd:YAG} \mathrm{LASER.} \mathrm{The} \mathrm{desired}$ location of the tip was again ascertained by duplex scanning. During an initial pilot phase optimal power of the LASER was investigated, ranging from 5 to 30 Watt. LASER energy was given in pulsed fashion instead of continuous beam. For the treatment, 3 pulses were given; one below fascia level, one at the fascia level and one above fascia level. Every pulse had an energy of approximately 60 joule. At the end of the LASER treatment a bandage was applied for 48 hours after which the patient should wear their elastic compression stockings. Most treated 
patients had C2 venous disease and only one patient had C6. Median diameter of all ICPV was $3.3 \mathrm{~mm}$ (range 1.1-8.0 mm) In the pilot phase, the use of a low LASER power (5-8 Watt) resulted in occlusion of 27 perforators. On day 1 post treatment all but one ICPV were occluded. There was shrinkage of $36 \%$ of all ICPV, but this was not statistically significant. Using high power LASER (940 nm; 30 Watt, $1320 \mathrm{~nm} ; 10$ Watt) all ICPV were occluded 1 day post treatment, with a significant shrinkage of $69 \%$ in the $1320 \mathrm{~nm}$ LASER group and a non-significant shrinkage in the $940 \mathrm{~nm}$ LASER group. Taking together all ICPV treated either with $940 \mathrm{~nm}$ or $1320 \mathrm{~nm}$, the mean diameter reduction was $79 \pm 33 \%$. This diameter reduction was achieved using a median LASER power of 220 joule. The 3 months follow up of 16 patients (27\%) showed no significant diameter change compared to 1 day postoperative. The most common side effects were ecchymosis (50\%), paresthesia (16\%) and hyperpigmentation (8\%). There were no major complications.

\section{Coil embolisation of ICPV}

Van Dijk and Wittens investigate the feasibility of ultrasound-guided percutaneous coil embolisation of incompetent perforating veins as minimally invasive treatment for venous ulcers and recurrent varicosities in the lower leg. ${ }^{12}$ In 15 patients (six women, nine men; mean age, 50 years), 18 incompetent perforating veins in the lower leg were treated by ultrasoundguided percutaneous placement of embolisation coils (Figure 7). Successful vein occlusion with one or more coils was achieved in 12 of the 18 veins (technical success rate, $67 \%$ ). Clinical symptoms improved in only three of the 15 patients (clinical success rate, 20\%).

\section{Figure 7}

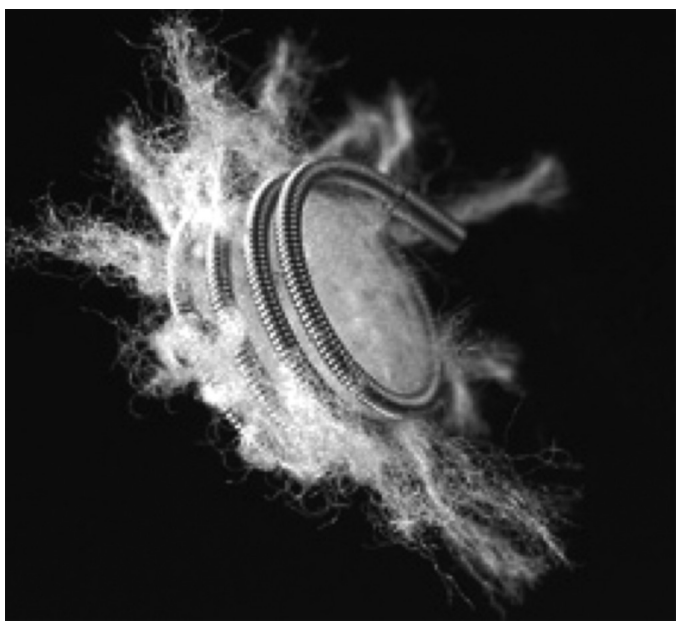


During follow-up (2-12 months), recanalization of coil embolized veins occurred in nine of the 12 initially occluded veins. They concluded that percutaneous ultrasound-guided coil embolisation does not appear to be as effective as subfascial endoscopic perforator surgery in the treatment of incompetent perforator veins.

\section{Duplex-Directed Interruption of Incompetent Perforator Veins (DDICPV)}

In an effort to minimize wound complications, circumvent difficult anatomy, and simplify the procedure, Seiwert and Comerota introduced a duplex-directed technique to interrupt ICPV using phlebectomy hooks, which is inexpensive and minimally invasive. ${ }^{13}$ Twenty-three extremities with ICPV were treated in 18 patients. Eighteen limbs had end-stage venous insufficiency (CEAP classes 4, 5, and 6). Two patients had undergone previous modified Linton procedures and one had prior subfascial endoscopic perforator surgery (SEPS). ICPV in the affected region were identified by duplex ultrasound. A Muller phlebectomy hook was introduced through a $1.5 \mathrm{~mm}$ incision placed in regions of healthy skin. Duplex ultrasound imaging allows the operator to engage the ICPV by the remote subcutaneous entry of the phlebectomy hook. ICPV interruption/avulsion is viewed real-time. Successful interruption is often accompanied by a short period of brisk bleeding easily controlled with direct pressure and cessation of flow in the perforator. Application of a compression dressing completed the procedure. ICPV disruption was confirmed in all limbs intraoperatively. Seventeen patients were discharged on the day of surgery. There were no wound complications and postoperative pain was minimal. Follow-up ranged from 3 to 52 months. Twelve limbs had ulcers healed and all patients noted significant improvement of leg symptoms. Two ulcers recurred within 24 months; one had either a missed or second ICPV, which was treated with DDICPV, and the other had severe deep venous reflux and was treated with compression after finding no additional ICPV. They concluded that DDICPV is a simple, inexpensive, and minimally invasive technique for interruption of ICPV under direct vision that has a short learning curve, is well tolerated by patients, and is effective in treating ICPV

\section{DISCUSSION}

When comparing these 6 alternatives for SEPS, one should notice the lack of randomized controlled trials. Group size, follow up, patient inclusion and definition of incompetence differed between the studies of these alternative techniques. Therefore we cannot recommend one of these techniques above another.

Ultrasound guided sclerotherapy showed good initial results in a highly selective patient group but after one month $32.4 \%$ of the patients had recurrence. Initial ulcer healing after USGS was $67.6 \%$ with a recurrence rate of $32.4 \%$. USGS requires intraluminal access of the ICPV that makes it difficult for the treatment of smaller ICPV. In follow up patients showed a decrease in their VCSS and VDS scores. USGS with foam might improve the results, but up till 
now the results are poor. The only reason why these poor results are accepted is that it can be repeated and it is cheap. But we should select the best therapy for the patient and not the cheapest.

Cryo perforator surgery showed an initial occlusion of all ICPV, however after 20 weeks only $43 \%$ was occluded. Contrary to USGS, CPS does not require an intraluminal approach of the ICPV. Even placed extraluminal, the cryoprobe will attach to the ICPV. This makes the treatment of small-diameter ICPV easier with CPS than with ultrasound-guided sclerotherapy. CPS has the potential to treat ICPV but needs some alterations to gain a higher success rate. There are two explanations for the low success rate of $43 \%$. The first explanation is related to the learning curve of this procedure. CPS is a complete new technique for the treatment of ICPV, which needs close cooperation between the surgeon and the vascular technician. The second explanation is related to the smooth surface of the cryoprobe used. During vigorous withdrawal, the ice cone often detaches from the tip of the cryoprobe. The integrity of the ICPV is, therefore, left unharmed as one fails to achieve the intended obliteration. The perioperative duplex cannot determine the level of damage as the ICPV thromboses as a result of cryomanipulation. After analyzing the results of this study, the surface of the tip of the probe was made rough by coating it with diamond dust (Figure 8). An extensive bench test was performed to determine pull strength of the original cryoprobe versus a diamond dust coated cryoprobe. The diamond dust coated cryoprobe was 3.6 times stronger than the original cryoprobe.

\section{Figure 8}

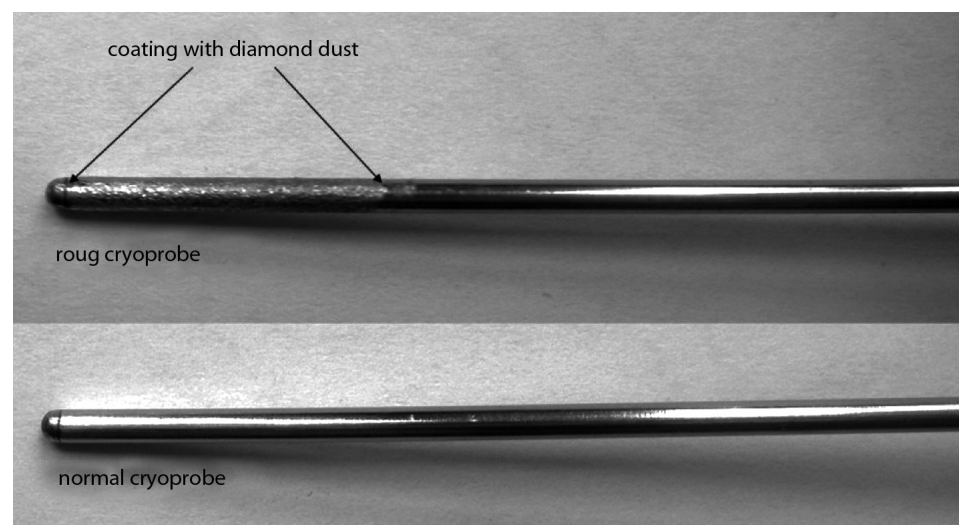

A study on CPS with the new diamond dust-coated cryoprobe will be performed. This study showed that CPS is feasible for the treatment of ICPV. Major advantages are that regardless of their anatomic location, all ICPV can be treated in an outpatient setting under local anesthesia 
and the cryoprobe does not need intraluminal insertion in the ICPV. Another advantage is that the cryoprobe is reusable.

Radiofrequency ablation of ICPV seems feasible, with a success rate of $79 \%$ after one year and $76 \%$ after two years. Just like USGS there is the need for intraluminal insertion of the RF catheter in the ICPV, which makes it less useful for small caliber ICPV. From the series mentioned no intention to treat data are available so we do not know how many time it was impossible to puncture the ICPV properly. But the occlusion rate after one year looks acceptable but far from optimal. A disadvantage is that the system is disposable and therefore expensive.

LASER ablation of ICPV is possible with a high success rate of almost $100 \%$, however just like USGS and RF ablation the LASER catheter needs to be intraluminal of the ICPV, which makes it unsuitable for the small caliber ICPV. Most disturbing side effect was a paresthesia incidence of $16 \%$, which was probably due to thermal damage of surrounding nerves. Coil embolisation of ICPV is shown to be unsuccessful.

The duplex directed disruption of ICPV is a supra-fascial technique that also does not need an intraluminal approach. As stated it is easy and cheap. The results seem promising but it can be theorized that because the entrance in the subcutaneous tissue has to be through a small incision in healthy skin the distance to the ICPV can be long causing more subcutaneous damage. The percutaneous direct approach with the cryoprobe might reduce this possible problem.

\section{CONCLUSION}

All these new techniques seem feasible in the treatment of ICPV. Cryo perforator surgery and duplex directed interruption of ICPV have an extra advantage to be an extraluminal treatment of ICPV and they are easy and cheap. Again, randomized controlled trials have to be performed to recommend any of these techniques above another. 


\section{REFERENCES}

1. van Gent WB, Hop WC, van Praag MC, Mackaay AJ, de Boer EM, Wittens $\mathrm{CH}$. Conservative versus surgical treatment of venous leg ulcers: a prospective, randomized, multicenter trial. J Vasc Surg. 2006 Sep;44(3):563-71.

2. Hauer G. Endoscopic subfascial discussion of perforating veins--preliminary report. Vasa. 1985; 14(1):59-61.

3. Van Gent WB, Wittens CHA. Subfascial endoscopic perforating vein surgery (SEPS): $C h 17,26^{\text {th }}$ symposium book Vascular and Endovascular challenges; Greenhalgh RM 2004

4. Thibault PK, Lewis WA. Recurrent varicose veins. P2: Injection of incompetent perforating veins using ultrasound guidance. J Derm Surg Oncol. 1992 Oct; 18(10):895-900.

5. Masuda EM, Kessler DM, Lurie F, Puggioni A, Kistner RL, Eklof B. The effect of ultrasound-guided sclerotherapy of incompetent perforator veins on venous clinical severity and disability scores. J Vasc Surg. 2006 Mar;43(3):551-6

6. de Waard MM, der Kinderen DJ. Duplex ultrasonography-guided foam sclerotherapy of incompetent perforator veins in a patient with bilateral venous leg ulcers. Dermatol Surg. 2005 May;31(5):580-3.

7. Klem TMAL, Wittens CHA. Cryoperforator Surgery: A New Treatment of Incompetent Perforating Veins. Vasc Endovascular Surg. 2008 Feb 7

8. Whiteley MS HJ, Price BA, Scott MJ, Gallagher TM. Radiofrequency ablation of refluxing great saphenous systems, Giacomini veins, and incompetent perforating veins using VNUS closure and TRLOP technique. Phlebology. 2003; 18:52

9. Roth SM. Endovenous radiofrequency ablation of superficial and perforator veins. Surg Clin North Am. 2007 Oct;87(5):1267-84, xii. Review

10. Peden E, Lumsden A. Radiofrequency ablation of incompetent perforator veins. Perspect Vasc Surg Endovasc Ther. 2007 Mar; 19(1):73-7.

11. Proebstle TM, Herdemann S. Early results and feasibility of incompetent perforator vein ablation by endovenous laser treatment. Dermatol Surg. 2007 Feb; 33(2):162-8.

12. van Dijk LC, Wittens CHA, Toonder I, Laméris J, du Bois NA, Pattynama PM. Ultrasound-guided percutaneous coil embolization of incompetent perforating veins: not effective for treatment of venous ulcers and recurrent varicosities. J Vasc Interv Radiol. 1999 Oct; 10(9):1271-4.

13. Seiwert AJ, Jones L, Comerota AJ. Duplex-Directed Interruption of Incompetent Perforator Veins (DDICPV) Poster presentation, American Venous Forum, 2006 


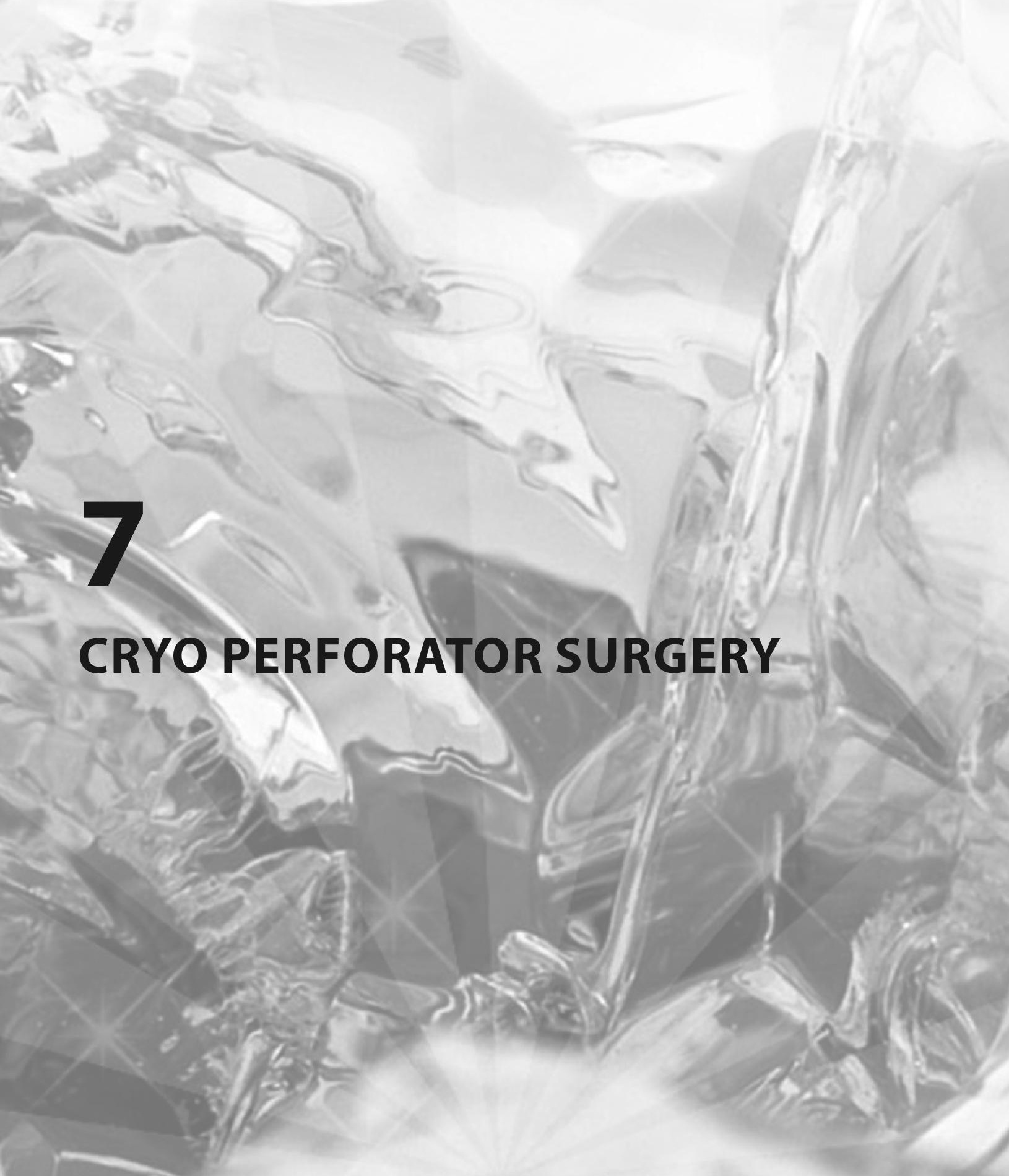




\section{ABSTRACT}

Purpose: This study was conducted to determine the feasibility of cryoperforator surgery in the treatment of incompetent perforating veins.

Methods: Fifteen patients with C2-C4 varicose disease (according to the Clinical-EtiologyAnatomy-Pathophysiology classification) were enrolled in this study. Under local anesthesia, incompetent perforating veins were treated with a duplex-guided cryoprobe. Duplex scans were performed 2 and 4 weeks after treatment. Fifteen patients with 28 incompetent perforating veins were treated with cryoperforator surgery. Distribution of the incompetent perforating veins was as follows: posterior tibial perforator, 12; paratibial perforator, 11; intergemellar perforator, 1 ; lateral leg perforator, 4 (range $=1-5$ incompetent perforating veins per patient).

Results: Follow-up showed successful treatment of 12 incompetent perforating veins (43\%).

Conclusions: This study showed that cryoperforator surgery is feasible for treatment of incompetent perforating veins. Higher success rates could be obtained with our modified diamond-dust coated cryoprobe. Major advantages are the treatment in an outpatient setting and the possibility of treating all incompetent perforating veins, intraluminal or extraluminal. 


\section{INTRODUCTION}

Worldwide, chronic venous diseases involve enormous costs for their treatment. ${ }^{1,2}$

Venous ulcers account for the majority of morbidity and treatment costs because of the slow healing and high recurrence rate. Treatment of the superficial venous system, in combination with dissection of incompetent perforating veins (ICPV), is perceived to be the best treatment for patients with chronic venous leg ulceration (C6 according to Clinical-Etiology-AnatomyPathophysiology [CEAP] classification). ${ }^{3,4}$ Improvements in surgical techniques could bring down costs and result in a higher patient satisfaction. There are various ways by which the superficial venous system can be surgically treated, such as classic stripping, cryostripping, radiofrequency ablation, and endovenous laser treatment of the great saphenous vein (GSV) or crossectomy of the small saphenous vein (SSV). Treatment of venous ulcers in areas above the ankle due to venous hypertension should involve the dissection of ICPV in combination with treatment of the incompetent superficial venous system. The objective of ICPV dissection is to decrease venous reflux and to reduce ambulatory venous hypertension. Dissection of ICPV can be done with subfascial endoscopic perforating vein surgery (SEPS), open perforantectomy, or ultrasound-guided sclerotherapy. Subfascial endoscopic perforating vein surgery was first performed by $\mathrm{Dr}$ G. Hauer ${ }^{5}$ in Germany in 1985 . For many vascular surgeons, it is currently the surgical technique of choice in treating ICPV. In inexperienced hands, SEPS can show poor results because of a challenging learning curve. Subfascial endoscopic perforating vein surgery is also known to have other limitations. This technique is mainly suitable for the treatment of ICPV on the medial aspect of the lower leg. ${ }^{6}$ The narrow confines due to compartmental tapering at the ankle have proven challenging for SEPS. Ultrasound guided sclerotherapy for treating ICPV showed poor long-term results in our clinic, and its use is not widespread. Cryoperforator surgery (CPS) was developed in our vascular laboratory as a new treatment of dissecting ICPV. Cryoperforator surgery is a minimal invasive technique, which provides unlimited access to all ICPV regardless of their location and can be performed under local anesthesia. In this article, we describe our study regarding the feasibility of CPS in treating ICPV.

\section{PATIENTS AND METHODS}

Over a period of 6 months, 15 patients with C2-C4 varicose veins (according to the CEAP classification) were enrolled in this study. An informed consent was obtained from all patients before surgery. A prospective registry of preoperative and postoperative duplex scans was created. During the duplex scan, incompetence or obliteration of the ICPV was noted, indicating the success of the treatment. Cryoperforator surgery was applied in patients with clinical complaints of chronic venous disease such as pain, fatigue, and heavy feeling of the leg. All patients had a competent deep venous system, and their superficial venous system was either competent or already treated. Therefore, the venous complaints could only be due 
to ICPV. Contraindications to participate in this study were peripheral arterial disease (ankle brachial index < 0.9), GSV or SSV incompetence, and incompetence or occlusion of the deep venous system. Because the effects of CPS in the proximity of a venous (healed) ulcer were uncertain, avoiding every risk, patients with $C 5$ and $C 6$ varicose veins were not enrolled in this study.

\section{Duplex Scanning}

Before treatment, all ICPV were identified and ink marked on the skin, using a duplex ultrasound with an ATL 5000 scanner (Advanced Technology Laboratories, Bothel, Washington) using a 5to $12-\mathrm{MHz}$ linear array transducer. Incompetence was defined when perforator reflux times exceeded 0.35 seconds. $^{7}$

\section{Operation}

The operation was performed under local anesthesia (1\% lidocaine). The ICPV were approached percutaneously, placing a 14-gauge cannula (Venflon; BD Medical, Swindon, United Kingdom) at the fascia defect under duplex ultrasound guidance. The cannula could be placed intraluminal or extraluminal small-diameter ICPV. The cryoprobe (Erbe, Tübingen, Germany), with a diameter of $1.6 \mathrm{~mm}$, was introduced through the cannula and frozen for 15 seconds at $-89^{\circ} \mathrm{C}$ (liquid nitrous oxide, $\mathrm{N}_{2} \mathrm{O}$ ). During the freezing, an ice cone was formed at the tip of the cryoprobe. The ICPV was freeze-attached to the ice cone, and dissection was obtained by withdrawing the probe vigorously. Treatment was considered successful perioperative when ICPV showed no signs of flow despite augmentation on the duplex scan. A compression bandage was applied in all patients and they were discharged 1 hour after the operation. Follow-up duplex scans were performed 2, 4, and 20 weeks after treatment. Total follow-up for all patients was 20 weeks.

\section{RESULTS}

Patients consisted of 3 men and 12 women with a median age of 55 years (age $=22-76$ years) and complaints of chronic venous disease. There was no comorbidity. Preoperative duplex scanning showed 28 ICPV in 15 patients. All ICPV were treated with CPS. Distribution of the ICPV was as follows: posterior tibial perforator, 12; paratibial perforator, 11; intergemellar perforator, 1 ; lateral leg perforator, 4 (range $=1-5$ per patient). The diameter (median) of the fascia defect was $2.8 \mathrm{~mm}$ (range $=1.8-6.8 \mathrm{~mm}$ ) and depth (median) of the fascia defect was $10.4 \mathrm{~mm}$ (range $=3.7-22.0 \mathrm{~mm}$ ). Perioperative duplex showed no signs of flow in all treated ICPV. Follow-up duplex after 2, 4, and 20 weeks showed successful treatment in 12 perforating veins (43\%; Table 1). Distribution of perforating veins in successful treatment: posterior tibial perforator, 4; paratibial perforator, 6; intergemellar perforator, 0 ; lateral leg perforator, 2 . There were no perioperative complications. Five patients developed a small hematoma on the leg, which healed within 2 weeks. All patients completed the follow-up period. 
Table 1: Results of Cryoperforator Surgery

\begin{tabular}{|c|c|c|c|c|}
\hline Main group & Subgroup & Depth, mm & Diameter, mm & Successful \\
\hline \multirow[t]{28}{*}{ Leg perforator } & Posterior tibial perforator (upper) & 3.7 & 2.2 & Yes \\
\hline & Posterior tibial perforator (upper) & 10.2 & 2.4 & No \\
\hline & Posterior tibial perforator (upper) & 10.0 & 2.0 & Yes \\
\hline & Posterior tibial perforator (middle) & 9.5 & 2.2 & No \\
\hline & Posterior tibial perforator (middle) & 11.0 & 3.9 & No \\
\hline & Posterior tibial perforator (middle) & 9.2 & 2.0 & No \\
\hline & Posterior tibial perforator (lower) & 9.0 & 6.8 & Yes \\
\hline & Posterior tibial perforator (lower) & 7.2 & 3.2 & No \\
\hline & Posterior tibial perforator (lower) & 21.0 & 2.1 & No \\
\hline & Posterior tibial perforator (lower) & 21.7 & 1.8 & No \\
\hline & Posterior tibial perforator (lower) & 21.7 & 1.9 & No \\
\hline & Posterior tibial perforator (lower) & 6.1 & 6.8 & Yes \\
\hline & Paratibial perforator & 10.0 & 2.5 & Yes \\
\hline & Paratibial perforator & 10.0 & 2.6 & Yes \\
\hline & Paratibial perforator & 13.0 & 3.8 & Yes \\
\hline & Paratibial perforator & 13.5 & 2.6 & Yes \\
\hline & Paratibial perforator & 13.8 & 2.1 & Yes \\
\hline & Paratibial perforator & 9.1 & 6.2 & No \\
\hline & Paratibial perforator & 10.5 & 4.9 & No \\
\hline & Paratibial perforator & 14.4 & 4.0 & No \\
\hline & Paratibial perforator & 13.6 & 3.0 & Yes \\
\hline & Paratibial perforator & 5.7 & 3.6 & No \\
\hline & Paratibial perforator & 22.0 & 4.1 & No \\
\hline & Intergemellar perforator & 11.6 & 5.2 & No \\
\hline & Lateral leg perforator & 6.5 & 2.9 & No \\
\hline & Lateral leg perforator & 6.8 & 3.9 & Yes \\
\hline & Lateral leg perforator & 22.0 & 2.2 & No \\
\hline & Lateral leg perforator & 18.7 & 2.4 & Yes \\
\hline Media & & 10.4 & 2.8 & \\
\hline Range & & $3.7-22.0$ & $1.8-6.8$ & $12 / 28(43 \%)$ \\
\hline
\end{tabular}




\section{DISCUSSION}

Venous leg ulceration accounts for a large percentage of total health budget. The desired procedure of this condition is the treatment of the superficial venous system in combination with dissection of ICPV. Until now, SEPS or open perforantectomy is the most commonly applied procedures for dissecting ICPV. A less invasive, outpatient treatment could lower morbidity and costs. Cryoperforator surgery has the potential to become an alternative to the conventional treatments applied today. Our study was performed to determine the feasibility of CPS. Our study shows that there are several advantages of CPS compared to SEPS and ultrasound guided sclerotherapy. Contrary to SEPS, CPS can reach all ICPV regardless of their anatomical location, resulting in a more extensive therapeutic range. Cryoperforator surgery can be performed under local anesthesia in an outpatient clinic setting and is less invasive than SEPS. In our clinic, ultrasound guided sclerotherapy showed poor long-term results, but good results were presented by Masuda et al. ${ }^{8}$ Contrary to this technique, CPS does not require an intraluminal approach of the ICPV. Even in extraluminal, the cryoprobe will attach to the ICPV. This makes the treatment of small-diameter ICPV easier with CPS than with ultrasoundguided sclerotherapy. Treatment of ICPV with radiofrequency ablation (Closure catheter, VNUS Medical Technologies, Sunnyvale, CA) or laser has been performed but shows no convincing long-term efficacy. ${ }^{9,10}$ We have found that CPS has the potential to treat ICPV but needs some alterations to gain a higher success rate. There are two explanations for the low success rate of $43 \%$. The first explanation is related to the learning curve of this procedure. Cryoperforator surgery is a complete new technique for the treatment of ICPV, which needs a close cooperation between the surgeon and the vascular technician. The second explanation is related to the smooth surface of the cryoprobe used. During vigorous withdrawal, the ice cone often detach from the tip of the cryoprobe. The integrity of the ICPV is, therefore, left unharmed as one fails to achieve the intended obliteration. The perioperative duplex cannot determine the level of damage as the ICPV thromboses as a result of cryo manipulation. After analyzing the results of this study, the surface of the tip of the probe was made rough by coating it with diamond dust. An extensive bench test was performed to determine pull strength of the original cryoprobe versus a diamond dust coated cryoprobe. The diamond dust-coated cryoprobe was 3.6 times stronger than the original cryoprobe. A study on CPS with the new diamond dust-coated cryoprobe was further carried out. This study showed that CPS is feasible for the treatment of ICPV. Major advantages are that regardless of their anatomic location, all ICPV can be treated in an outpatient setting under local anesthesia, and the cryoprobe does not need intraluminal insertion in the ICPV. In conclusion, CPS is feasible for the treatment of ICPV. Higher success rates can be obtained with the modified diamond-dust cryoprobe. Major advantages are the minimal-invasive treatment in an outpatient setting and the possibility of reaching all ICPV, intraluminal or extraluminal. 


\section{REFERENCES}

1. Hume M. Venous ulcers, the vascular surgeon, and the Medicare budget. J Vasc Surg. 1992; 16:671-673.

2. Tenbrook JA Jr, lafrati MD, O'donnell TF Jr, et al. Systematic review of outcomes after surgical management of venous disease incorporating subfascial endoscopic perforator surgery. J Vasc Surg. 2004; 39:583-589.

3. Bianchi C, Ballard JL, Abou-Zamzam AM, Teruya TH. Subfascial endoscopic perforator vein surgery combined with saphenous vein ablation: results and critical analysis. J Vasc Surg. 2003; 38:67-71.

4. van Gent WB, Hop WC, van Praag MC, Mackaay AJ, de Boer EM, Wittens CH. Conservative versus surgical treatment of venous leg ulcers: a prospective, randomized, multicenter trial. J Vasc Surg. 2006; 44:563-571.

5. Hauer G, Bergan JJ, Werner A, Mitterhusen M, Nasralla F. Development of endoscopic dissection of perforating veins and fasciotomy for treatment of chronic venous insufficiency. Ann Vasc Surg. 1999; 13:357-364.

6. de Rijcke PA, SchenkT, van Gent WB, Kleinrensink GJ, Wittens CH. Surgical anatomy for subfascial endoscopic perforating vein surgery of laterally located perforating veins. J Vasc Surg. 2003; 38:1349-1352.

7. Labropoulos N, Tiongson J, Pryor L, et al. Definition of venous reflux in lower-extremity veins. J Vasc Surg. 2003; 38:793798.

8. Masuda EM, Kessler DM, Lurie F, Puggioni A, Kistner RL, Eklof B. The effect of ultrasound-guided sclerotherapy of incompetent perforator veins on venous clinical severity and disability scores. J Vasc Surg. 2006; 43:551-556.

9. Chang DW, Levy D, Hayashi RM, Starrett RW, Smith D. Percutaneous ultrasound-guided radiofrequency ablation (VNUS) can be used to treat perforator incompetence: 1- year results and how to do it. Oral presentation at: Veith Symposium; November 18, 2005; New York, NY.

10. Proebstle TM, Moehler T, Gul D, Herdemann S. Early results and feasibility of incompetent perforator vein ablation by endovenous laser treatment. Dermatol Surg. 2007; 33:162-168 



\section{ABSTRACT}

Purpose: Cryo perforator surgery (CPS) showed in a earlier study that it could be an effective surgical technique in the treatment of ICPV. Modification of the cryoprobe with a diamond dust coating (DDC) showed better results in vitro. A second study was performed to determine the efficacy and safety of CPS with the DDC cryoprobe.

Methods: All patients had clinical complaints and ICPV. CPS consisted of DDC cryoprobe insertion in or near the ICPV. The efficacy of the procedure was determined with duplex ultrasound, 1 month after the procedure.

Results: Eleven women with 15 ICPV were treated with CPS. In 2 patients (18\%) the treatment was successful with 3 occluded perforating veins (20\%). One patient developed a persistent painfully paresthesia on the medial side of the lower leg.

Conclusions: CPS cannot perform a dissection of ICPV. It is a painful and difficult procedure with a disturbing success rate. CPS should be considered obsolete. 


\section{INTRODUCTION}

There is still no definitive consensus if treatment of the superficial venous system, in combination with dissection of incompetent perforating veins (ICPV), is the best treatment for patients with chronic venous leg ulceration. ${ }^{1-3}$ Improvements in surgical techniques for treatment of ICPV have the potential to reduce costs and result in a higher patient satisfaction.

There are numerous techniques by which the superficial venous system can be surgically treated. Conventional stripping, cryo stripping, radiofrequency thermo ablation, and laser thermo ablation for the great saphenous vein. Ligation or laser thermo ablation for the small saphenous vein.

Treatment of active venous ulcers in the area above the ankle could involve the dissection of ICPV in combination with treatment of the incompetent superficial venous system. The idea behind ICPV dissection is to decrease venous reflux and to reduce ambulatory venous hypertension. Dissection of ICPV can be done with subfascial endoscopic perforating vein surgery (SEPS), open perforantectomy, ultrasound guided sclerotherapy and laser or radiofrequency thermo ablation. For many vascular surgeons, SEPS is the surgical technique of choice in treating ICPV, however it can show poor results because of a challenging learning curve. SEPS is also mainly suitable for the treatment of ICPV on the medial aspect of the lower leg and the narrow confines due to compartmental tapering at the ankle have proven challenging. ${ }^{4,5}$ Ultrasound guided sclerotherapy for treating ICPV showed poor long-term results in our hospital, and its use is not widespread. The treatment of ICPV with radiofrequency or laser thermo ablation is a rather new technique which has to show its potential in future trials.

Cryo perforator surgery (CPS) showed in an earlier study that it could treat ICPV, however there was a large percentage (57\%) of unsuccessful procedures. ${ }^{6}$ CPS was developed in our vascular laboratory as a new treatment of dissecting ICPV. It is a minimal invasive technique, which provides unlimited access to all ICPV regardless of their location and can be performed under local anesthesia. After analysis of the results of the earlier CPS study, the new hypothesis was that the smooth surface of the cryoprobe was the reason for the low success rate. A more rough (increased) surface by means of diamond dust coating (DDC) of the cryoprobe could increase the number of successful procedures. In this article, we describe the feasibility of CPS in treating ICPV with a DDC cryoprobe.

\section{PATIENTS AND METHODS}

Over a period of 4 months, 11 patients with clinical severity class 2-4 venous disease were enrolled in this study. An informed consent was obtained from all patients before surgery. A prospective registry of preoperative and postoperative duplex scans was created. During the 
duplex scan, incompetence or obliteration of the ICPV was noted, indicating the success of the treatment. CPS was applied in patients with clinical complaints of chronic venous disease such as pain, fatigue, and heavy feeling of the leg. All patients had a competent deep venous system, and their superficial venous system was either competent or already treated. Therefore, the venous complaints could only be due to ICPV. Contraindications to participate in this study were peripheral arterial disease (ankle brachial index < 0.9), GSV or SSV incompetence, and incompetence or occlusion of the deep venous system. Because the effects of CPS in the proximity of a venous (healed) ulcer were uncertain, avoiding every risk, patients with clinical severity class 5-6 venous disease were not enrolled in this study.

\section{Duplex Scanning}

Before treatment, all ICPV were identified and ink marked on the skin, using duplex ultrasound with an ATL 5000 scanner (Advanced Technology Laboratories, Bothel, Washington) using a 5- to $12 \mathrm{MHz}$ linear array transducer. Incompetence was defined when perforator reflux times exceeded 0.35 seconds. ${ }^{7}$

\section{Conventional cryoprobe and DDC cryoprobe}

A conventional cryoprobe (Erbe, Tübingen, Germany) has a diameter of $1.6 \mathrm{~mm}$ and a smooth metallic surface. After freezing for 15 seconds at $-89^{\circ} \mathrm{C}$ (liquid nitrous oxide, $\mathrm{N}_{2} \mathrm{O}$ ) an ice cone will form at the tip of the probe which attaches to the adherent venous structure. After pulling the probe the adherent venous structure will be destroyed. After analysis of the results of the earlier study we came to the conclusion that detachment of the ice cone from the cryoprobe was the main reason for the high failure rate. The integrity of the ICPV is left unharmed as one fails to achieve the intended obliteration. A conventional cryoprobe was coated on the tip (1.5 $\mathrm{cm}$ ) with diamond dust (Ackermann Instrumente, Rietheim-Weilheim, Germany). After bench testing the rough (increased) surface of the DDC cryoprobe resulted in an 3.6x increased pull strength. This DDC cryoprobe was further used in this study.

\section{Operation}

The operation was performed under local anesthesia (1\% lidocaine). The ICPV were approached percutaneously, placing a 14-gauge cannula (Venflon; BD Medical, Swindon, United Kingdom) at the fascia defect under duplex ultrasound guidance. The cannula could be placed intraluminal or extraluminal in small diameter ICPV. The DDC cryoprobe was introduced through the cannula and frozen for 15 seconds. During the freezing, an ice cone was formed at the tip of the DDC cryoprobe. The ICPV was freeze attached to the ice cone, and dissection was obtained by withdrawing the probe vigorously. Treatment was considered successful perioperative when ICPV showed no signs of flow despite augmentation on the duplex scan. A compression bandage was applied in all patients and they were discharged 1 hour after the operation. Follow-up duplex scan was performed 4 weeks after treatment and a final physical examination 8 weeks after treatment. Total follow-up for all patients was 8 weeks. 


\section{RESULTS}

Patients consisted of 11 women with a median age of 61 years (age $=40-87$ years) and complaints of venous disease. There was no diabetes or cardiopulmonal comorbidity. Preoperative duplex scanning showed 15 ICPV in 11 patients. All ICPV were treated with CPS. Distribution of the ICPV was as follows: thigh perforators, 6; leg perforators, 9. The median diameter of the ICPV was $4 \mathrm{~mm}$ (range $=2.0-6.2 \mathrm{~mm}$ ). Perioperative duplex showed no signs of flow in all treated ICPV. Follow-up duplex after 4 weeks showed successful treatment in 3 perforating veins (20\%) in 2 patients (18\%) (Table 1). Distribution of perforating veins in successful treatment: thigh perforator, 1 ; leg perforator, 2 . There was one complication: one patient had a persistent painful paresthesia of the medial aspect of the leg after CPS of a thigh perforator (femoral canal). This was probably caused by a lesion of the saphenous nerve or deeper side branch of the femoral nerve. Four patients developed a small hematoma on the leg, which healed within 2 weeks. All patients complained of pain during CPS. All patients completed the 8 week follow-up period. Because of these troublesome results no further patients were included in this study.

Table 1: Results of Cryoperforator Surgery

\begin{tabular}{|c|c|c|c|c|}
\hline Main group & Subgroup & Depth, mm & Diameter, mm & Successful \\
\hline \multirow[t]{20}{*}{ Leg perforator } & Posterior tibial perforator (upper) & 3.7 & 2.2 & Yes \\
\hline & Posterior tibial perforator (upper) & 10.2 & 2.4 & No \\
\hline & Posterior tibial perforator (upper) & 10.0 & 2.0 & Yes \\
\hline & Posterior tibial perforator (middle) & 9.5 & 2.2 & No \\
\hline & Posterior tibial perforator (middle) & 11.0 & 3.9 & No \\
\hline & Posterior tibial perforator (middle) & 9.2 & 2.0 & No \\
\hline & Posterior tibial perforator (lower) & 9.0 & 6.8 & Yes \\
\hline & Posterior tibial perforator (lower) & 7.2 & 3.2 & No \\
\hline & Posterior tibial perforator (lower) & 21.0 & 2.1 & No \\
\hline & Posterior tibial perforator (lower) & 21.7 & 1.8 & No \\
\hline & Posterior tibial perforator (lower) & 21.7 & 1.9 & No \\
\hline & Posterior tibial perforator (lower) & 6.1 & 6.8 & Yes \\
\hline & Paratibial perforator & 10.0 & 2.5 & Yes \\
\hline & Paratibial perforator & 10.0 & 2.6 & Yes \\
\hline & Paratibial perforator & 13.0 & 3.8 & Yes \\
\hline & Paratibial perforator & 13.5 & 2.6 & Yes \\
\hline & Paratibial perforator & 13.8 & 2.1 & Yes \\
\hline & Paratibial perforator & 9.1 & 6.2 & No \\
\hline & Paratibial perforator & 10.5 & 4.9 & No \\
\hline & Paratibial perforator & 14.4 & 4.0 & No \\
\hline
\end{tabular}


Table 1: Results of Cryoperforator Surgery

\begin{tabular}{llccc} 
Main group & Subgroup & Depth, $\mathbf{~ m m}$ & Diameter, $\mathbf{~ m m}$ & Successful \\
\hline & Paratibial perforator & 13.6 & 3.0 & Yes \\
& Paratibial perforator & 5.7 & 3.6 & No \\
& Paratibial perforator & 22.0 & 4.1 & No \\
& Intergemellar perforator & 11.6 & 5.2 & No \\
& Lateral leg perforator & 6.5 & 2.9 & No \\
& Lateral leg perforator & 6.8 & 3.9 & Yes \\
& Lateral leg perforator & 22.0 & 2.2 & No \\
Media & Lateral leg perforator & 18.7 & 2.4 & Yes \\
Range & & 10.4 & 2.8 & \\
& & $3.7-22.0$ & $1.8-6.8$ & $12 / 28(43 \%)$
\end{tabular}

\section{DISCUSSION}

Venous leg ulceration accounts for a large percentage of total health budget. $^{8}$ Although there is no definitive consensus, most physicians believe that the desired procedure of this condition is the treatment of the superficial venous system in combination with dissection of ICPV. SEPS or open perforantectomy are still commonly applied procedures for dissecting ICPV. Less invasive, outpatient treatment could reduce morbidity and costs. In theory CPS has many advantages like intra or extra- luminal treatment of ICPV regardless of their anatomical location and treatment under local anesthesia in an outpatient clinic setting. CPS however has shown in this study that it cannot perform an adequate dissection of ICPV.

The explanation for the low success rate of $20 \%$ is not fully understood. There is definitively a learning curve effect of this procedure. CPS needs a close cooperation between the surgeon and the vascular technician. The DDC cryoprobe was expected to perform better in patients, as it did in vitro, when compared to the conventional cryoprobe. Perioperative assessment of the ICPV is difficult as the duplex scan cannot determine the level of damage as the ICPV thromboses as a result of cryo manipulation.

In theory, freezing time could have resulted in these low success rates. In 15 seconds a rather large ice-cone will form around the cryoprobe which adheres to all surrounding tissues. When freezing times are shortened a smaller ice cone will form and more selective adherence of the ICPV could occur. The reason for the higher success rate in the earlier study with the conventional cryoprobe could be the fact that the median diameter of ICPV was smaller (2.8 
$\mathrm{mm}$ ) compared to this group of patients $(4.0 \mathrm{~mm})$. In this study also patients with incompetent thigh perforators were treated, which are situated rather deeper than leg perforators.

Because of the low success rates of CPS, the fact that it is a painful procedure and the persistent neural damage in one patient our department stopped using CPS.

Our conclusion is that CPS cannot perform a dissection of ICPV, it is a difficult and painful procedure with a disturbing success rate and it should be considered obsolete.

Minimally invasive techniques for dissection of ICPV could be in the form of radiofrequency or laser thermo ablation. These modalities have to show their potential in future trials. 


\section{REFERENCES}

1. Bianchi C, Ballard JL, Abou-Zamzam AM, Teruya TH. Subfascial endoscopic perforator vein surgery combined with saphenous vein ablation: results and critical analysis. J Vasc Surg. 2003; 38:67-71.

2. Tenbrook JA Jr, lafrati MD, O'donnell TF Jr, et al. Systematic review of outcomes after surgical management of venous disease incorporating subfascial endoscopic perforator surgery. J Vasc Surg. 2004; 39:583-589.

3. Klem TM, Wittens $\mathrm{CH}$. Minimally invasive alternatives for the treatment of perforating veins. In: Wittens $\mathrm{CH}$, editor. Innovative treatment of venous disorders. 1st ed. Maastricht (The Netherlands, Europe): Edizioni Minerva Medica; 2009. p. 187-97.

4. van Gent WB, Hop WC, van Praag MC, Mackaay AJ, de Boer EM, Wittens CH. Conservative versus surgical treatment of venous leg ulcers: a prospective, randomized, multicenter trial. J Vasc Surg. 2006; 44:563-571.

5. de Rijcke PA, Schenk T, van Gent WB, Kleinrensink GJ, Wittens CH. Surgical anatomy for subfascial endoscopic perforating vein surgery of laterally located perforating veins. J Vasc Surg. 2003; 38:1349-1352.

6. Klem TM, Wittens $\mathrm{CH}$. Cryoperforator surgery: a new treatment of incompetent perforating veins. Vasc Endovascular Surg. 2008; 42:239-42.

7. Labropoulos N, Tiongson J, Pryor L, et al. Definition of venous reflux in lower-extremity veins. J Vasc Surg. 2003; 38:793798.

8. Hume M. Venous ulcers, the vascular surgeon, and the Medicare budget. J Vasc Surg. 1992; 16:671-673. 


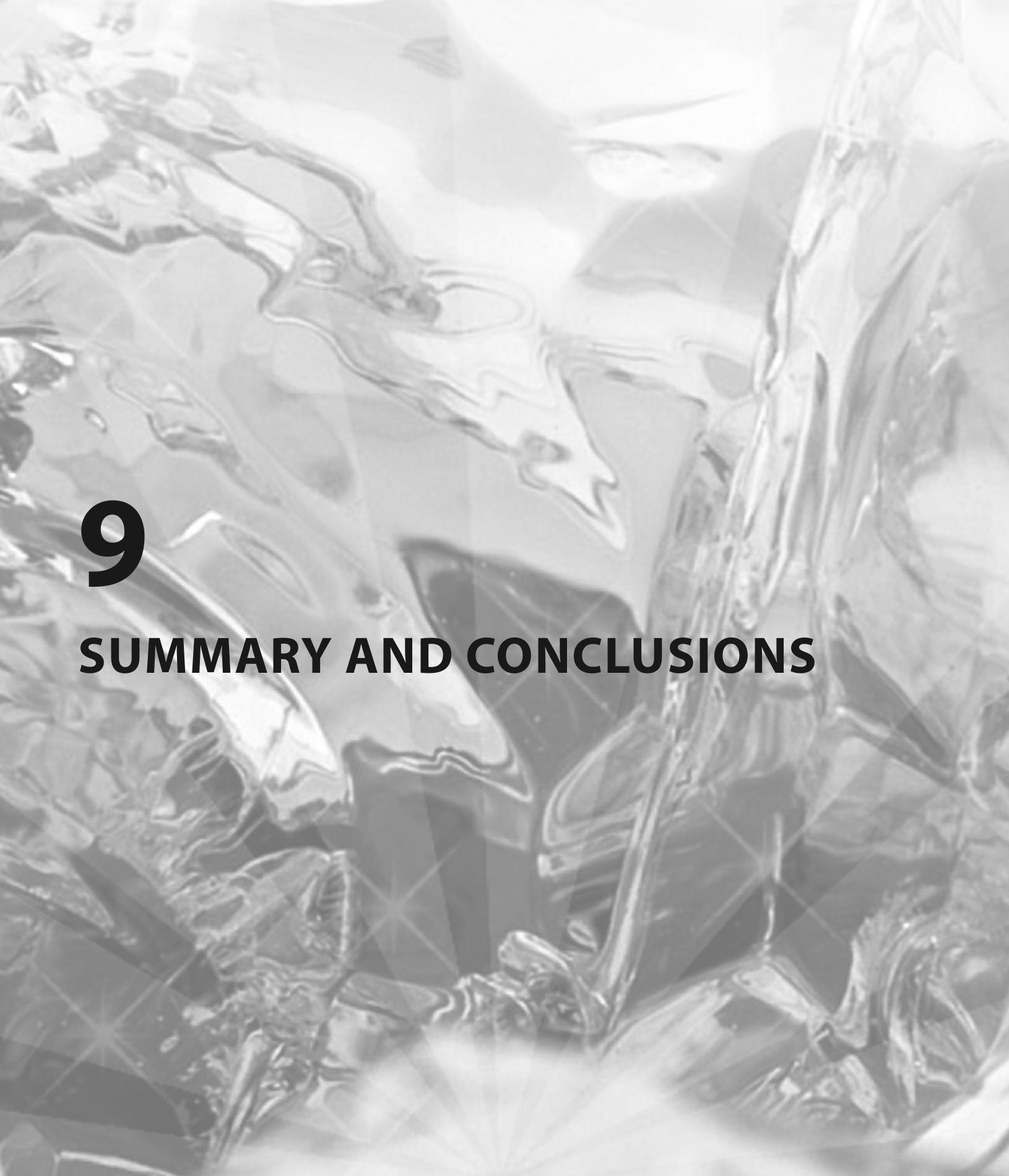




\section{SUMMARY AND CONCLUSIONS}

This thesis describes studies on the aspect of venous cryo surgery of the leg and quality of life measurement. In chapter 1, the rationale for this research is presented. Venous disease of the leg has an estimated prevalence of $60 \%$ and accounts for substantial morbidity, costs and loss in quality of life. Small changes in (surgical) therapy can therefore have large effects. The alternative therapy, cryo stripping, is introduced in the light of anatomical, epidemiological, etiological and socio-economic aspects of venous disease of the leg.

To measure quality of life in a Dutch population with venous disease of the leg, a validated quality of life questionnaire was necessary. In chapter 2, a health specific quality of life questionnaire (Aberdeen Varicose Vein Questionnaire) was validated, according to international guidelines, for the Dutch language.

In chapter 3, the use of the Dutch translated Aberdeen Varicose Vein Questionnaire was evaluated. This study showed that the questionnaire could differentiate between groups of patients with different severity classes of venous disease and groups before and after therapy.

A review of all surgical techniques for the treatment of the incompetent great saphenous vein is presented in chapter 4. Surgical stripping of the great saphenous vein is still used in the majority of cases. Minimally invasive methods like laser and radiofrequency thermo ablation have gained popularity in the last decade. We conclude that all treatment modalities appear to be effective and safe with short and midterm follow up. Before considering endovenous treatments as first choice treatment, large high quality randomized trials with long term follow up are needed.

In chapter $\mathbf{5}$ the results are described of a prospective randomized trial, comparing the results of conventional stripping to cryo stripping of the incompetent great saphenous vein. The primary outcome was residual great saphenous after 6 months, confirmed by duplex ultrasound. Secondary outcomes were quality of life measurements, neural damage and operation time. The conclusion is that cryo stripping with a rigid cryoprobe accounts for numerous procedural failures and hence residual GSV in patients. Health-related QOL measured by the AVVQ showed small but significantly better results for patients after conventional stripping. Cryo stripping has no benefits over conventional stripping.

In chapter 6 indications and different techniques are reviewed in the minimally invasive treatment of incompetent perforating veins. SEPS is not considered minimally invasive when new treatments like laser, radiofrequency ablation and CPS are available. Further studies will shed light which treatment should become the new gold standard. 
In chapter $\mathbf{7}$ the results are described of a cohort patients with incompetent perforating veins who received Cryo Perforator Surgery (CPS). In this study poor results were found which were probably related to the smooth surface of the cryoprobe.

With a modified cryoprobe which was coated with diamond dust, a new cohort patients with incompetent perforating veins was treated. The results are described in chapter $\mathbf{8}$. The conclusion is that CPS give very poor results and should be considered obsolete. 



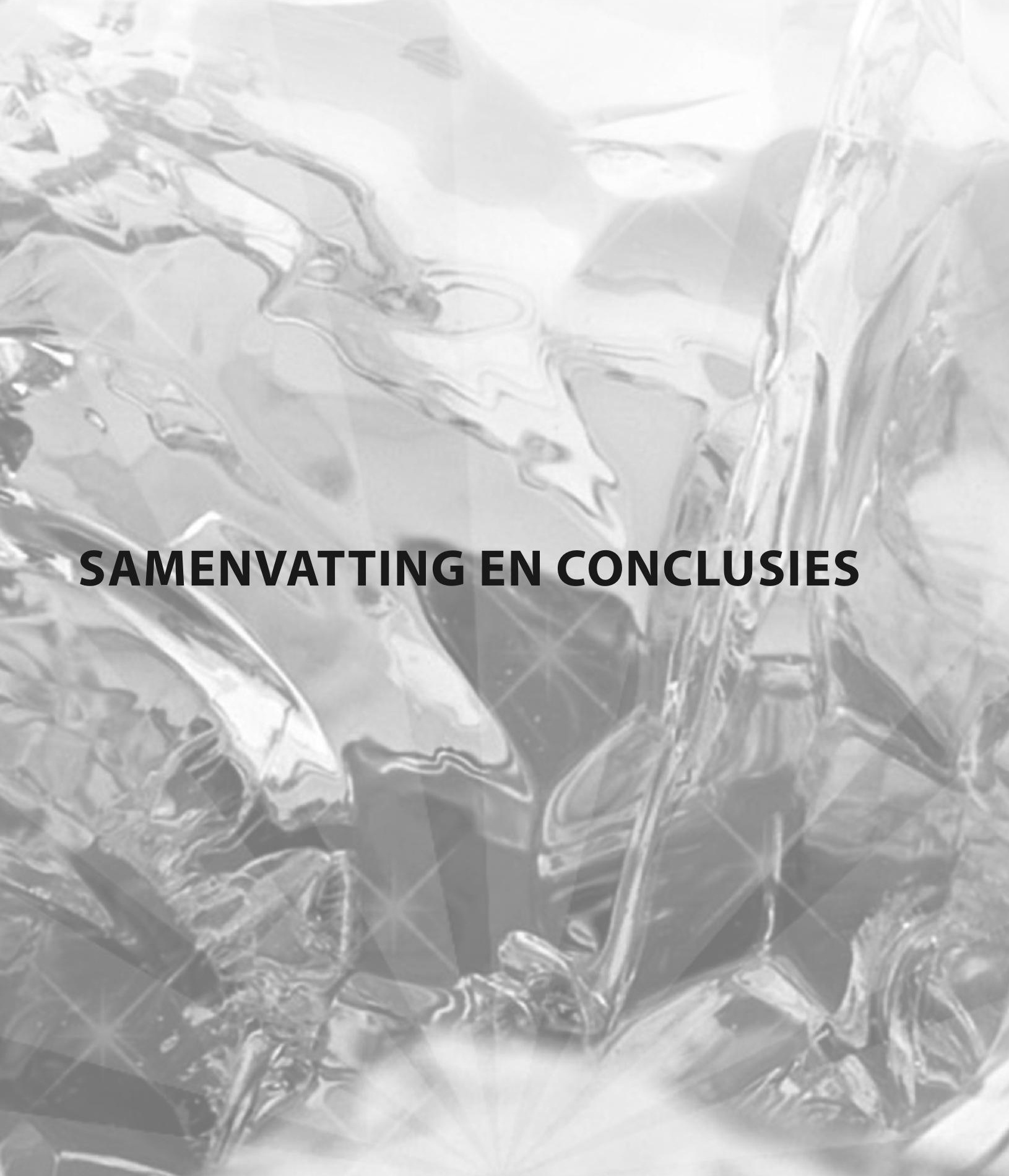




\section{SAMENVATTING EN CONCLUSIES}

Dit proefschrift beschrijft studies met betrekking tot veneuze cryo chirurgie van het been en 'Quality of life' metingen. In hoofdstuk 1, wordt de rationale voor dit onderzoek uitgelegd. Veneuze ziekte van het been heeft een geschatte prevalentie van $60 \%$ en een substantiële morbiditeit, kosten en verlies van 'quality of life'. Kleine veranderingen in (chirurgische) therapie kunnen daardoor grote effecten hebben. De alternatieve cryo strip behandeling wordt geïntroduceerd in het kader van anatomische, epidemiologische, etiologische en socioeconomische aspecten van veneuze ziekte van het been.

Om 'quality of life' te meten in een Nederlandse populatie met veneuze ziekte van het been was het noodzakelijk dat er een gevalideerde 'quality of life' questionnaire kwam. In hoofdstuk 2, wordt een ziekte specifieke 'quality of life' questionnaire (Aberdeen Varicose Vein Questionnaire) gevalideerd voor de Nederlandse taal.

In hoofdstuk 3, wordt het gebruik van de Nederlands vertaalde Aberdeen Varicose Vein Questionnaire geëvalueerd. Deze studie kwam tot de conclusie dat de questionnaire prima kon differentiëren tussen groepen patiënten met verschillende ernst van veneuze ziekte voor en na behandeling.

Een overzicht van alle chirurgische technieken voor behandeling van de insufficiënte vene saphena magna wordt beschreven In hoofdstuk4. Deklassieke chirurgische strip wordt nog zeer veel gebruikt wereldwijd. Minimaal invasieve methoden zoals laser en radiofrequency ablatie zijn in korte tijd zeer populair geworden. De conclusie is dat alle behandelingsmethoden veilig en geschikt zijn voor de behandeling op korte en middellange termijn. Voordat endoveneuze behandeling de behandeling van eerste keuze wordt zijn er meer grote gerandomiseerde studies noodzakelijk met een lange follow-up termijn.

In hoofdstuk 5 worden de resultaten beschreven van een prospectief gerandomiseerde trial. Hierin wordt de conventionele strip vergeleken met een cryostrip van de insufficiënte vene saphena magna. Het primaire eindpunt was residu van de vene saphena magna, 6 maanden na behandeling, bevestigd door duplex ultrasound. Secundaire eindpunten waren 'quality of life' metingen, zenuwletsel en operatietijd. De conclusie is dat een cryo strip veel operatieve problemen geeft en daardoor een zeer teleurstellend resultaat oplevert. 'Quality of life' metingen Laten kleine maar significante verschillen zien ten voordele van de klassieke strip. De cryo strip heeft geen meerwaarde ten opzichte van een klassieke strip.

In hoofdstuk 6 worden de indicaties en verschillende technieken beschreven in de minimaal invasieve behandeling van insufficiënte perforatoren. SEPS is langere tijd de gouden standaard geweest, maar is in vergelijking met laser, radiofrequency ablatie en CPS niet echt minimaal 
invasief. Verdere studies zullen moeten uitmaken wat de nieuwe gouden standaard gaat worden in de behandeling van insufficiënte perforatoren.

In hoofdstuk 7 worden de resultaten beschreven van een cohort patiënten met insufficiënte perforatoren die Cryo Perforator Surgery (CPS) ondergingen. In deze studie werden zeer slechte resultaten gevonden na deze behandeling. Het was waarschijnlijk dat de slechte resultaten te wijten waren aan het gladde oppervlak van de cryoprobe.

Met een aangepaste cryoprobe, die een coating had gekregen met diamantstof werd een nieuw cohort patiënten behandeld met insufficiënte perforatoren. De resultaten werden beschreven In hoofdstuk 8. De conclusie is dat CPS zeer matige resultaten oplevert en dat het als een obsolete behandeling moet worden beschouwd. 



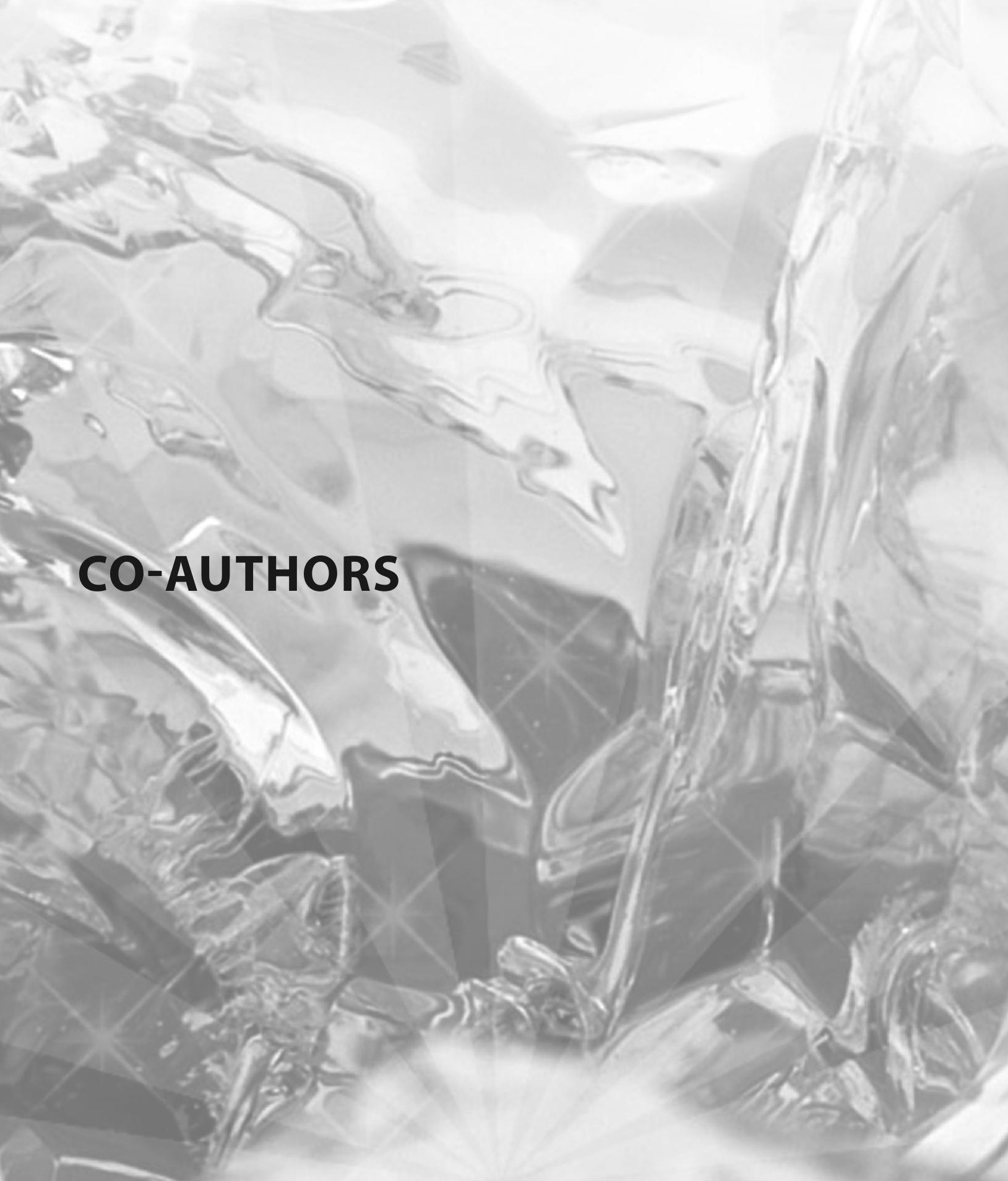




\section{CO-AUTHORS}

Peter van der Boezem, MD. Department of Surgery, Gelderse Vallei Hospital, Ede, The Netherlands.

Jerome van Brussel, MD, PhD. Department of Surgery, Sint Franciscus Gasthuis, Rotterdam, The Netherlands.

Emile le Cocq d'Armandville, MD. Stichting venous research, Rotterdam, The Netherlands.

Marie louise Essink-Bot, PhD. Department of Social Medicine, Academic Medical Center, Amsterdam, The Netherlands.

Arie C. van der Ham, MD, PhD. Department of Surgery, Sint Franciscus Gasthuis, Rotterdam, The Netherlands.

Wim Hop, MSc, PhD. Department of Epidemiology and Biostatistics, Erasmus Medical Center, Rotterdam, The Netherlands.

Marco J.M. Schnater, MD, Phd. Department of Surgery, Albert Schweitzer Hospital, Dordrecht, The Netherlands.

P.R. Schütte, MD, PhD. Department of Surgery, Albert Schweitzer Hospital, Dordrecht, The Netherlands.

Hans J.E.M. Sybrandy, MD. Department of Surgery, Gelderse Vallei, Ede, The Netherlands.

Cees H.A. Wittens, MD, PhD. Department of Surgery, Academic Hospital Maastricht, Maastricht, The Netherlands. 


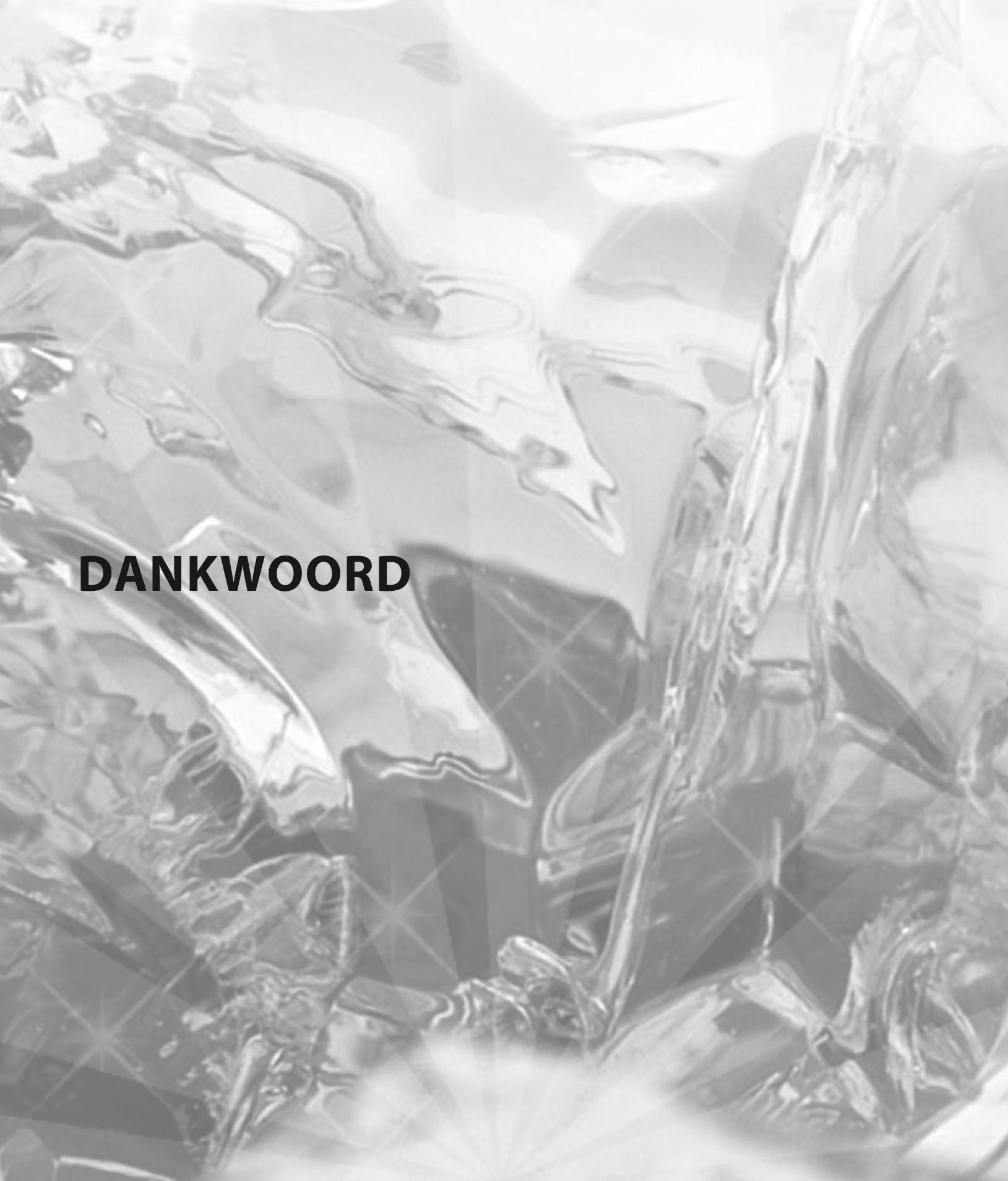




\section{DANKWOORD}

Gedurende mijn onderzoek zijn er velen geweest die hebben bijgedragen aan het tot stand komen van dit proefschrift.

Mijn promotor en oud opleider, professor dr. C.H.A. Wittens, beste Cees, ik dank je voor de mogelijkheden die je me hebt geboden. Je hebt een heldere, analytische kijk op zaken. Je hebt veel goede onderzoeksideeën en de veneuze chirurgie is in prima handen bij jou. Ik waardeer je altijd positieve instelling. Ik heb veel van je geleerd.

Mijn copromotor, dr. A.C. van der Ham, beste Arie, ik wil je hartelijk bedanken voor de begeleiding tijdens mijn onderzoek en opleiding. Je hebt keer op keer tijd gevonden om de artikelen te reviseren. Ook nu nog steeds is het zeer plezierig samenwerken, ook op onderzoeksgebied.

Professor dr. G.W.H. Schurink, professor dr. H.A.M. Neumann, professor dr. M. de Maeseneer, dr. Sommer en dr. B. Bruijninckx, hartelijk dank voor jullie bereidheid deel te nemen aan de promotiecommissie en voor het beoordelen van het manuscript.

Marco Schnater, hartelijk dank voor het zeer nauwkeurig begeleiden en communiceren van de cryo studie in het Albert Schweitzer Ziekenhuis.

Peter van de Boezem en Emile le Cocq d'Armandville, hartelijk dank voor de samenwerking aan het review artikel, het was een enorm werk, maar het resultaat is fraai geworden.

Dr. Wim Hop, hartelijk dank voor het verrichten en begrijpbaar maken van de statistiek in de cryo studie.

Professor dr. J. IJzermans, dank voor de goede en leuke opleidingsjaren in het Erasmus MC.

Wijnand van Gent en Hans Sybrandy, hartelijk dank voor de introductie in de veneuze onderzoeksgroep en snowboarden. Tevens voor een zeer leuke opleidingstijd in het SFG.

May Lind, hartelijk dank voor de begeleiding van mijn eerste publicatie in het EJVES, het was een leerzame ervaring.

Cora Hazelzet, zeer veel dank voor de nauwkeurigheid van de dataverzameling en het bijhouden van de database. Daarnaast was het altijd erg gezellig om langs te komen in het trialbureau.

Annemieke Kulk, altijd gezellig en goede raad en altijd positief. Al 20 jaar wormen en onkruid, en de komende 30 jaar in het SFG. 
WietskeVrijland, bewaker van de kwaliteit op vele gebieden. Ik ben zeer blij met je vooruitziende blik, goede ideeën en een andere kijk op de zaken. De boot moet weer snel gaan varen.

Dank aan Lew Asby en Tom Araya voor hun inzichten. Het zou maar saai zijn zonder jullie.

Al mijn maten: Guido, Bert, Jerome, Henk, Hans, Victor en Peter. Ik hoop dat we nog veel mooie jaren tegemoet gaan.

Alle assistenten, fellows, chivos, chefs: zonder jullie, geen opleiding, geen kritische noot, geen skiweekend, geen VIP bar, geen schone tafels, geen spanning, geen driekwart broeken, ik hoop dat jullie, net als ik, kunnen terugkijken op een mooie opleidingstijd.

Aad Klem en Marius Klem, hartelijk dank voor de enorme technische hulp en inzichten bij de cryoprobe trekkracht metingen. Ik heb er zeel veel van geleerd.

Nienke, veel dank voor de Autocad tekeningen en de appeltaarten. Laat de volgende lading maar komen.

Tinie, alias de allerleukste, het is nu eindelijk af. Jenny Saville, Morena Baccarin en Andrea Lehmann vallen natuurlijk in het niets bij jou.

Evi, Alek en Mare; lieve beesten, ik kan nog veel van jullie leren. 



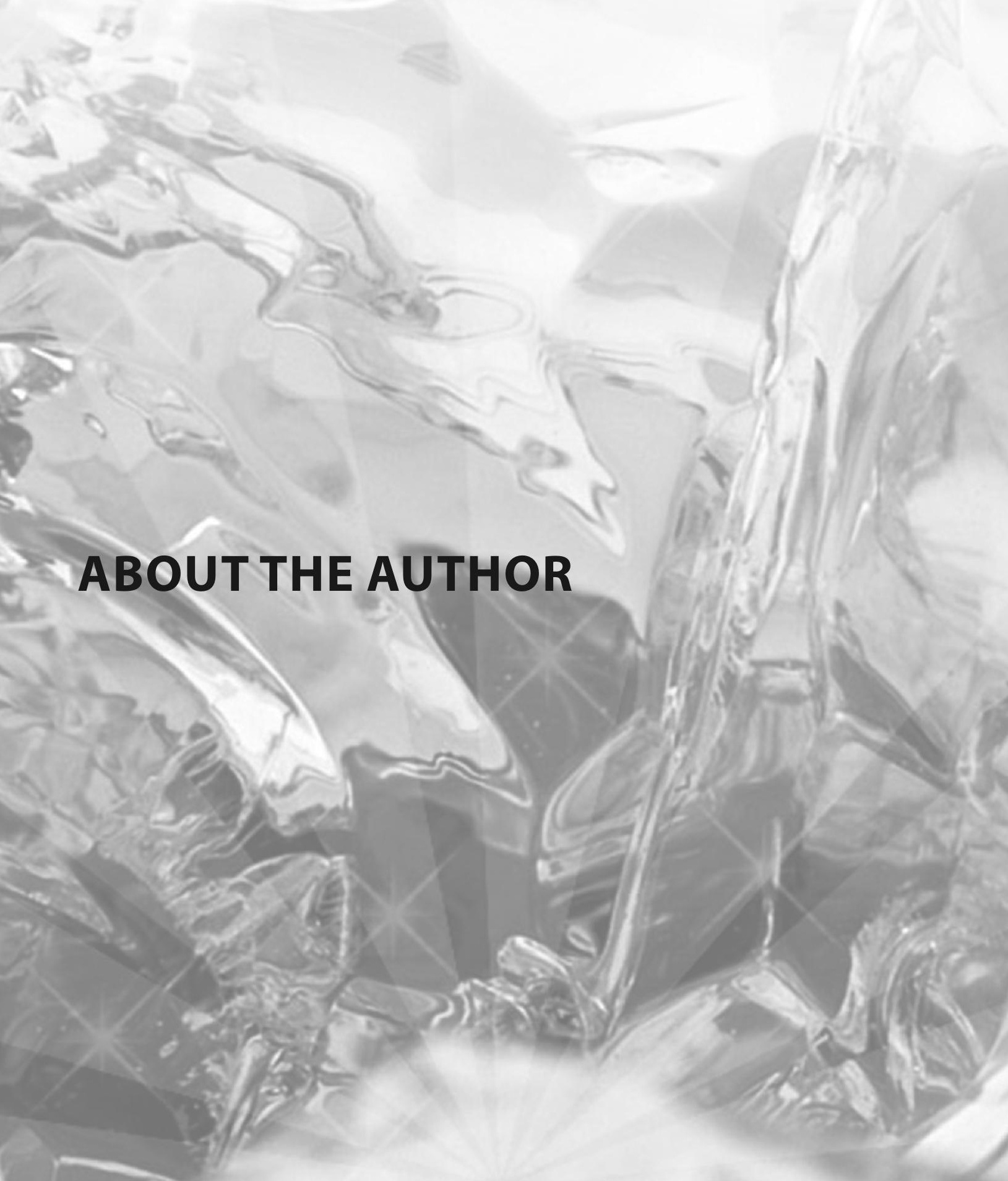




\section{ABOUT THE AUTHOR}

Taco Marius Adrianus Leonardus was born on June $19^{\text {th }}, 1972$, in Benthuizen, The Netherlands. He graduated in 1991 at the Onze Lieve Vrouwe lyceum in Breda.

In the same year he attended medical school at the Faculty of Medicine of the Erasmus University in Rotterdam. In 1998, he obtained his medical degree.

After travelling for one year in Asia, he started as a resident surgery end 1999.

In 2002 he started his surgical training at the Sint Franciscus Gasthuis Rotterdam and the Erasmus Medical Center in Rotterdam. In 2008 he completed his surgical training.

Since September 2009 he works as trauma surgeon and oncology surgeon at the Sint Franciscus Gasthuis Rotterdam.

"It is one of those books that you cannot wait to share with your friends." - Dallas Morning News

"It was definitely one of those books that kept me thinking long after I was finished with it, and I continue to ponder its true meaning and message" - Times Literary Supplement

"It was a page-turner through and through" - Guardian

"This is one of those books that is not only a page-turner, when you get to the end you peek under the back cover hoping there's another four hundred pages." - Los Angeles Times 